\title{
The Effects of Non-Trading on the Illiquidity Ratio
}

\begin{abstract}
Using a simulation analysis we show that non-trading can cause an overstatement of the observed illiquidity ratio. Our paper shows how this overstatement can be eliminated with a very simple adjustment to the Amihud illiquidity ratio. We find that the adjustment improves the relationship between the illiquidity ratio and measures of illiquidity calculated from transactions data. Asset pricing tests show that without the adjustment, illiquidity premia estimates can be understated by more than 17\% for NYSE securities and by more than 24\% for NASDAQ securities.
\end{abstract}




\section{Introduction}

Amihud (2002) provides a compelling motivation for the use of an illiquidity ratio, specifically the annual average of the ratio of daily absolute return to daily dollar volume, in asset pricing tests. Having been scrutinized within a range of empirical frameworks, there is now a wealth of support for the existence of a premium associated with the illiquidity ratio. Moreover, the use of the Amihud illiquidity ratio has become a commonly used measure of illiquidity in a wide range of finance applications and settings.

Evidence of its widespread use as a measure of illiquidity is also evident by entering the phrase "Amihud Illiquidity Ratio" in the Google search engine which renders over 7,000 responses ${ }^{1}$. Moreover, scrutiny of Science-Direct, the archive for Elsevier publications, indicates that between its publication date and November 2013 over three hundred and eighty finance papers have been published on this database alone utilising the Amihud illiquidity ratio. Despite its widespread use there has been virtually no attention placed on the empirical properties of the illiquidity ratio.

In this paper we show that the Amihud (2002) illiquidity ratio is a biased measure of the true illiquidity ratio when the measurement period includes days during which securities do not trade. We then develop an adjustment for the observed illiquidity ratio that reduces the effects of non-trading days ${ }^{2}$. The measurement problem arises because the illiquidity ratio is the annual average of the daily ratio of absolute return to dollar volume. Mathematical software that is used to calculate the illiquidity ratio cannot divide by zero, so treats days of zero volume as missing values. Therefore, the ratio is calculated by averaging

\footnotetext{
${ }^{1}$ This exercise was undertaken in November 2013.

${ }^{2}$ Non-trading days are those days on which markets are open for trading but there is zero volume for individual securities.
} 
over only those days with non-zero volume. We show how the elimination of non-trading days, which is necessary to avoid divisions by zero, can distort the computation of the illiquidity ratio. We propose a simple and effective remedy.

Using simulation analysis, we show that non-trading has two opposing affects on the measured illiquidity ratio. The impact on the properties of absolute returns serves to decrease the illiquidity ratio, while the elimination of zero volume days acts to increase the ratio. The net effect overall is an upward bias in the ratio. We find that even when there is a small to moderate amount of thin trading, the magnitude of this upward bias in the measurement of illiquidity is substantial. This allows security illiquidity to be miscalibrated, potentially misrepresenting the relationship between illiquidity and other financial variables. Moreover, a bias in illiquidity measurement can potentially give rise to inaccurate rankings when securities are stratified into groups or portfolios on the basis of illiquidity or variables, such as size, that tend to be highly correlated with illiquidity.

We propose an adjustment to the illiquidity ratio, which scales back the upward bias arising from non-trading. This adjustment is derived from the two opposing effects that non-trading has on the calculation of the ratio, and involves scaling the Amihud illiquidity ratio by a factor composed of the number of possible trading days, over which the ratio is being measured, and the number of days that the stock actually traded within those days. We show that for securities that experience some thin trading, but are not characterized by extreme thin trading (thin trading probabilities above 70\%) our proposed measure eradicates most of the potential measurement bias. When thin trading probabilities rise above $70 \%$ our proposed measure does not fully eliminate the bias in the unadjusted 
illiquidity ratio. But even at thin trading levels this high, the bias in our preferred measure is still one third to one fifth lower than that associated with the un-scaled measure.

We use NYSE TAQ data over the period 1993 to 2008 to estimate the Kyle (1985) price impact measure and the fixed-cost component of the bid-ask spread using the method of Glosten and Harris (1988) and show that the adjustment that we propose enhances the relationship between the Amihud ratio and measures of illiquidity obtained from transactions data. Using CRSP monthly return data for NYSE/AMEX securities between 1960 and 2008 and NASDAQ securities listed 1983-2008, we show that measurement bias in the illiquidity ratio is also important for the estimation of the illiquidity premium. We undertake cross-section Fama and MacBeth (1973) asset pricing tests. Our model specifications examine in turn the scaled and un-scaled illiquidity ratios. ${ }^{3}$ These tests reveal that the illiquidity premium associated with each of our computed illiquidity ratios is significant, while differences between the time-series averages of the illiquidity measures show that omitting zero volume days reduces the illiquidity premium significantly.

Although the magnitude of this potential understatement of the illiquidity premium varies according to the cross-section specification and the market being studied, the effects of omitting zero volume days are not inconsequential. We find that omitting these days leads to an understatement in the illiquidity premium that is over $17 \%$ for NYSE/AMEX stocks and over $24 \%$ for NASDAQ stocks. This discovery is of particular importance for investors that make long term portfolio allocation decisions that aim to exploit the illiquidity premium. The results we report are robust to the influence of market beta, firm

\footnotetext{
${ }^{3}$ The cross section variation in the scaling, which is different for each security as it reflects the extent of non-trading for each security, means that this comparison is not a purely mechanical exercise. The impact of the non-trading adjustment on estimated illiquidity premia is an empirical question. This point is discussed in more depth in Section 3.1.
} 
size, the Fama and French (1993) HML, SMB and momentum (Mom) factors, the systematic illiquidity risk factor proposed by Pastor and Stambaugh (2003) and a range of firm characteristics.

The relevance of our results is not exclusive to the Amihud-illiquidity ratio but also extends to related measures of illiquidity/liquidity such as the Amivest liquidity ratio, which is the average of the ratio of daily volume to daily absolute return. This ratio has been applied previously by, for example, Cooper, Groth and Avera (1985), Amihud, Mendelson and Lauterbach (1997), Berkman and Elsewarapu (1998), Pagano and Schwartz (2003), Chelley-Steeley (2015) and Chelley-Steeley et al (2015) to measure liquidity. A measurement bias may exist also for the Amivest ratio, which would need to exclude cases of zero returns since the ratio of volume to absolute return will be undefined on these days. ${ }^{4}$

Although our results have important implications for NYSE/AMEX and NASDAQ stocks, they will apply to any market that has some securities that are thinly traded. In many European or emerging stock markets thin trading levels are much higher than those usually associated with the US ${ }^{5}$. Moreover, use of the illiquidity ratio is not and need not be limited to stock markets. ${ }^{6}$ Adapting the illiquidity ratio for thin trading bias will also be important for the study of illiquidity in the context of other less active asset markets.

The Amihud illiquidity ratio has been used in a wide range of applications which can be broadly decomposed into the following categories, asset pricing, event analysis of illiquidity, rankings and the intertemporal analysis of illiquidity. Asset pricing tests that

\footnotetext{
${ }^{4}$ Lesmond, Ogden and Trzcinka (1999) and Bekaert, Harvey and Lundblad (2007) have shown how the information in zero returns per se may be harnessed as a measure of illiquidity.

${ }^{5}$ For example, Lim, Habibullah and Hinich (2009) study thin trading effects in the Shenzen and Shanghai markets in China, while Antoniou and Holmes (1997) discuss thin trading patterns in emerging markets.

${ }^{6}$ For example, Dick-Nielsen et al (2012) examine a range of liquid and illiquid corporate bonds around the onset of the subprime crisis.
} 
examine the risk premium to the illiquidity ratio (see for example Amihud 2002, Chan et al (2008) or Asparouhova et al (2010)) understate the true illiquidity premium when assets are thinly traded causing investors to be less able to make optimal asset allocation decisions. The effect of this understatement may cause underinvestment in stocks characterised by thin trading because overall risk premiums will appear supressed.

A range of studies have examined how the Amihud illiquidity changes in response to an exogenous shock (see Henke and Lauterbach (2005), Becker-Blease and Paul (2006), and Chelley-Steeley (2008)) ${ }^{7}$. When such events alter not only the true illiquidity ratio but also change the amount of non-trading, the effect of the event on the observed illiquidity ratio will be overstated. This happens because a reduction in post-event thin trading reduces the bias. This will be most acute when exogenous shocks also influence the cost of trading because as noted by Lesmond et al (1999) lower trading costs will incentivise trading activity and reduce non-trading days. Use of the adjusted illiquidity ratio we propose will mitigate this problem.

The correct ranking of securities on the basis of the illiquidity ratio will also be corrupted as the thin trading bias we have discovered causes some securities to appear more illiquid than they really are. Moreover, during periods when markets are under stress and non-trading is likely to be higher the adjusted measure will project a more accurate measure of illiquidity during these periods.

Our paper proceeds as follows. In Section 2 we describe the simulation analysis. This section shows how non-trades bias the measurement of the illiquidity ratio and

\footnotetext{
${ }^{7}$ Henke and Lauterbach (2005) and Chelley-Steeley (2008) use the illiquidity ratio to show that changing the trading mechanism leads to an increase in liquidity, Becker-Blease and Paul (2006) use the illiquidity ratio to examine the impact that index addition has on the investment opportunities of firms with different levels of illiquidity while Gaspar and Massa (2007) use the illiquidity ratio to show that ownership structure influences security illiquidity.
} 
documents the relationship between the magnitude of the bias and the degree of thin trading. This section concludes by proposing an adjustment to the illiquidity ratio that reduces most of the bias associated with thin trading levels documented for US securities. Section 3 describes the data we have used in this study and the empirical methodology we utilize. In Section 4 we report our empirical results. We provide summary statistical analysis of the illiquidity ratio for US stocks, the results of the examination of the relationship between our proposed adjustment and transactions level measures of illiquidity and the results of the Fama and MacBeth asset pricing tests. Our empirical results end with robustness tests using sub-samples of data and the square root transformation of the illiquidity ratio introduced by Hasbrouck (2009). Section 5 provides a summary of the main findings of the paper and offers some conclusions.

\section{Non-trading and the illiquidity ratio: A simulation analysis}

In this section, we consider the influence of thin trading on the measurement of security illiquidity using a simulation analysis. The Amihud (2002) illiquidity ratio for a single stock is the annual average of the ratio of daily absolute return to daily dollar volume. Specifically, for stock $i$ in year $y$, the illiquidity ratio, $\operatorname{ILLIQ}_{i, y}$, is calculated as

$$
\operatorname{ILLIQ}_{i, y}=\frac{1}{T_{i, y}} \sum_{t=1}^{T_{i, y}} \frac{\left|R_{i, y, t}\right|}{V_{i, y, t}}
$$

where $T_{i, y}$ is the number of days for which data are available for stock $i$ in year $y,\left|R_{i, y, t}\right|$ is the absolute return of stock $i$ on day $t$ of year $y . V_{i, y, t}$ is the dollar volume for stock $i$ on day $t$ of year $y$. 
For a given volume, the bigger the price impact measured by the absolute return, the more illiquid is the stock and the larger is the illiquidity measure. Similarly, for a given absolute return, lower volume stocks will register as being more illiquid. Difficulties may arise in the application of this measure where securities do not trade every day. On a day of zero volume, the ratio would be mathematically undefined. In the calculation of this ratio, most statistical packages will replace an instance of division by zero with a missing value. This has the effect of changing the calculation of the illiquidity ratio to

$$
\operatorname{ILLIQ}_{i, y}=\frac{1}{T_{i, y}-\tau_{i, y}} \sum_{t=1}^{T_{i, y}-\tau_{i, y}} \frac{\left|R_{i, y, t}\right|}{V_{i, y, t}}
$$

where $\tau_{i, y}$ is the number of non-trading days by stock $i$ in year $y$, and $\tau_{i, y}<T_{i, y} \cdot{ }^{8}$ Other terms are as previously defined. In the presence of non-trading days, there will therefore be fewer observations used to calculate the average daily ratio.

However, in the presence of non-trading days, the illiquidity ratio is affected in ways other than just by the reduction in the number of observations that can be directly seen in equation (2). Models of non-synchronous trading, such as those of Scholes and Williams (1978) and Lo and MacKinlay (1990), show that the moment properties of observed returns change when, following periods of non-trading, observed returns are the accumulation of a sequence of underlying unobserved returns. Our simulations show that observed absolute returns, which make up the numerator of the illiquidity ratio, are reduced by the effects of non-trading. By itself, the effect on observed absolute returns would make stocks appear more liquid than they really are. However, we show also that the representation of non-

\footnotetext{
${ }^{8}$ To simplify the summation notation in equation (2), it is assumed that the daily illiquidity ratios, within $T_{i, y}$ have been sorted in decreasing order of volume. This does not affect the results of the summations.
} 
trading days by missing values (just the change in the number of observations, in isolation of other effects) generates an increase in the illiquidity ratio. This increase in the illiquidity ratio, arising from omitting zero volume days, could potentially offset the decrease in the ratio, arising from the effect on observed absolute returns. The key result from our simulation analysis is that this increase in the illiquidity ratio is relatively much larger, so that the combined effect on the illiquidity ratio leaves it overstating the illiquidity of stocks. This means that after zero volume days have been omitted, an additional downward correction to the illiquidity ratio is required. Our simulations suggest what this adjustment should be.

\subsection{The Simulation Analysis}

We assume that daily unobservable $(\log )$ security returns, $R_{t}^{*}$, are normally distributed with an annualized mean excess return of 8 percent and standard deviation of 20 percent. $^{9}$ The series of unobservable returns is converted into a price series, through

$$
s_{t}^{*}=\exp \left(\ln \left(s_{t-1}^{*}\right)+R_{t}^{*}\right)
$$

To simulate non-trading, we follow the method adopted by Dimson (1979). We take 100,000 independent drawings, $U_{t}$ from a uniform distribution on the range $0-1$. For a non-trading probability, $p$, if the uniformly distributed variate for period $t$ is less than or equal to this probability value, trading does not occur in period $t$ and if the variate is greater

\footnotetext{
${ }^{9}$ We examined the robustness of the simulation analysis to wide variations in the parameters of the unobservable returns series. Wide ranging pparameter variation induced less than a $1 / 10^{\text {th }}$ of 1 percent change in the induced bias in the illiquidity ratio at non-trading probabilities less than 27 percent, and less than a 1 percent change at probabilities up to 93 percent. All these additional results are in a supplementary document available on request to the authors.
} 
than the probability value then trading does take place in period $t .{ }^{10}$ If we define a trade indicator variable as $V_{p, t}=0$ (if $U_{t} \leq p$; no trade) or $V_{p, t}=1$ (if $U_{t}>p$; trade), then “observed” prices are generated by

$$
s_{p, t}=s_{p, t-1}+V_{p, t}\left(s_{t}^{*}-s_{p, t-1}\right)
$$

Thus, if trading does not take place, then $s_{p, t}=s_{p, t-1}$ and the "observed" return will be zero. If trading does occur, then $s_{p, t}=s_{t}^{*}$, and the "observed" return, $R_{p, t}$, is calculated as

$$
R_{p, t}=\ln \left(s_{p, t} / s_{p, t-1}\right)
$$

so "observed” returns represent the accumulation of any "unobserved” returns since the last “observed” return.

For each of the one hundred percentile non-trading probabilities, between zero and 99 inclusive, that is, $(p=0,1,2, \ldots, 99)$, we use the series of 100,000 unobserved prices, from equation (3) and the no-trade generator in (4) to create 100 observable returns series, each of 100,000 observations. Each series has a different incidence of non-trading days, $\tau \approx p \times 10^{5}$, but each has the same underlying parameters determining the unobservable returns. ${ }^{11}$ The first "observed" returns series with the zero non-trading probability, $(p=0)$ is the original series of unobserved returns, undisturbed by non-trading. The second

\footnotetext{
${ }^{10}$ At this stage, we are assuming, therefore, that non-trading arises randomly. Although informed traders may engage in forms of endogenous non-trading, the presence of liquidity traders with exogenous trading motives, is consistent with random occurrences of zero volume. In the next section, we extend our model to allow for the possibility of an association between volume and price changes. We also repeated the simulation exercise introducing a simple time dependency into the daily non-trading probabilities. Time dependency increased the bias in the illiquidity ratio, but this was barely detectable at non-trading probabilities less than 50 percent. These additional results are in a supplementary document available on request to the authors.

${ }^{11}$ The only parameter that is changed between one non-trading probability percentage point and the next is the nontrading probability itself. The unobserved returns and prices series are common to each probability, as is the uniform distribution used in the no-trade generator. As the number of observations, $\mathrm{n}$, increases, $\tau \rightarrow p \times n$.
} 
"observed" returns series has a non-trading probability of 1 percent, the third series a probability of 2 percent, and so on. The one hundredth series has a probability of nontrading of 99 percent.

To concentrate our focus on where within the illiquidity ratio information is lost as a result of zero volume days, we model the volume series as a simple binary process. If there is no trading, dollar volume is zero, and if there is trading, dollar volume is unity. This assumption permits a key simplification to the illiquidity ratio, that both exposes the affects of non-trading and ultimately suggests a remedy. ${ }^{12}$

As the no-trade generator produces a volume series with the property that $\left|R_{p, t}\right|=0$, if $V_{p, t}=0$, and $\left|R_{p, t}\right|>0$, if $V_{p, t}=1$, the formula for the illiquidity ratio, equation (2), can be simplified to

$$
\operatorname{ILLIQ}=\frac{1}{T-\tau} \sum_{t=1}^{T-\tau}\left|R_{p, t}\right|
$$

in which case the illiquidity ratio is equal to the mean absolute return, calculated over trading days. The year and security identifying subscripts have been suppressed to simplify the notation.

For each of the 100 series of 100,000 simulated observable returns, we calculate the illiquidity ratio, equation (6), using $T_{i, y}=T=200$, which gives 500 simulated "years" to calculate the illiquidity ratio of the stock, for the non-trading probability corresponding to

\footnotetext{
${ }^{12}$ We examined the robustness of our simulation analysis to more general returns and volume processes. We introduced the possibility that returns could be non-zero even if volume is zero, and also introduced low and high levels of non-zero volume, together with differing levels of price adjustment. While these generalizations did impact the bias in the illiquidity ratio, none were of sufficient magnitude to outweigh the dominant influence of the change to absolute returns that happens when observed returns are the accumulation of unobserved returns following periods of non-trading. These additional results are available in a supplementary document available from the authors.
} 
the particular observable returns series. For each non-trading probability, the 500 annual values for the stock are averaged to give an "observed" measurement of the illiquidity ratio. ${ }^{13}$ We then normalize the illiquidity ratio from each observed return series, ( $p=0,1,2, \ldots, 99)$, by dividing it by the illiquidity ratio of unobserved returns, $(p=0)$, to expose the impact on the ratio of increasing levels of thin trading. ${ }^{14}$ Figure 1 shows the normalized illiquidity ratios plotted against the probability of non-trading. It can be seen that the illiquidity ratio for observed returns diverges increasingly from the ratio for unobserved returns $(p=0)$ as the incidence of non-trading increases.

\section{[Figure 1]}

This simulation result indicates that to adjust the illiquidity ratio for non-trading, it is necessary to reduce its size. Since non-trading is itself a manifestation of illiquidity, it is tempting to expect that correcting the illiquidity ratio for the effects of non-trading, would require an increase in the illiquidity ratio. But this would be to imply that the illiquidity ratio can represent two forms of illiquidity, both the price impact of changes in dollar volume and non-trading, when it is only designed to measure the former. Hence, we are seeking to adjust the illiquidity ratio for the potential information losses arising from the omission of zero volume days rather than construct a multidimensional measure of illiquidity.

\footnotetext{
${ }^{13}$ Since the unobservable returns are independent drawings by construction, the average of the 500 annual illiquidity ratios is the same as the average of all individual 100,000 daily ratios.

${ }^{14}$ The illiquidity ratio for unobserved returns (the case of no zero volume days) can also be calculated directly from the initial parameter settings (mean and variance) for the unobserved returns, without the need for simulation, by using the properties of the absolute values of normal variates, see Leone et al (1961). The ratio calculated from the 100,000 simulated "unobserved" returns was within one tenth of one percent of the ratio calculated directly from the initial parameters of the unobserved returns series.
} 
Nevertheless, we can demonstrate that the act of omitting zero volume days per se does indeed raise the illiquidity ratio, but that the information losses arising from this cause the ratio to increase too much, requiring a further downward adjustment to the illiquidity ratio. We do this by separating the two ways by which the illiquidity ratio for observed returns (with zero volume days) and unobserved returns (without zero volume days) are different.

Differences between the mean absolute returns for observed and unobserved returns come from two sources, differences between observed and unobserved absolute returns and differences in the number of observations. To separate the impacts of each of these two differences, we can scale the simplified illiquidity ratio for observed returns in equation (6) by $(T-\tau) / T$ to give

$$
\begin{aligned}
\text { ILLIQ }^{0} & =\frac{(T-\tau)}{T} \text { ILLIQ } \\
& =\frac{1}{T} \sum_{t=1}^{T-\tau}\left|R_{p, t}\right|
\end{aligned}
$$

This removes the influence of the change in the number of observations (induced by days of zero volume) and focuses on the impact on the illiquidity ratio of the difference between observed and unobserved absolute returns. The ratio $\operatorname{ILLIQ}^{\circ}$ is equivalent to computing the illiquidity ratio as in equation (6) but, rather than omitting zero volume days, introducing a zero-valued observation on non-trading days. Figure 2 plots the ratio of $\operatorname{ILLIQ}^{\circ}$ to the illiquidity ratio for unobserved returns. It can be seen, therefore, that the 
information losses due to non-trading generate a reduction in absolute returns, and so the illiquidity ratio. Thus, the required correction to this downward bias is to increase the illiquidity ratio, back to the horizontal level, which corresponds to the ratio for unobserved returns. As shown in Figure 1, eliminating zero volume days does increase the illiquidity ratio, but by too much resulting in an illiquidity ratio that is greater than that for unobserved returns. Therefore, the illiquidity ratio, with zero volume days eliminated, needs to be adjusted back downwards to better reflect the information in the underlying unobserved returns series, which is lost through the effects of non-trading.

[Figure 2]

\subsection{A non-trading adjustment for the Illiquidity Ratio}

A comparison of Figures 1 and 2 shows that the (net) downward adjustment required to the illiquidity ratio is approximately equal to the amount by which the ratio $\operatorname{ILLIQ}^{\circ}$ is itself biased downwards. That is, the upward bias in ILLIQ is roughly equal in magnitude and opposite in sign to the downward bias in ILLIQ ${ }^{\circ}$. This points to a simple solution; use the average of the ratios ILLIQ and ILLIQ ${ }^{0} .{ }^{15}$ Combining equations (6) and (7) to create this average produces the adjusted illiquidity ratio, ILLIQ_A,

\footnotetext{
${ }^{15}$ We compared the reduction in bias from using the adjusted illiquidity measure in equation (8) to that obtained from using a wide variety of alternative uneven and non-linear weightings between ILLIQ and ILLIQ ${ }^{0}$. The evidence suggested that an equal-weighted linear combination, as implied by ILLIQ_A, delivered an adjustment of similar benefit to the various alternative weighting schemes, but with by far the simplest design. These comparative results are also available in the supplementary document.
} 


$$
\begin{aligned}
\text { ILLIQ }_{\mathrm{A}} & =\left(\left(\frac{1}{T} \sum_{t=1}^{T-\tau}\left|R_{p, t}\right|\right)+\left(\frac{1}{T-\tau} \sum_{t=1}^{T-\tau}\left|R_{p, t}\right|\right)\right) / 2 \\
& =\frac{(T-\tau) \sum_{t=1}^{T-\tau}\left|R_{p, t}\right|+T \sum_{t=1}^{T-\tau}\left|R_{p, t}\right|}{2 T(T-\tau)} \\
& =\left(\frac{2 T-\tau}{2 T}\right)\left(\frac{1}{T-\tau}\right) \sum_{t=1}^{T-\tau}\left|R_{p, t}\right| \\
& =\left(\frac{2 T-\tau}{2 T}\right) \text { ILLIQ }
\end{aligned}
$$

The adjusted illiquidity ratio, in equation (8), is therefore a simple scaling on the conventionally applied illiquidity ratio, ILLIQ. This scaling uses the total number of trading days, $T$, and the number of zero volume days, $\tau$, to reduce the over-adjustment of absolute returns that occurs by simply removing zero volume days from the calculation of the illiquidity ratio. Figure 3 shows a plot of the normalized adjusted ratio ILLIQ_A. It can be seen that the upward bias in the un-scaled ratio, ILLIQ, in Figure 1, for non-trading probabilities less than 70 percent, has been almost completely eliminated by applying the scaling in the adjusted ratio ILLIQ_A.

[Figure 3]

To summarize the potential improvement to the illiquidity ratio provided by the scaling factor in equation (8), we calculate the mean absolute percentage error (difference), across different ranges of non-trading probabilities, between the true illiquidity ratio and the observed illiquidity ratio, with and without the scaling factor. These error measures are reported in Table 1 . The size of the errors for the scaled illiquidity ratio is less than one percent and at least an order of magnitude better than the un-scaled illiquidity ratio for all 
non-trading probabilities up to 50 percent. ${ }^{16}$ Above 50 percent non-trading probabilities, the scaled illiquidity ratio provides between a three- to five-fold improvement in the measure.

\section{[Table 1]}

While the simple simulation design facilitates the isolation of the effects of nontrading on the illiquidity ratio, it has done so by implicitly ignoring the possibility that trading, returns and volumes might be driven by the same common factors, in particular new information and investors' differences of opinion. ${ }^{17}$ Perhaps even more important is the possibility that the probability of trading is itself correlated with the path of 'theoretical returns'. This argument is provided by Lesmond, Ogden, and Trzcinka (1999) who argue that investors trade only if the value of accumulated information exceeds the marginal cost of trading. If trading costs are substantial, new information must accumulate longer before investors engage in trading. One implication of Lesmond, Ogden, and Trzcinka (1999) is that the probability of trading is greater when (absolute) 'theoretical returns' are higher. Since transaction costs reduce the eagerness of market participants in trading, only large changes in prices can reward investors from entering into new transactions, and the proposed adjustment may be discarding that aspect of market liquidity.

To explicitly account for the possibility of an association between volatility and nontrading, we modify the simulation as follows. The volume variable changes to

\footnotetext{
${ }^{16}$ When grouped by quintile, the range of non-trading probabilities for which the scaled illiquidity ratio represents an order of magnitude improvement extends to 60 percent.

${ }^{17}$ Many empirical studies have analyzed the association between volumes and returns, including Karpoff (1987), Chordia and Swaminathan (2000) and Gervais, Kaniel, and Mingelgrin (2001) which report that stock returns are related to trading volume. Other studies document a positive association between expected future volatility and volumes (Gallant, Rossi, and Tauchen, 1992), and between volume and dispersion of beliefs (Ajinkya, Atiase, and Gift, 1991).
} 


$$
V_{t}= \begin{cases}0 & \text { if }\left|R_{t}^{*}\right| \leq v \sigma_{R^{*}} \\ 1 & \text { if }\left|R_{t}^{*}\right|>v \sigma_{R^{*}}\end{cases}
$$

Where $v$ is a constant of proportionality and $\sigma_{R^{*}}$ is the standard deviation of the unobserved returns $R_{t}^{*}$. Thus, the security only trades if the current unobserved absolute return is greater than a threshold that is some multiple of the standard deviation away from the mean of the unobserved returns. We use a range of possible thresholds from zero to three standard deviations away from the mean. For the normally distributed simulated returns series, three standard deviations contain $99.7 \%$ of the distribution. The threshold represents the marginal cost of trading. In the simulations, we divide the range between zero and three standard deviations into 100 increments. Within the parameterization of the simulation described earlier, each increment therefore corresponds to an increase in the costs of trading of approximately 0.038 percent. This modification to the simulation generates the relationship between the absolute return and the likelihood of trading that is shown in Figure $4 .{ }^{18}$ This figure shows that the higher is the threshold that the absolute return must exceed, to induce trading, the more likely is there to be non-trading. Using the simulated data, which now has non-trading days dependent upon absolute returns, we calculate again the observed illiquidity ratio, ILLIQ, and our adjusted ratio, ILLIQ_A. These are shown in Figure 5. Comparing Figure 5 to Figures 1 and 3, which display the corresponding illiquidity ratios for independently distributed non-trading days, we can see

\footnotetext{
${ }^{18}$ The same set of simulation parameters was used to generate these dependent non-trading probabilities as was used to generate the unobserved returns used to compute the illiquidity ratios in Figures 1,2 and 3, so direct comparison can be made.
} 
that the dependence introduced into non-trading increases the bias in ILLIQ. However, the ability of ILLIQ_A to reduce this bias is not noticeably altered.

[Figure 4]

[Figure 5]

While the modification in equation (9) permits non-trading to be caused by low volatility, it does not include a mechanism to permit low volatility to arise following a period of non-trading, and to persist at a lower level. To address this, we make two further adjustments to our simulations, to more closely represent the variety of empirical relations observed between volume and volatility, see for example Gallant, Rossi and Tauchen (1992). First, we allow for persistence in the volatility of returns, by introducing an $\mathrm{ARCH}(1)$ process into the conditional variance of unobserved returns. ${ }^{19}$ Second, we impose a drop in the absolute return immediately following a non-trading day, and this drop is reversed gradually over the subsequent 10 trading days, such that over a period of 10 days following a period of non-trading, the volatility returns to its pre-non-trading level. Specifically, the time dependent scaling factor $\varphi_{q}$ is applied to absolute unobserved returns, where $q \leq 10$ is the number of days following a period of non-trading, and $\left(1-\varphi_{0}\right)$ is the proportional fall in absolute returns immediately following the period of non-trading. The scaling factor operates like a reverse partial adjustment mechanism, specifically $\varphi_{q-1}=$ $\varphi_{q}+\omega\left(\varphi_{0}-\varphi_{q}\right)$, where $\omega$ is an adjustment coefficient and $\varphi_{10}=1$. Following a drop in the magnitude of the returns of size $(1-\varphi)$, the return magnitude adjustment reverts back

\footnotetext{
${ }^{19}$ In the supplementary document, we report the simulation results for a wide range of values for the ARCH coefficient. The results that we report here use a coefficient value of 0.90 . This value generated the greatest excess kurtosis in the unobserved returns and the greatest autocorrelation in the squared unobserved returns. This value implies a half-life of shocks to the variance of around 7 trading days.
} 
to 1 , over a period of 10 days by following a convex increasing path. Initially, the reversion from the initial drop in volatility is slow, to build in persistence, but it speeds up as the end of the 10 day window is approached. ${ }^{20}$ The interaction of the ARCH process with the scaling factor allows yet further persistence to the drop in volatility following non-trading. We calibrate the value of $\varphi_{0}$ from the returns data set that we use for our empirical analysis. ${ }^{21}$ Using both a 10 day window and a 4 day window either side of periods of nontrading, we compute the average absolute returns (across firms and days) for each window. We then calculate the percentage change in absolute returns from before to after periods of non-trading. We do this exercise on a year by year basis, as the illiquidity ratio is calculated empirically on a yearly basis. We use differing window lengths to mitigate measurement error from closely proximate periods of non-trading. ${ }^{22}$ The empirical distribution of changes in absolute return, using the yearly observations to form a sample, is shown in Figure 6. While the median change in absolute return is indeed negative (a 5 percent reduction using the 10 day window, and a 1 percent reduction using the 4 day window), there is much variation, with the upper quartiles indicating increases in volatility (7 percent and 4 percent, respectively). The largest reduction in absolute returns is 15 percent for the 10 day window and, excepting one clear outlier, 12 percent for the 4 day window. Taking a conservative approach, we set the reduction $(1-\varphi)$ to 15 percent. Figure 7 shows the graphs of the illiquidity ratio, ILLIQ, and our adjusted ratio, ILLIQ_A, with the further

\footnotetext{
${ }^{20}$ Amihud and Mendelson (1987) pioneered the use of a partial adjustment mechanism to model the adjustment of stock prices. The supplementary document contains an example of the adjustment process path for volatility.

${ }^{21}$ The returns data set is described in Section 3.1 below.

${ }^{22}$ Since volatility has been observed to increase following weekends, see e.g., French and Roll (1986), any dampening effect of non-trading could be offset by such an increase if the non-trading period starts on a Monday. So, to provide the most conservative estimate, we exclude non-trading periods that commence on a Monday. This actually has very little effect on the observed changes in volatility following non-trading that we find.
} 
modifications to the simulations to permit reductions in volatility and persistence in volatility following periods of non-trading. Comparing Figure 7 to Figure 5, which has neither of these features, we can see that the combined effects of persistence and the drop in volatility causes a small reduction in the bias in ILLIQ. Again, however, the ability of ILLIQ_A to reduce this bias is not noticeably altered. Thus, our adjusted illiquidity ratio continues to perform well in the presence of complex interrelationships between volume and volatility. ${ }^{23}$

[Figure 6]

[Figure 7]

The next two sections explain the methods and report the results of our empirical analysis to both validate our proposed non-trading adjustment and explore the consequences of non-trading in the empirical measurement of the illiquidity ratio.

\section{Data and Empirical Methods}

\subsection{Cross-section asset pricing tests}

We estimate illiquidity premia using Fama and MacBeth (1973) cross-sectional asset pricing regressions. Each month excess stock returns are regressed against stock characteristics, including the illiquidity ratio, along with estimated betas from market-wide risk factors. The time series means of the monthly regression slopes generate standard tests of whether the components of the risk premia are priced. We compute time series means of

\footnotetext{
${ }^{23}$ While our simulations show that non-trading effects act mostly through the numerator of the Amihud ratio, two recent studies indicate that for cross section asset pricing the denominator of the ratio may also be important. Lou and Shu (2014) isolate the volume component of the ratio and suggest that it is dominant in explaining return premia. Brennan et al (2013), using a turnover (rather than dollar volume) based measure, find that order flow sign influences the pricing of the Amihud ratio.
} 
the coefficients from cross-section regressions which utilize one of the two illiquidity ratios and examine whether there are differences in the slope coefficients of the two measures.

The data used in this sample includes all NYSE/AMEX/NASDAQ ordinary common stocks listed on the CRSP/COMPUSTAT merged database between the period January 1960 to December $2008^{24}$. From this database, we extract, for each security, return, volume and market equity information. Following, Fama and French (1992), we match the market equity information for fiscal year ends in calendar year $t-1$ with the returns from July of year $t$ to June of year $t+1$, to ensure that these variables are known when returns are generated. We also require that the stocks have at least 2 years of monthly returns preceding July in year $t$ for the calculation of pre-ranking betas.

The estimation of betas on market-wide risk factors makes use of the two-step procedure described by Fama and French (1992). In June each year, stocks are allocated to one of twenty-five portfolios formed on the basis of independent quintile rankings of size and then individual stock beta estimates (we use between two and five years of prior data, as available, to estimate beta).

Monthly percentage portfolio returns are created as the cross-section average of component stock returns in excess of the risk free rate. Portfolio betas are estimated using time-series regressions of portfolio returns on the overall market return, the Fama and French (1993) HML, SMB and momentum (Mom) factors, and a market-wide measure of illiquidity risk. Chordia et al (2000), Hasbrouck and Seppi (2001) and Eckbo and Norli (2002) are representative of studies that are increasingly recognizing the role of an

\footnotetext{
${ }^{24}$ Ordinary common stocks are identified using the CRSP share codes 10 and 11 . The sample for NYSE/AMEX stocks ranges from 1960-2008. Due to the limited availability of volume data required to calculate the illiquidity ratio the NASDAQ sample ranges from 1983-2008.
} 
illiquidity-based systematic risk factor while Pastor and Stambaugh (2003) and Acharya and Pederson (2005) provide evidence that systematic illiquidity risk generates a risk premium.

The data on market returns and returns to the Fama and French (1993) HML, SMB and momentum (Mom) risk factors are obtained from Kenneth French's website. Our measure of market-wide illiquidity risk is the innovation variable (ps_innov) based on equation (8) of Pastor and Stambaugh (2003, page 652). ${ }^{25}$ This has been used previously by Asparouhova, Bessembinder and Kalcheva (2010) and Hasbrouck (2009) to capture systematic illiquidity.

The resulting full-period post rank beta estimates for a portfolio are assigned to each stock contained in that portfolio, and are combined with stock characteristics in the monthly cross-section regressions. We also use a range of firm risk characteristics as recommended by Daniel and Titman (1997). Size is the logarithm of the security market equity value at the end of the previous year, book-to-market value $(\mathrm{B} / \mathrm{M})$ is the ratio of book equity to market equity of the firm measured at the end of the previous year. We are motivated to include the previous six month security return to capture the relationship between prior return and current return to capture momentum effects. We use six monthly returns, as Hong et al (1999) show this to be the most profitable momentum strategy. Jegadeesh and Titman (1993) find that turnover is an important predictor of return and so we therefore include turnover as an alternative measure of liquidity. We also include the Roll (1984) effective spread measure, recently used in asset pricing tests by Asparouhova et al (2010) and Hasbrouck (2009).

\footnotetext{
${ }^{25}$ This data was obtained from the WRDS.
} 
Illiquidity is measured using either the un-scaled or scaled Amihud illiquidity ratio, in a standardized form. Since market-wide illiquidity is time varying, Amihud (2002) recommends dividing the illiquidity ratio by the average illiquidity ratio of the market. For example, in the case of ILLIQ $\mathrm{i}_{\mathrm{y}}$, which is the annual average daily ratio (for stock $i$ in year $y$ ) of absolute return to volume (multiplied by $10^{6}$ ), with zero volume days omitted, the average illiquidity ratio across all stocks is given by

$$
\operatorname{AILLIQ}_{y}=\frac{1}{N_{y}} \sum_{i=1}^{N_{y}} \operatorname{ILLIQ}_{i, y}
$$

where $\mathrm{N}_{\mathrm{y}}$ is the number of stocks in year $\mathrm{y}$. The standardized illiquidity ratio for each security is given by ILLIQMA $_{i, y}=\operatorname{ILLIQ}_{\mathrm{i}, \mathrm{y}} /$ AILLIQ $_{\mathrm{y}}$. The monthly cross-section regressions use the standardized illiquidity ratio calculated using data from the previous calendar year.

The adjusted illiquidity ratio, ILLIQ_ $A_{i, y}$, is obtained by adjusting ILLIQ ${ }_{i, y}$, as given in equation (2), by the scaling identified in equation (8), to give

$$
\text { ILLIQ } A_{i, y}=\left(\frac{2 T_{i, y}-\tau_{i, y}}{2 T_{i, y}}\right) \frac{1}{T_{i, y}-\tau_{i, y}} \sum_{t=1}^{T_{i, y}-\tau_{i, y}} \frac{\left|R_{i, y, t}\right|}{V_{i, y, t}}
$$

A standardized version of the adjusted measure, ILLIQMA_A $A_{i, y}$, is obtained by dividing ILLIQ_ $A_{i, y}$ by the average value across all firms in the year, in the same manner as for the unadjusted measure. 
In each cross-section equation we utilize in turn as a measure of illiquidity, ILLIQMA and ILLIQMA_A. ${ }^{26}$ This allows time-series averages of coefficient differences between ILLIQMA and ILLIQMA_A to be examined. These differences are important because, if statistically significant, they capture the magnitude by which the illiquidity premium coefficients are potentially distorted.

Since the ILLIQMA_A adjusted illiquidity measure is a downward scaled version of the ILLIQMA illiquidity measure, it is tempting to expect that the estimated coefficient in the cross section regressions will be greater. This would imply that the upward bias in the illiquidity ratio identified in the simulations generates a downward bias in the premium on illiquidity. However, this line of reasoning ignores the cross section variation in the scaling itself, which depends on the extent of non-trading days for each security. ${ }^{27}$ The adjusted illiquidity ratio is effectively an interaction variable, which measures the effect of the interaction of both the number of non-trading days and the illiquidity ratio (measured from trading days only). As it is possible for the number of non-trading days and the illiquidity ratio to be correlated empirically, the covariance and variance terms that make up the regression coefficient of this interaction variable are complicated functions of the means, variances and pair-wise covariances between average returns, the illiquidity ratio and the number of non-trading days, and also of these moments of the squared values of these three variables, see Bohrnstedt and Goldberger (1969). Therefore, the sign of the difference

\footnotetext{
${ }^{26}$ We drop the firm and year identifying subscripts from here onwards, so the variable definitions can become the variable names.

${ }^{27}$ If there is no cross section variation in the non-trading days among securities, and it is assumed that the illiquidity ratio is not scaled by the average ratio across stocks, it is simple to show that the regression coefficient on the unadjusted ratio would indeed be lower. The scaling on the adjusted ratio reduces the variance component of the regression coefficient by the scaling factor squared and only reduces the covariance element by the scaling factor. Since the scaling factor is between zero and one, the overall impact would be to raise the regression coefficient on the adjusted ratio.
} 
between the estimated regression coefficients on the illiquidity ratio and the adjusted ratio is an empirical matter.

In common with Amihud (2002) and later applications that utilize the illiquidity ratio, we exclude stocks from the sample in any year when CRSP data is available for less than 200 days. This excludes from the sample firms with extreme thin trading, although our earlier analysis shows that lower levels of thin trading can still generate important biases. Within the final sample there are on average 2390 NYSE/AMEX stocks each month and an average of 4180 NASDAQ stocks.

\subsection{Testing the relationship with transaction measures of illiquidity}

Amihud (2002) showed that ILLIQ is positively related to both the Kyle (1985) price impact measure, which we denote $\lambda$, and the fixed-cost component of the spread, which we denote as $\psi$. Using estimates of the Kyle impact measure and the fixed cost component obtained from a Glosten and Harris (1988) regression of intraday quotes and transactions for the year 1984, Amihud showed that the illiquidity ratio was strongly related to these transaction based estimates of illiquidity. It is important therefore to establish that our adjustment to the illiquidity ratio does not diminish the relationship between the illiquidity ratio and the price impact measure and fixed-cost component of the spread. To achieve this, we re-examine the regression equation employed by Amihud,

$$
y_{i, t}=\alpha+\beta \lambda_{i, t}+\gamma \psi_{i, t}+\varepsilon_{i, t}
$$

where $y_{i, t}$ is, in turn, the Amihud ratio, ILLIQ $\mathrm{i}_{\mathrm{i}, \mathrm{t}}$ or our adjusted ratio ILLIQ_A $\mathrm{A}_{\mathrm{i}, \mathrm{t}}$. 
We use the NYSE trades and quotes (TAQ) database for the period 1993-2008 to estimate the Kyle impact factor and fixed-cost component using the procedure developed in Glosten and Harris (1988), and match the data to CRSP return and volume data over the same period for the calculation of the illiquidity ratios. We then undertake the regression as a panel using both time and firm fixed effects for the period 1993-2008, using samples based on all firms and for firms sorted into quintiles by size. We undertake a test of the null hypothesis that the difference between the average R-squared from the regression with ILLIQ_A $\mathrm{A}_{\mathrm{i}, \mathrm{t}}$ and the companion regression with ILLIQ $_{\mathrm{i}, \mathrm{t}}$ is zero, by estimating the regression model separately for each year, and using the R-squared values from each year to calculate a mean, either for a given size quintile or for the full sample. Additionally, we re-run the regressions of the equation pairs (ILLIQ ${ }_{i, t}$ and ILLIQ_A $A_{i, t}$ ) as a SUR system and test whether the coefficients $\beta$ and $\gamma$ are significantly different across the equation pairs. We also examine a regression of the difference between $\operatorname{ILLIQ}_{i, t}$ and ILLIQ_A $A_{i, t}$ against the price impact measure and fixed cost component measure to examine how the bias adjustment itself relates to these measures.

\section{Empirical Results}

\subsection{Summary Statistics}

To gauge the likelihood of needing to adjust the illiquidity ratio for zero volume days, Panels A and B of Table 2, report the observed proportions of zero volume days for stocks, sorted into deciles by capitalization, on the NYSE/AMEX (1960-2008) and NASDAQ (1983-2008) exchanges, respectively. It can be seen that the small firm decile proportions of zero volume days are 21.56 percent for NYSE/AMEX stocks and 22.89 percent for 
NASDAQ stocks. Even at such modest levels of thin trading, the observed illiquidity ratio, in Figure 1 is around 12 percent higher than the illiquidity ratio would be if calculated for unobserved returns. Moreover, the full sample averages conceal considerable variation in the annual proportions that reach values as high as 39.93 percent and 45.57 percent, respectively.

\section{[Table 2]}

Table 3 provides summary statistics on security market value, daily volume, the un-scaled and scaled measures of illiquidity along with the inflation adjusted un-scaled and scaled illiquidity ratio ${ }^{28}$. For comparability with other studies, we also report summary statistics for the portfolio betas associated with the risk factors and also present summary information for the risk characteristics. Statistics are provided for three sample periods, 1960-2008, 1960-2000 and 2001-2008 for NYSE/AMEX, in Panel A, and 1983-2008, 1983-2000 and 2001-2008 for NASDAQ, in Panel B. The sample break at 2001 recognizes the introduction of decimalization at this time.

On average, illiquidity is higher for NASDAQ securities during its full sample period than it is for NYSE/AMEX during its full sample ${ }^{29}$. The mean values of ILLIQ and ILLIQ_A for NYSE/AMEX securities are 15.85 and 14.52 respectively (p value for the difference using a t-test and a Wilcoxon test is 0), and are 20.94 and 18.04 for NASDAQ securities ( $\mathrm{p}$ value for the difference using a t-test and a Wilcoxon test is 0 ). We find that

\footnotetext{
${ }^{28}$ Dollar volume is adjusted to real dollar volume by using the US consumer price index. Using real volume we then calculate the unscaled and scaled illiquidity ratio as outlined previously.

${ }^{29}$ Had we been able to study an earlier period for NASDAQ these differences would have been even larger as the earlier period represented a period of higher illiquidity.
} 
inflation modified illiquidity ratios are much larger due to the deflation of dollar volume ${ }^{30}$. Over time there is a high correlation between the inflation modified and unmodified illiquidity ratios (correlations are about $45 \%$ for NYSE/AMEX and about $90 \%$ for NASDAQ). Adjusting for inflation reveals that real illiquidity was highest for NYSE/AMEX stocks during the 1970's oil crisis. Real illiquidity is elevated during the early 1990's for NYSE/AMEX Stocks and NASDAQ stocks. We also find that both markets have elevated illiquidity during the 2007-2008 financial crash but the rise in illiquidity at this time is especially acute for NASDAQ stocks and even more pronounced than was evident with non inflation adjusted illiquidity ratios.

[Table 3]

Comparisons of the two sub-sample periods for the NYSE/AMEX stocks indicate that during the period 2001-2008 there has been a substantial decline in illiquidity. The values of ILLIQ and ILLIQ_A fall from 16.37 and 15.05 in the 1960-2000 period to 4.98 and 4.65 respectively in the 2001-2008 period. This may be explained by the huge increase in volume that takes place during the 2001-2008 period, caused by decimalization and the increased prevalence of high frequency traders. During the period 2001-2008 the potential measurement bias in ILLIQ also declines, probably due to the increased trading activity that takes place. The NASDAQ sample also displays a decline in illiquidity in this later period and a corresponding increase in volume. These changes are smaller than those observable for the NYSE/AMEX markets but also generate a reduction in the divergence between illiquidity measures. Overall, the illiquidity characteristics of stocks on NYSE/AMEX and

\footnotetext{
${ }^{30}$ Differences between the two inflation adjusted measures are also significant using a t-test and a Wilcoxon test for both NYSE and NASDAQ stocks.
} 
NASDAQ are consistent with the potential biases in the measurement of illiquidity due to non-trading. Relatively large divergences between the adjusted and unadjusted measures are seen for the relatively more illiquid NASDAQ market.

\subsection{Relation to transactions measures of illiquidity}

Table 4, Panel A, shows the estimated coefficients from the regressions relating ILLIQ and ILLIQ_A to the Kyle (1985) price impact measure, $\lambda$, and the fixed-cost component of the spread, $\psi$, estimated as a panel across all firms and for all years. It can be seen that both ILLIQ and ILLIQ_A are significantly related to both the price impact measures and to the fixed-cost component measure. The significance levels are stronger for both variables in the case of our adjusted measure, ILLIQ_A, and this is reflected in a higher R-squared. In Panel A, we also show the results of the regression of the difference between ILLIQ and ILLIQ_A on the price impact measure, $\lambda$, and the fixed-cost component

of the spread, $\psi$, which shows that the bias adjustment is significantly related to both of these measures.

To determine whether the observed increase in R-squared for our measure is significant, we re-estimate the model separately for each year in the sample, to estimate a mean R-squared value. We do this for each of ILLIQ and ILLIQ_A. We then use these means and the sampling distribution across the years to test whether the difference between the means is significantly different from zero. We report these results in Panel B of Table 4. For the full sample, we reject the hypothesis that the average difference in R-squared is zero $(\mathrm{p}<0.01)$, and so conclude that ILLIQ_A has a stronger relation to the transactions 
measures of illiquidity than did ILLIQ. When we repeat this exercise for separate sizebased quintiles, we find that the differences in the R-squared values are positive in each case, indicating a stronger relationship with ILLIQ_A, and that the differences are greater for smaller firms, where we would expect the differences between ILLIQ and ILLIQ_A to matter most. The differences are significantly higher for all except the large firm quintile. From Table 2, we can see that there is relatively little thin trading in the two deciles containing the largest firms, and so this means that ILLIQ_A and ILLIQ are likely to be equal for the vast majority of firms of this size anyway. When we undertake the same exercise using the R-squared values from the regressions of the difference between ILLIQ and ILLIQ_A on the transactions based measures, we find confirmatory results. These are shown in Panel C of Table 4.

We also run the regressions relating ILLIQ and ILLIQ_A to the Kyle (1985) price impact measure, $\lambda$, and the fixed-cost component of the spread, $\psi$, as a two equation SUR system. This enables us to test directly whether the coefficients on $\lambda$ and $\psi$ are equal across the two equations. Chi-squared tests indicate that the coefficients across the two equations are significantly different $\left(\lambda: \chi^{2}=47.70, \mathrm{p}<0.01\right)$ and $\left(\psi: \chi^{2}=19.02, \mathrm{p}<0.01\right)$. In all cases, therefore, ILLIQ_A never produces a worse relationship to transactions measures of illiquidity, and mostly produces an improved relationship.

We also find that the scaled illiquidity ratio has a slightly higher correlation with volume and effective spread than the unscaled measure. However, because the effective spread and volume are different types of liquidity to the price impact effects, increases in correlation are in the region of 2-3\%. 
[Table 4]

\subsection{Cross-section asset pricing tests}

In this section we examine how the illiquidity premium could be influenced by the potential bias in the measurement of illiquidity. Tables 5 and 6 report the time series averages of OLS estimates of Fama and MacBeth cross-section regressions using all available NYSE/AMEX or NASDAQ securities, for the periods 1960-2008 and 1983-2008 respecitvely. Panel A of each table reports results of regressions of stock returns on market beta, $\beta_{\mathrm{rm}}$ and illiquidity, Panel B reports results for a five factor model augmented with illiquidity, Panel C reports the results for a five factor model plus illiquidity, size, firm level momentum and the book-to-market ratio. Panel D provides the results for the model in Panel C which is further extended by the inclusion of two widely used alternative measures of liquidity; the Roll spread and turnover. For each market, and for each specification, there are two versions of the cross-section models. Each version in turn uses one of the two measures of illiquidity; ILLIQMA and ILLIQMA_A as defined earlier. The column DIF reports the time series mean of the difference in the cross-sectional estimate of the coefficients from the model containing ILLIQMA and the same specification containing ILLIQMA_A instead. From this column we are particularly interested to discover whether significant differences exist between the coefficients on ILLIQMA and ILLIQMA_A. If these differences reflect a bias in the measurement of illiquidity, then this DIF coefficient will be statistically significant. The t-statistics are computed using the Shanken (1992) 
adjustment for errors-in-variables, ${ }^{31}$ which as noted by Hasbrouck (2009) is equivalent to a generalized method of moments (GMM) estimation.

The regressions undertaken for NYSE/AMEX securities, reported in Table 5, demonstrate that the illiquidity premium associated with ILLIQMA is statistically significant. The results contained in Panel A show that the coefficient on ILLIQMA is 0.168. As we add more explanatory variables the illiquidity premium coefficient tends to fall. In Panel D the coefficient on ILLIQMA is 0.084 . We find that the coefficient on ILLIQMA is below the coefficient on the adjusted illiquidity ratio, ILLIQMA_A, which ranges from 0.189 in Panel A to 0.092 in Panel D. Moreover, as shown by the results in the DIF column, differences between the ILLIQMA and ILLIQMA_A coefficients range from -0.023 in Panel B to -0.008 in Panel D and are significant in all specifications. ${ }^{32}$

[Table 5]

Figure 6 traces out the proportion of the illiquidity premium that this difference between the ILLIQMA and ILLIQMA_A coefficients represents and shows that omitting zero volume days, without a re-adjustment to the measurement of illiquidity, potentially leads to a substantial understatement of the illiquidity premium in each specification. Figure 8 shows that this understatement in the illiquidity premium coefficients (and therefore the premium) is between $-17.3 \%$ (Panel B results) and $-8.6 \%$ (Panel C). This potential understatement in the illiquidity premium is also significant in economic terms.

\footnotetext{
${ }^{31}$ The errors-in-variables problem arises as betas from the first pass are estimated with error, causing an underestimate of beta risk and an overstatement in the second pass coefficients of other variables. Although using portfolios to estimate beta in the first pass mitigates this problem, the use of Shanken (1992) t-statistics allows any residual errors-in-variables biases to be corrected.

${ }^{32}$ Asparouhova et al (2010) recommend using weighted least squares (WLS) to account for possible correlation between the measure of illiquidity and noise in prices. We re-examine all the cross section regression specifications using WLS. The difference in coefficients between ILLIQMA and ILLIQMA_A remains statistically significant.
} 
The standard deviation of ILLIQMA during the period 1960-2008 is 2.76. For a researcher estimating the effect on expected returns of a two standard deviation change in ILLIQMA would understate the change in the illiquidity premium by $2 * 2.76 *-0.023=0.13 \%$ on a monthly basis, based on the Panel B results in Table 5. This is equivalent to $1.52 \%$ on an annualized basis. The results in Panel D indicate an understatement in the change on the illiquidity premium of $2 * 2.76 *-0.008=-0.044 \%$ on a monthly basis, or $-0.53 \%$ when annualized.

[Figure 8]

The results presented for NASDAQ securities are broadly consistent with those found for NYSE/AMEX stocks. Panel A of Table 6 shows that the coefficients on ILLIQMA and ILLIQMA_A are 0.140 and 0.165 respectively. As we move from Panel A to Panel D these coefficients decline in value. Panel D reports coefficients on ILLIQMA and ILLIQMA_A of 0.033 and 0.041 respectively. These differences within each panel point to an under-estimation of the premium using the unadjusted illiquidity measure, ILLIQMA. The coefficient on illiquidity in the DIF column is negative in each of Panel A to D, ranging from -0.025 in Panel A to -0.008 in Panel D. Coefficients decline in value and significance as we move to Panel $\mathrm{D}$ because there is collinearity between the different liquidity measures and the illiquidity ratios ${ }^{33}$. Figure 9 shows that this bias in the illiquidity premium ranges from -24.24\% (based on Panel D) to $-15.3 \%$ (based on Panel C). Although the point estimates vary slightly from one specification to another the impact on the illiquidity premium is quite robust and slightly larger than for the NYSE.

\footnotetext{
${ }^{33}$ For example, the correlation between the illiquidity ratios and the effective spread is over $60 \%$ while there is strong negative correlation between volume and the illiquidity ratios.
} 
A change in ILLIQMA by two standard deviations leads to an under-estimate of the change in the illiquidity premium of $2 * 2.75 *-0.25=-0.14 \%$ a month, or $-1.65 \%$ on an annualised basis, based on the results in Panel A. For Panel D’s specification, the underestimate would be $2 * 2.75 *-0.008=-0.044 \%$ a month, or $-0.53 \%$ on an annualised basis. The impact of the monthly bias on NASDAQ stocks is therefore comparable to that for the NYSE/AMEX stocks.

[Table 6]

[Figure 9]

As a robustness exercise we also undertake a two stage regression. In the first stage we regress ILLIQMA_A on ILLIQMA. The residuals from this regression leave a measure of illiquidity that is free from the Amihud unadjusted measure while retaining the difference between the Ahihud ratio and the adjusted ratio. We then regress the residuals from this regression against variables used in the cross-section of expected returns (Table 5 and 6). The illiquidity variable in these regressions comprises of the residuals from the first stage regression. The results of the second stage regression are provided in Table 5 for NYSE firms and Table 6 for NASDAQ firms and shows that in all four panels the residuals are significant. This suggests that the adjusted measure of illiquidity contains elements that are priced by returns and these can not be related to the unadjusted Amihud ratio as these have already been extracted.

The cross section regression results have important implications not only for the pricing of illiquidity risk, but also for the pricing of many of the other risk variables and firm characteristics that are included in the regressions. Many of these variables are priced 
and the use of a potentially biased illiquidity measure may cause significant bias in their coefficient values also. There are many instances in Tables 5 and 6 of significant coefficient differences, in the DIF column, for explanatory variables other than the measure of illiquidity. Significant values of DIF capture the understatement in the premium due to the bias in the illiquidity ratio. Since thin trading causes the bias in the Amihud ratio, DIF will be partially correlated with the number of zero volume days. As shown by Lesmond et al (1999) the number of zero volume days can be a useful measure of illiquidity in itself although it is designed to capture a very different aspect of illiquidity to the Amihud ratio (which is concerned with price impacts). However, our concern in this paper is to make the Amihud ratio as effective as possible at capturing the form of illiquidity it sets out to measure ${ }^{34}$.

\subsection{Sub-period Analysis}

The cross section asset pricing tests indicate that the upward bias in the measurement of illiquidity results in an understatement of the illiquidity premium. In this section, we report the results from estimating the cross section asset pricing models for the following subsamples. For the NYSE/AMEX sample of stocks, we use the two periods 1960-2000 and 2001-2008. For NASDAQ, we examine the periods 1983-2000 and 2001-2008. We split the sub-periods into before and after 2001 as from this period several important changes took place to the trading environment which may have had an impact on non-trading.

\footnotetext{
${ }^{34}$ There are a range of different measures of illiquidity including the effective spread, volume, number of trades, zero volume days as well as the illiquidity ratio. Each of these measures captures a different dimension to liquidity/illiquidity and as shown by Aitken and Comerton-Forde (2003) who shown that illiquidity measures are not always highly correlated with each other.
} 
On January 29, 2001 the NYSE introduced decimal pricing ${ }^{35}$ and reduced the minimum tick size to one per cent. These changes, coupled with the increased utilisation of high frequency trading algorithms and changes to the trading environment have led to reduced spreads (Bessembinder (2003)) and an increase in trading volume (Chakravarty, Van Ness and Van Ness (2005)) especially in small stocks.

The results are reported in Tables 7 to 10, where Panel A reports results of regressions of stock returns on market beta $\beta_{\mathrm{rm}}$, and one of the two measures of illiquidity, while Panel B to D report results for the extended specifications, which include the wider range of explanatory variables.

\section{[Table 7]}

In Table 7, for NYSE/AMEX stocks during the period 1960-2000, the coefficients on ILLIQMA and ILLIQMA_A displayed in Panel A are 0.179 and 0.201, respectively. As more explanatory variables are included in the specification the size of the coefficients on illiquidity tend to fall. In Panel D, the two illiquidity coefficients are 0.087 and 0.096 respectively. The magnitudes of the coefficients on the illiquidity measures across the different cross-section regressions specifications are comparable to those reported in Table 5 for the full-sample period, 1960 to 2008. In all specifications, the difference between the coefficient values of ILLIQMA and ILLIQMA_A are significant. The coefficient differences range from -0.024 to -0.008 again showing that the coefficients on the unadjusted ratio, ILLIQMA, are potentially understated. Figure 8 shows that these differences imply an understatement of the illiquidity premium in the period 1960-2000

\footnotetext{
${ }^{35}$ Decimalization actually took place in four stages. Seven stocks traded by one specialist converted to decimal pricing in August 2000, 57 stocks on September 25 2000, 94 stocks on December $4^{\text {th }}$ and the remaining stocks January 292001.
} 
equivalent to $16.7 \%$ (Panel B) and 8.94\% (Panel C) of its value. These differences are also of similar magnitude to those found for the full sample period.

In Table 8, we report the results for NYSE/AMEX stocks for the period 2001-2008. During this relatively short period, both ILLIQMA and ILLIQMA_A are priced in all specifications, although the coefficient magnitudes tend to be smaller than during the period 1960-2000. The other risk variables that we use in the various specifications fail to be significantly priced, with the exception of the previous six month return and the effective spread. The coefficient differences for the illiquidity measures in the DIF column are significant in all specifications, but are lower in this period than in either the full sample or the sub-period 1960-2000. Although the difference between the measures, and so the impact on the illiquidity premium has fallen in this more recent sub-sample, this does not mean that the adjustment for non-trading is less important. On the contrary, because the overall level of liquidity has been increasing in recent years, which is responsible for reducing the size of both measures of illiquidity, the size of the coefficient differences between the two measures increases in relative importance. For the period, 2001-2008, the potential understatement of the illiquidity premium ranges between 21.13\%, using Panel B results, see Figure 8, and $8.00 \%$ of the premium using Panel C results.

[Table 8]

Table 9 reports the results for NASDAQ during the period 1983-2000. The ILLIQMA and ILLIQMA_A coefficients displayed in Panel A are 0.147 and 0.173 respectively. The price of illiquidity risk declines as we move from Panel A to Panel D and is not significant in Panel C or D. The coefficient difference values in the DIF column are significant in both Panel A and B, ranging from -0.026 in Panel A to -0.023 Panel B. Figure 
9 shows that these magnitudes imply that the illiquidity premium of ILLIQMA is understated during the period 1983-2000 by between 17.68\% (Panel A) and $17.29 \% \%$ (Panel B). These for this sub-sample are comparable to the results discussed in Table 6 for the full -period 1983-2008. Table 10 provides the results for NASDAQ stocks during the 2001-2008 period. The coefficients associated with illiquidity are lower than for the period 1983-2000, but remain significant in all specifications except that of Panel D. The coefficient difference values in the DIF column are comparable to those presented for the earlier period, and imply that the illiquidity premium of ILLIQMA is understated during the period 2001-2008 by between 21.05\% (Panel A) and 17.88\% (Panel B) ${ }^{36}$.

Comparison of the results for NASDAQ in Table 10 with those presented in Table 8 for NYSE/AMEX stocks, which both use the same sample period of 2001-2008, shows that on average across the cross section specifications the potential understatement of the illiquidity premium is larger for NASDAQ than for NYSE/AMEX stocks during this period.

[Table 9]

[Table 10]

\subsection{The Square Root Transformation of the Illiquidity Ratio}

Although most applications of the illiquidity ratio utilize the ratio which is computed exactly as shown by Amihud (2002), Hasbrouck (2009) noted that a square root transformation of the illiquidity ratio may perform better empirically. Recent applications of the illiquidity ratio by both Hasbrouck (2009) and Asparouhova, Bessembinder and

\footnotetext{
${ }^{36}$ We also examine other sub-periods including sub-periods of equal length for each market and find our findings that the Amihud ratio understates the risk premium associated with illiquidity is robust.
} 
Kalcheva (2010) have used this version of the illiquidity ratio. So, in this section, we show that our results are robust to this transformation. However, we also note that if no adjustments are made for thin trading bias, utilisation of the square root transformation will provide slightly less biased measures of the illiquidity premium.

We calculate the square root illiquidity ratio, $\sqrt{ }$ ILLIQMA, following the procedure used by Hasbrouck (2009). We compute daily values of ILLIQ (the daily absolute return to volume ratio), the square root transformation is then applied. These values are averaged over the year to obtain a transformed security illiquidity ratio, لILLIQ. For use in the crosssection tests, we scale the transformed security ratios by the average (transformed) ratio across all available stocks in the market, to generate $\sqrt{ }$ ILLIQMA. Days which contain zero volume are omitted. The non-trading adjusted measure, VILLIQMA_A, is calculated by

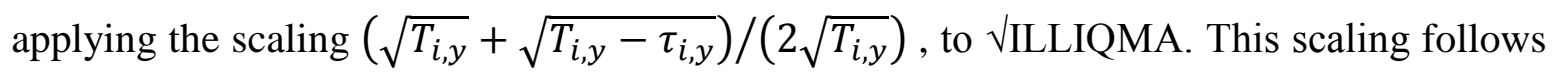
from equation (8).

\section{[Table 11]}

In Table 11 we report the Fama and MacBeth cross section regression results for NYSE/AMEX stocks for the same four model specifications used in earlier tests. The results show that the illiquidity premium coefficients are larger than was the case without the square root transformation and are comparable to the estimates provided by Hasbrouck (2009) and Asparouhova, Bessembinder and Kalcheva (2010) who also use the square root transformation. The values of the coefficients on VILLIQMA and VILLIQMA_A are 0.357 and 0.377 respectively (Panel A). The illiquidity coefficients are significant in all specifications. In Panel A to C the coefficient values are similar but are slightly lower in 
Panel D, the specification containing the greatest number of explanatory variables. The coefficient difference for the illiquidity measures in column DIF is also significant in all equations, again indicating a potential downwards bias in the illiquidity premium, ranging from -0.033 in Panel B to -0.006 in Panel D. The results presented for NYSE/AMEX stocks show that the square root transformation reduces the bias but does not eliminate it. This provides further support for using the square root transformation, especially if our proposed adjustment for thin trading is not made.

The results for NASDAQ stocks are contained in Table 12. The magnitude and pattern of results associated with illiquidity are comparable to those presented for the NYSE/AMEX stocks contained in Table 11. All measures of illiquidity are highly significant. The coefficients on VILLIQMA and VILLIQMA_A contained in Panel A are 0.341 and 0.369 respectively and fall to 0.067 and 0.078 in panel D. The DIF coefficient values for the illiquidity measures range from -0.032 in Panel B to -0.014 in Panel C signifying that in each specification there is a potential understatement of the illiquidity premium. Our results regarding the size of the potential bias are consistent with the findings for the NYSE/AMEX sample. The square root transformation reduces the bias but does not eliminate it.

[Table 12]

\section{Conclusions}

The Amihud-illiquidity ratio is now widely used to capture illiquidity in asset markets. However, the impact that thin trading has on its measurement has not been explored previously. This paper has examined the possible empirical biases that could be introduced 
both to the measurement of the illiquidity ratio and to estimates of the illiquidity premium because of thin trading.

We assess, through a simulation analysis, the relationship between thin trading and the measurement of illiquidity. When calculating the illiquidity ratio, which is an average of the daily ratios of absolute return to volume, it is standard practice to extract days of zero volume because the illiquidity ratio is mathematically undefined in these cases. Our simulations show that omitting these days from the computation of the illiquidity ratio can cause an upwards bias in the estimate of the illiquidity ratio. To counter this potential bias, we propose an almost bias free illiquidity ratio that is easily computed and will reflect the original measure when there is no thin trading. This measure involves applying a scaling factor to the illiquidity ratio that is a function of the number of possible trading days and the number of these days in which the stock actually traded.

We analyse the illiquidity ratios of stocks listed on the NYSE/AMEX and NASDAQ exchanges. The computation of the scaled and un-scaled illiquidity ratios suggests that there may be important biases in empirical since we find sizeable differences between the two ratios. Comparison of the NYSE/AMEX and the NASDAQ samples show that these differences are larger on the less liquid NASDAQ. When we analyse for each market groups of companies formed into deciles on the basis of market value we find that the divergence between the different illiquidity measures increases as we move from the large firm decile to the small firm decile. We also examine the measures of illiquidity using data observed at different frequencies. For lower frequency data, we find smaller differences between the two illiquidity measures. These results regarding both firm size and data 
observation frequency are consistent with thin trading being the underlying cause of the divergences between the illiquidity ratios.

Our summary statistics are complemented by a range of Fama and MacBeth style asset pricing tests, which include a range of control variables including alternative measures of liquidity. These regressions show that there are significant differences between the coefficients on the adjusted and unadjusted illiquidity ratios. During the period 19602008 the regression results suggest that, by omitting zero volume days when calculating the illiquidity ratio, the illiquidity premium coefficient associated with NYSE/AMEX stocks may be biased downwards by over $17 \%$. For NASDAQ securities during the later period 1983-2008 the regressions suggest that the illiquidity premium may be biased downwards by up to $24 \%$. These results are robust to re-examination in sub-samples of the full timespan of data and to use of the square-root form of the illiquidity ratio proposed by Hasbrouck (2009).

\section{References}

Acharya, Viral V., Pedersen, Lasse Heje, 2005. Asset pricing with illiquidity risk. Journal of Financial Economics 77, 375-410.

Aitken, M., Comerton-Forde C., 2003. How liquidity should be measured. Pacific Basin Finance Journal 11, 45-59.

Ajinkya, B. B., Atiase, R. K., \& Gift, M. J., 1991. Volume of trading and the dispersion in financial analysts' earnings forecasts. Accounting Review 66, 389-401.

Amihud, Yakov, 2002. Illiquidity and stock returns: cross-section and time-series effects. Journal of Financial Markets 5, 31-56.

Amihud, Y., Mendelson, H., Lauterbach, B., 1997. Market microstructure and securities values: evidence from the Tel Aviv Exchange. Journal of Financial Economics 45, 365-390.

Antoniou, A., and Holmes P., Market efficiency, thin trading and non-linear behaviour: evidence from an emerging market. European Financial Management. 3, 175-190. 
Asparouhova, E., Bessembinder, H., and Kalcheva, I., 2010. Liquidity biases in asset pricing tests, Journal of Financial Economics, 96, 215-237.

Bekaert, G., Harvey, C.R., and C. Lundblad, 2007, Liquidity and expected returns: Lessons from emerging markets, Reviews of Financial Studies 20, 1783-1831.

Becker-Blease, J.R., Paul D.L., 2006. Stock liquidity and investment opportunities: Evidence from index additions. Financial Management, 35-51.

Berkman, H., Eleswarapu, V.R., 1998. Short term traders and liquidity: a test using Bombay Stock Exchange data. Journal of Financial Economics 47, 339-355.

Bessembinder, H., (2003) Trade execution costs and market quality after decimalization, Journal of Financial and Quantitative Analysis,

Bohrnstedt, G.W., and A.S. Goldberger, 1969. On the exact covariance of products of random variables. Journal of the American Statistical Association 64, 1439-1442.

Boudoukh J., Richardson M.P., and Whitelaw R.F., 1994. A tale of three schools: insights on autocorrelation of short horizon stock returns. Review of Financial Studies 7, 539-573.

Brennan, M., Huh, S-W, and A. Subrahmanyam, 2013. An analysis of the Amihud Illiquidity Premium, The Review of Asset Pricing Studies 3, 133-176.

Chakravarty, S., Bonnie F. Van Ness and Robert A. Van Ness (2005). The effect of decimalization on trade size and adverse selection costs, Journal of Business Finance and Accounting, 32, 1063-1081.

Chan, J.S.P., Hong, D., Subrahmanyam, M.G., 2008. A tale of two prices: liquidity and asset prices in multiple markets. Journal of Banking and Finance 32, 947-960.

Chelley-Steeley, P.L., 2008. Market quality changes in the London Stock Market, Journal of Banking and Finance, 32 393-416.

Chelley-Steeley, P.L., (2015). The Role of Pre-existing Liquidity in Determining Price Efficiency and Liquidity Gains Following the Introduction of SETSmm, European Financial Management 21 360-376.

Chelley-Steeley, P.L., N. Lambertides and J.M. Steeley (2015). Risk Shifting Behavior at the Turn of the Year, forthcoming, International Review of Financial Analysis.

Chordia, T., Roll, R., Subrahmanyam, A., 2000. Commonality in illiquidity. Journal of Financial Economics 56, 3-28.

Chordia, T., and Swaminathan, B., 2000. Trading volume and cross-autocorrelations in stock returns. The Journal of Finance 55, 913-935.

Chordia, Tarun, Goyal A., G. Sadka, R. Sadka and L. Shivakumar, 2009. Illiquidity and post-earningsannouncement drift, Financial Analysts Journal, 65, 6-10.

Cooper, S.K., Groth, J.C., Avera, W.E., 1985. Liquidity, exchange listing and common stock performance. Journal of Economics and Business 37, 19-33.

Daniel, K., and Titman S., 1997. Evidence on the characteristics of cross-sectional variation in stock returns. The Journal of Finance 52, 1-33. 
Dick-Nielsen, J., Feldhutter, P., and Lando, D., 2012, Corporate bond liquidity before and after the onset of the subprime crisis, Journal of Financial Economics 103, 471-492.

Dimson, E., 1979. Risk, measurement when shares are subject to infrequent trading. Journal of Financial Economics 7, 197-226.

Eckbo, B.E., Norli, O., 2002. Pervasive liquidity risk. Unpublished working paper Dartmouth College.

Fama, Eugene. F., French, Kenneth.R., 1992. The cross-section of expected returns. The Journal of Finance 47, 427-465.

Fama, Eugene F., French, Kenneth, R. 1993, Common risk factors in the returns on stocks and bonds .Journal of Financial Economics 33, 3-56.

Fama, Eugene F., MacBeth, James D., 1973. Risk, return and equilibrium: empirical tests. Journal of Political Economy 71, 427-465.

French, K., and R. Roll, 1986, Stock price variances: The arrival of information and the reaction of traders. Journal of Financial Economics 17, 5-26.

Gallant, A. R., Rossi, P. E., \& Tauchen, G., 1992. Stock prices and volume. Review of Financial studies 5, 199-242.

Gaspar, J.M., Massa, M., 2007, Local ownership as private information: evidence on the illiquiditymonitoring trade-off. Journal of Financial Economics, 76 135-165.

Gervais, S., Kaniel, R., \& Mingelgrin, D. H., 2001. The high-volume return premium. The Journal of Finance 56, 877-919.

Glosten, L.R., and Harris, L.E., 1988. Estimating the components of the bid/ask spread, Journal of Financial Economics, 21, 123-42.

Hong, H., Lim, T., and Stein J., 1999. Bad news travels slowly; size, analyst coverage and the profitability of momentum strategies. The Journal of Finance 55, 265-295.

Hasbrouck, Joel 2009, Trading costs and returns for U.S. equities : Estimating effective costs from daily data . Journal of Finance 64, 1445-1477.

Hasbrouck, J., Seppi, D., 2001. Common factors in prices, order flows and liquidity. Journal of Financial Economics 59, 383-411.

Hendershott, T., C. Jones and A. Menkveld (2011). Does algorithmic trading improve liquidity? Journal of Finance 66, 1-33.

Henke, H., Lauterbach, B., 2005, Firm initiated and exchange initiated transfers to continuous trading: Evidence from the Warsaw Stock Exchange, Journal of Financial Market 8, 310-324.

Jegadeesh, N., and Titman, S., 1993. Returns to buying winners and selling losers, implications for stock market efficiency. The Journal of Finance 48, 65-91.

Karpoff, J. M., 1987. The relation between price changes and trading volume: A survey. Journal of Financial and Quantitative Analysis 22, 109-126. 
Kyle, A.S., 1985, Continuous auctions and insider trading, Econometrica, 53, 1315-1335.

Leone, F.C., Nottingham, R.B., and Nelson, L.S., 1961. The folded normal distribution. Technometrics, 3 (4) 543-550.

Lesmond, D.A., Ogden, J.P., and Trzcinka. C.A., 1999. A New Estimate of Transaction Costs, Review of Financial Studies, 12, 1113-1141.

Lo, A. W., A.C. MacKinlay, 1990. An econometric analysis of nonsynchronous trading, Journal of Econometrics 45, 181-211.

Lou, X.,and T. Shu, 2014. Price Impact or Trading Volume: Why is the Amihud (2002) Illiquidity Measure Priced? Available at SSRN: http://ssrn.com/abstract=2291942.

Lim, K-P., Habibullah., M.S., and Hinich, M., J., 2009. The weak-form of efficiency of Chinese Stock markets, Journal of Emerging Markets, 8, 133-163.

Pagano, M.S., Schwartz, R.A., 2003, A Closing Call’s Impact on Market Quality at Euronext Paris. Journal of Financial Economics 68, 439-484.

Pastor, L., Stambaugh, R., 2003. Iliquidity risk and expected stock returns. The Journal of Political Economy $111,642-685$.

Roll, R., 1984. A simple implicit measure of the effective bid-ask spread in an efficient market. The Journal of Finance 39, 1127-39.

Scholes, M., and J. Williams, 1977. Estimating betas from nonsynchronous data, Journal of Financial Economics, 5, 309-327.

Shanken, J., 1992. On the estimation of beta-pricing models, Review of Financial Studies, 5 1-55. 


\section{Table 1: Mean absolute percentage errors for liquidity measures calculated from simulated returns data}

Summary statistics on the mean absolute percentage error between a liquidity measure featuring non-trading and the measure for the same simulated returns when the non-trading probability is zero. ILLIQ is the Amihud (2002) measure with non-trading days excluded. ILLIQ_A is the measure ILLIQ scaled by (2T- $\tau$ )/2T, where $T$ is the number of possible trading days and $\tau$ is the number of zero volume days within $T$. The absolute percentage error for a given percentile is the absolute percentage error between the liquidity measure for that percentile non-trading probability and the measure with a zero non-trading probability.

\begin{tabular}{|c|c|c|c|c|c|c|c|c|c|c|c|}
\hline \multirow[b]{2}{*}{ Illiquidity Ratio } & \multicolumn{10}{|c|}{ Non-trading probability deciles } & \multirow{2}{*}{$\begin{array}{c}\text { Full } \\
\text { Sample }\end{array}$} \\
\hline & 1 & 2 & 3 & 4 & 5 & 6 & 7 & 8 & 9 & 10 & \\
\hline ILLIQ & 2.49 & 7.37 & 13.73 & 21.17 & 30.42 & 43.82 & 61.80 & 89.06 & 144.31 & 363.18 & 74.85 \\
\hline ILLIQ_A & 0.42 & 1.00 & 1.01 & 0.66 & 0.60 & 3.73 & 8.78 & 18.04 & 40.04 & 141.69 & 20.38 \\
\hline
\end{tabular}

\section{Table 2: Zero Volume Days for NYSE/AMEX and NASDAQ stocks}

Summary statistics relating to occurrences of zero daily volume on trading days for stocks on NYSE/AMEX (1960-2008) and NASDAQ (1983-2008), sorted by capitalization. The proportion of zero volume days is calculated for each stock as the number of zero volume days divided by the number of trading days within the year. This proportion is then averaged across all stocks in the decile for a given year, and then averaged across all the years for each decile. Decile number 1 contains the smallest stocks by capitalization. The figures in parentheses below the zero volume proportions are the standard deviation of the annual figures giving a measure of the variation in the proportion of zero volume days across time. Zero volume days with non-zero returns gives the percentage of trading days where volume was zero and the return was non-zero, and is computed following the same steps as for the proportion of zero volume days.

\begin{tabular}{|c|c|c|c|c|c|c|c|c|c|c|}
\hline & \multicolumn{10}{|c|}{ Averages across stocks by capitalization decile } \\
\hline & 1 & 2 & 3 & 4 & 5 & 6 & 7 & 8 & 9 & 10 \\
\hline & \multicolumn{10}{|c|}{ Panel A NYSE-AMEX 1960-2008 } \\
\hline \multirow[t]{3}{*}{ Zero volume days (\%) } & 21.56 & 12.56 & 8.08 & 4.93 & 3.01 & 2.02 & 1.27 & 0.83 & 0.32 & 0.07 \\
\hline & $(8.44)$ & (5.78) & (4.09) & (3.29) & $(2.48)$ & $(2.00)$ & $(1.25)$ & $(0.98)$ & $(0.47)$ & $(0.12)$ \\
\hline & \multicolumn{10}{|c|}{ Panel B NASDAQ 1983-2008 } \\
\hline \multirow[t]{2}{*}{ Zero volume days (\%) } & 22.89 & 16.81 & 13.15 & 9.44 & 7.08 & 5.00 & 3.41 & 2.28 & 1.21 & 0.41 \\
\hline & (10.39) & (7.79) & (6.16) & $(5.00)$ & (4.38) & (3.92) & (3.11) & (2.15) & $(1.25)$ & $(0.48)$ \\
\hline
\end{tabular}


Table 3: Summary Statistics

This table reports mean, median, standard deviation (St Dev.) values of the following variables. MV is the logarithm of December market value. Volume is daily volume in millions of US dollars. ILLIQ and ILLIQ_A are the illiquidity ratios computed from daily information multiplied by $10^{6}$. ILLIQ is computed using all available data but excluding zero volume days. ILLIQ_A is ILLIQ scaled by scaled by $(2 T-\tau) / 2 T$, where $T$ is the number of possible trading days and $\tau$ is the number of zero volume days within T. ILLIQ-ILLIQ_A \% Diff is the percentage difference between ILLIQ and ILLIQ_A. iILLIQ and iILLIQ_A are the inflation adjusted illiquidity ratios, $\beta_{\mathrm{rm}}$ is the estimated portfolio market beta from the twenty five portfolios, $\beta_{\mathrm{SMB}}$ is the estimated beta on the FamaFrench SMB factor from the twenty five portfolios, $\beta_{\mathrm{HML}}$ is the is the estimated beta on the Fama-French HML factor from the twenty five portfolios. $\beta_{\mathrm{ps}}$ is the beta on the Pastor-Stambaugh market-wide illiquidity factor from the twenty five portfolios. $B_{\text {Mom }}$ is the beta on the Fama-French Mom factor from the twenty five portfolios. $\mathrm{R}(-6)$ is the prior six month return, B/M is the book-to-market ratio of the firm, Roll Spread is the Roll (1984) effective spread, Turnover is the stock turnover measured as volume divided by number of shares issued. Panel A presents results for NYSE/AMEX stocks for the periods 1960-2008, 1960-2000 and 2001-2008,. Panel B presents results for NASDAQ stocks 1983-2008, 1983-2000 and 2001-2008.

\begin{tabular}{|c|c|c|c|c|c|c|c|c|c|}
\hline & \multicolumn{9}{|c|}{ Panel A: NYSE/AMEX } \\
\hline & \multicolumn{3}{|c|}{$1960-2008$} & \multicolumn{3}{|c|}{$1960-2000$} & \multicolumn{3}{|c|}{ 2001-2008 } \\
\hline & Mean & Median & St Dev. & Mean & Median & St.Dev. & Mean & Median & St.Dev. \\
\hline MV & 11.7902 & 11.6484 & 9.0622 & 11.5331 & 11.4030 & 8.9386 & 13.2366 & 13.4205 & 9.1632 \\
\hline Volume & 0.2151 & 0.0119 & 1.2798 & 0.0766 & 0.0084 & 0.3352 & 1.0094 & 0.2357 & 3.1055 \\
\hline ILLIQ & 15.853 & 12.164 & 11.821 & 16.3728 & 4.3739 & 33.5605 & 4.9834 & 0.0992 & 26.6680 \\
\hline ILLIQ_A & 14.522 & 11.278 & 10.719 & 15.0506 & 4.3606 & 27.8997 & 4.6536 & 0.0992 & 24.7795 \\
\hline ILLIQ-ILLIQ_A \% Diff & 0.0155 & 0.0000 & 0.0472 & 0.0171 & 0.0000 & 0.0495 & 0.0058 & 0.0000 & 0.0291 \\
\hline lilliq & 39.3244 & 36.0312 & 19.9177 & 41.6758 & 37.3115 & 18.3015 & 31.4562 & 22.1838 & 19.1644 \\
\hline iILLIQ_A & 36.3653 & 33.4604 & 15.6462 & 37.4934 & 34.3372 & 15.0290 & 29.3258 & 34.1320 & 18.0117 \\
\hline$\beta_{\mathrm{rm}}$ & 1.0627 & 1.0636 & 0.2077 & 1.0633 & 1.0636 & 0.2077 & 1.0597 & 1.0636 & 0.2078 \\
\hline$\beta_{S M B}$ & 0.7312 & 0.7594 & 0.4539 & 0.7323 & 0.7594 & 0.4552 & 0.7260 & 0.7594 & 0.4475 \\
\hline$\beta_{\mathrm{HML}}$ & 0.5171 & 0.5312 & 0.1741 & 0.5173 & 0.5312 & 0.1736 & 0.5160 & 0.5338 & 0.1769 \\
\hline$\beta_{p s}$ & 1.0003 & 1.4856 & 2.6065 & 0.9951 & 1.4856 & 2.6121 & 1.0260 & 1.4856 & 2.5781 \\
\hline$\beta_{\text {Mom }}$ & -0.098 & -0.0983 & 0.0736 & -0.0989 & -0.0988 & 0.0733 & -0.0975 & -0.0989 & 0.0747 \\
\hline$R(-6)$ & 1.2070 & 0.0000 & 12.4457 & 1.2974 & 0.0000 & 12.1732 & 0.6612 & 4.7707 & 7.0222 \\
\hline $\mathrm{B} / \mathrm{M}$ & 2.4350 & 0.6569 & 432.32 & 2.7272 & 0.6890 & 462.61 & 0.4370 & 0.4997 & 6.7237 \\
\hline Roll Spread & 0.2940 & 0.2077 & 0.3253 & 0.2941 & 0.2095 & 0.3230 & 0.2932 & 0.1956 & 0.3371 \\
\hline Turnover & 2.8834 & 1.6509 & 4.1539 & 2.2253 & 1.4375 & 2.9572 & 6.6526 & 4.7707 & 7.0222 \\
\hline
\end{tabular}


Table 3: Summary Statistics (cont.)

\begin{tabular}{|c|c|c|c|c|c|c|c|c|c|}
\hline \multicolumn{10}{|c|}{$\begin{array}{l}\text { This table reports mean, median, standard deviation (St Dev.) values of the following variables. MV is the } \\
\text { daily volume in millions of US dollars. ILLIQ and ILLIQ_A are the illiquidity ratios computed from daily in } \\
\text { using all available data but excluding zero volume days. ILLIQ_A is ILLIQ scaled by scaled by }(2 T-\tau) / 2 T \text {, wher } \\
\text { is the number of zero volume days within } T \text {. ILLIQ-ILLIQ_A \% Diff is the percentage difference between } \\
\text { inflation adjusted illiquidity ratios, } \beta_{\mathrm{rm}} \text { is the estimated portfolio market beta from the twenty five port } \\
\text { French SMB factor from the twenty five portfolios, } \beta_{\mathrm{HML}} \text { is the is the estimated beta on the Fama-French } \\
\text { the beta on the Pastor-Stambaugh market-wide illiquidity factor from the twenty five portfolios. } B_{\text {Mom is }} \\
\text { the twenty five portfolios. R(-6) is the prior six month return, B/M is the book-to-market ratio of the firm } \\
\text { Turnover is stock turnover. Panel A presents results for NYSE/AMEX stocks for the periods } 1960-2008 \\
\text { results for NASDAQ stocks } 1983-2008,1983-2000 \text { and } 2001-2008 \text {. }\end{array}$} \\
\hline & \multicolumn{9}{|c|}{ Panel B: NASDAQ } \\
\hline & \multicolumn{3}{|c|}{ 1983-2008 } & \multicolumn{3}{|c|}{$1983-2000$} & \multicolumn{3}{|c|}{ 2001-2008 } \\
\hline & Mean & Median & St.Dev. & Mean & Median & St.Dev. & Mean & Median & St. Dev \\
\hline MV & 11.3172 & 11.2051 & 8.6534 & 11.0235 & 10.9211 & 8.5274 & 12.0077 & 11.9718 & 8.7420 \\
\hline Volume & 0.2291 & 0.0220 & 1.6098 & 0.0926 & 0.0156 & 0.5707 & 0.6034 & 0.0893 & 2.9356 \\
\hline ILLIQ & 20.9403 & 3.8465 & 68.0399 & 22.8572 & 6.0237 & 64.0053 & 15.6836 & 0.5201 & 77.8008 \\
\hline ILLIQ_A & 18.0394 & 3.7207 & 53.0677 & 19.1894 & 5.7466 & 43.9850 & 14.8855 & 0.5201 & 72.2509 \\
\hline ILLIQ-ILLIQ_A \% Diff & 0.0383 & 0.0000 & 0.5313 & 0.0497 & 0.0020 & 0.0964 & 0.0072 & 0.0000 & 0.0298 \\
\hline iILLIQ & 111.4275 & 97.4792 & 46. 1718 & 109.1033 & 97.0031 & 46.1789 & 116.3268 & 83.1957 & 108. 2604 \\
\hline iILLIQ_A & 96.2081 & 82.7129 & 4.6615 & 91.8300 & 82.4938 & 34.3610 & 111.3506 & 82.2621 & 104.3428 \\
\hline$\beta_{\mathrm{rm}}$ & 1.0594 & 1.0718 & 0.2749 & 1.0686 & 1.0934 & 0.2740 & 1.0429 & 1.0718 & 0.2756 \\
\hline$\beta_{S M B}$ & 0.7186 & 0.7448 & 0.2125 & 0.7185 & 0.7448 & 0.2113 & 0.7189 & 0.7448 & 0.2147 \\
\hline$\beta_{\mathrm{HML}}$ & 0.3120 & 0.4031 & 0.2840 & 0.3064 & 0.4031 & 0.2868 & 0.3219 & 0.4391 & 0.2786 \\
\hline$\beta_{\mathrm{ps}}$ & 0.1983 & -0.5034 & 3.2977 & 0.1838 & -0.5034 & 3.3128 & 0.2243 & -0.5034 & 3.2703 \\
\hline$\beta_{\text {Mom }}$ & -0.1242 & -0.0929 & 0.1078 & -0.1268 & -0.0932 & 0.1075 & -0.1196 & -0.0929 & 0.1083 \\
\hline$R(-6)$ & 1.0154 & 0.0000 & 16.065 & 1.0684 & 0.0000 & 16.371 & 0.8666 & 0.0000 & 20.181 \\
\hline $\mathrm{B} / \mathrm{M}$ & 0.5718 & 0.5347 & 19.232 & 0.5865 & 0.5479 & 21.81 & 0.5252 & 0.5025 & 5.5768 \\
\hline Roll Spread & 0.5275 & 0.3745 & 0.5339 & 0.5716 & 0.4113 & 0.5709 & 0.4004 & 0.2859 & 0.3816 \\
\hline Turnover & 5.0391 & 2.7603 & 7.6303 & 4.2951 & 2.5554 & 6.1198 & 7.1312 & 4.1290 & 10.520 \\
\hline
\end{tabular}




\section{Table 4: Regressions against transactions measures of illiquidity}

Panel A presents the estimated coefficients of the regression equation,

$$
y_{i, t}=\alpha+\beta \lambda_{i, t}+\gamma \psi_{i, t}+\varepsilon_{i, t}
$$

where $y_{i, t}$ is, in turn, $I L L I Q_{i, t}$, the Amihud (2002) illiquidity ratio, equation (2), ILLIQ_A $A_{i, t}$, the adjusted illiquidity ratio proposed in equation (11), or the difference between the two measures, for all firms with NYSE TAQ data for the period 1993 to 2008. The regressions are run as a panel with both firm and time fixed effects. The explanatory variables are $\lambda$ the Kyle (1985) price impact measure and $\psi$ the fixed-cost component of the spread, and are estimated from intraday quotes and transactions using the method of Glosten and Harris (1988). In Panel B, we calculate a mean difference in the R-squared values from each of the regressions for $I L L I Q_{i, t}$, and ILLIQ_A $A_{i, t}$, using estimates for each year separately to constitute a sample. We do this for the full sample of all firms, and separately by size quintile. In Panel $\mathrm{C}$, we examine the R-squared for regressions for the difference between the two measures, using estimates for each year separately to constitute a sample, both for the full sample of firms and for each size quintile. The * implies significance at a $10 \%$ level, $* *$ at a $5 \%$ level and $* * *$ at a $1 \%$ level. The figures in parentheses are t-statistics.

\begin{tabular}{|c|c|c|c|c|c|c|}
\hline \multicolumn{7}{|c|}{ Panel A: Panel Regression Results (all firms, all years) } \\
\hline & \multicolumn{2}{|r|}{ Constant } & $\lambda($ Kyle) & \multicolumn{2}{|c|}{$\psi$ (Fixed Cost) } & $\mathrm{R}^{2}$ \\
\hline \multirow[t]{2}{*}{$\mathrm{I} L L I Q_{i, t}$} & \multicolumn{2}{|r|}{1.425} & 1.641 & \multicolumn{2}{|c|}{10.491} & $3.35 \%$ \\
\hline & \multicolumn{2}{|r|}{$(45.91)^{* * *}$} & $(23.41)^{* * *}$ & \multicolumn{2}{|c|}{$(20.23)^{* * *}$} & \\
\hline \multirow[t]{2}{*}{$\mathrm{I} L L I Q_{-} A_{i, t}$} & \multicolumn{2}{|r|}{1.394} & 1.605 & \multicolumn{2}{|c|}{10.216} & $3.37 \%$ \\
\hline & \multicolumn{2}{|r|}{$(46.18)^{* * *}$} & $(23.54)^{* * *}$ & \multicolumn{2}{|c|}{$(20.26)^{* * *}$} & \\
\hline \multirow[t]{2}{*}{$\mathrm{I} L L I Q \_A_{i, t}-\mathrm{I} L L I Q_{i, t}$} & \multirow{2}{*}{\multicolumn{2}{|c|}{$\begin{array}{c}-0.031 \\
(-11,10) * * *\end{array}$}} & -0.036 & \multicolumn{2}{|c|}{$\begin{array}{c}-0.275 \\
(-5.81) * * *\end{array}$} & $0.23 \%$ \\
\hline & $(-11.10) * * *$ & & $(-5.67)^{* * *}$ & \multicolumn{2}{|c|}{$(-5.81)^{* * *}$} & \\
\hline \multicolumn{7}{|c|}{ Panel B: Test of null hypothesis of zero difference between the $\mathrm{R}^{2}\left(\mathrm{H}_{0}: \Delta \mathrm{R}^{2}=0\right)$ for $\mathrm{I} L L I Q_{i, t}$ and $\mathrm{I} L L I Q_{-} A_{i, t}$} \\
\hline & \multicolumn{5}{|c|}{ Quintiles sorted by firm size } & \multirow[t]{2}{*}{ Full Sample } \\
\hline & Small & 2 & 3 & 4 & Large & \\
\hline Average $\Delta \mathrm{R}^{2}$ & 0.00243 & 0.00190 & 0.00016 & 0.00007 & $<0.00001$ & 0.00078 \\
\hline \multirow[t]{4}{*}{ t-stat } & $(2.21)^{* *}$ & $(2.54)^{* *}$ & $(3.33)^{* * *}$ & $(1.98)^{*}$ & $(1.00)$ & $(3.12)^{* * *}$ \\
\hline & \multicolumn{5}{|c|}{ Panel C: Test of null hypothesis of zero for the $\mathrm{R}^{2}\left(\mathrm{H}_{\mathrm{o}}: \mathrm{R}^{2}=0\right)$ for $\mathrm{I} L L I Q_{i, t}-\mathrm{I} L L I Q_{-} A_{i, t}$} & \\
\hline & \multicolumn{5}{|c|}{ Quintiles sorted by firm size } & \multirow[t]{2}{*}{ Full Sample } \\
\hline & Small & 2 & 3 & 4 & Large & \\
\hline Average $\mathrm{R}^{2}$ & 0.04860 & 0.08086 & 0.01161 & 0.03547 & 0.00822 & 0.01403 \\
\hline t-stat & $(3.81)^{* * *}$ & $(2.00)^{*}$ & $(3.48)^{* * *}$ & $(1.69)^{*}$ & $(1.00)$ & $(3.52)^{* * *}$ \\
\hline
\end{tabular}


Table 5: Fama-MacBeth Cross Section Results NYSE/AMEX 1960-2008

Reported estimates are the time series average of coefficients from cross-sectional Fama-MacBeth regressions using monthly return data for NYSE/AMEX stocks over the period 1960-2008. Panel A reports results of monthly returns regressed on the estimated market beta $\left(\beta_{\mathrm{rm}}\right)$ and one of the two illiquidity measures ILLIQMA, or ILLIQMA_A. ILLIQMA has been computed as described in Amihud (2002) and omits any zero volume days. ILLIQMA_A is ILLIQMA scaled by $(2 T-\tau) / 2 T$, where $T$ is the number of possible trading days and $\tau$ is the number of zero volume days within $T$. The column headed DIF reports the time series average of the difference between the cross section coefficients obtained from the regressions using each of the two illiquidity measures. Panel $B$ contains estimates where the cross-section model specification also includes $\beta_{\mathrm{ps}}$ the market-wide illiquidity risk factor, and the estimated betas on the Fama-French SMB $\left(\beta_{\mathrm{SMB}}\right), \mathrm{HML}\left(\beta_{\mathrm{HML}}\right)$ and Mom ( $\left.\beta_{\text {Mom }}\right)$ factors. Panel $C$ are the results from the specification that augments the regressions with market value (Size), book-to-market value (B/M), and the prior six month return, $\mathrm{R}(-6)$. Panel $D$ extends the model further by including two alternative measures of liquidity, the Roll (1984) effective spread (Spread) and turnover (Turnover). The * implies significance at a $10 \%$ level, ${ }^{* *}$ at a $5 \%$ level and ${ }^{* * *}$ at a $1 \%$ level using Shanken (1992) adjusted t-statistics. Two-Stage are the results of the two stage regression in which ILLIQMA_A is regressed against ILLIQMA. Second stage results are reported in which these residuals, risk factors and characteristics are regressed against one year ahead returns. In this second stage regression the illiquidity variable are the residuals from the first stage regression.

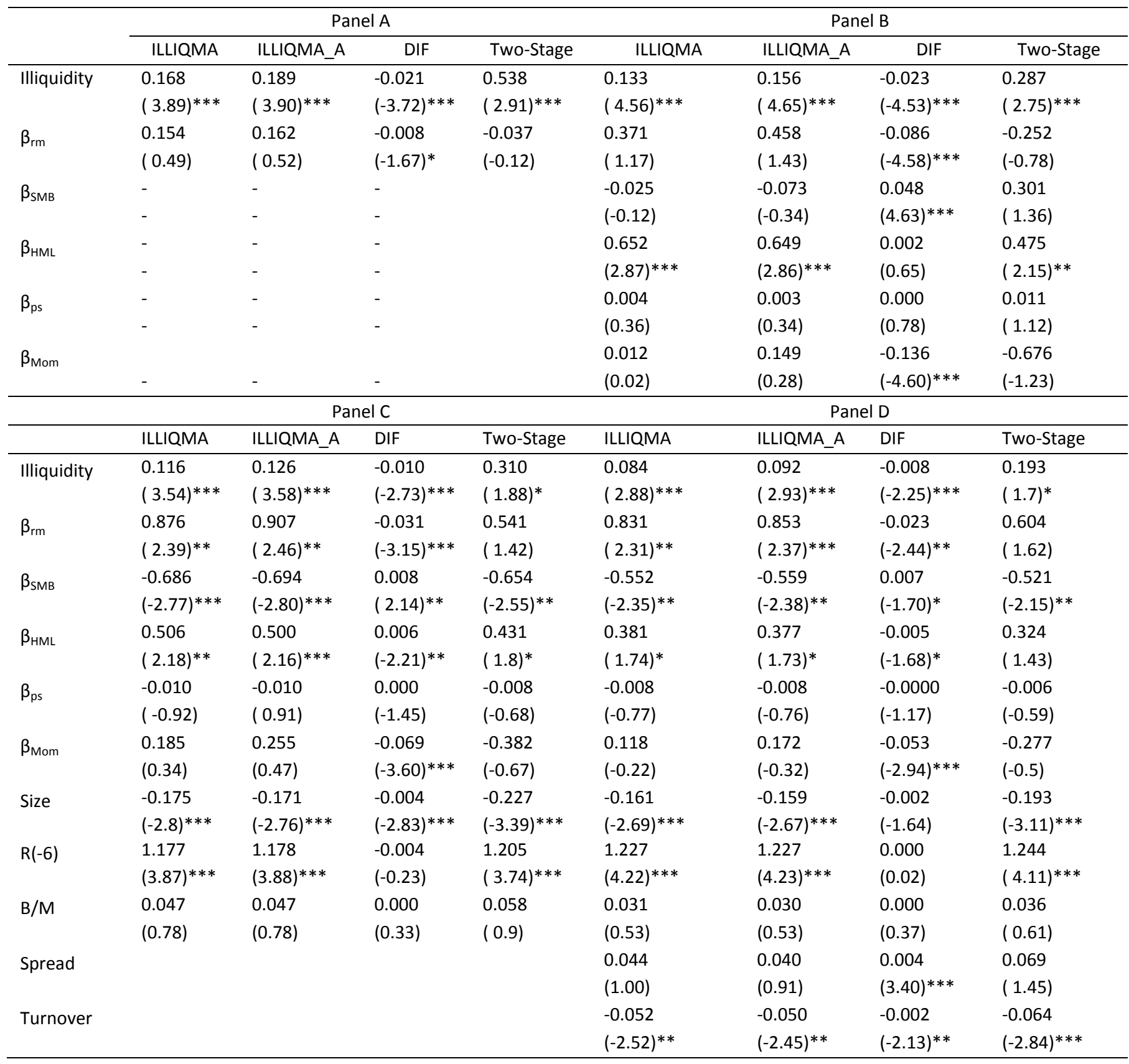


Table 6: Fama-MacBeth Cross-Section Results NASDAQ 1983-2008

Reported estimates are the time series average of coefficients from cross-sectional Fama-MacBeth regressions using monthly return data for NASDAQ stocks over the period 1983-2008. Panel A reports results of monthly returns regressed on the estimated market beta $\left(\beta_{\mathrm{rm}}\right)$ and one of the two illiquidity measures ILLIQMA, or ILLIQMA_A. ILLIQMA has been computed as described in Amihud (2002) and omits any zero volume days. ILLIQMA_A is ILLIQMA scaled by $(2 T-\tau) / 2 T$, where $T$ is the number of possible trading days and $\tau$ is the number of zero volume days within $T$. The column headed DIF reports the time series average of the difference between the cross section coefficients obtained from the regressions using each of the two illiquidity measures. Panel B contains estimates where the cross-section model specification also includes $\beta_{p s}$ the market-wide illiquidity risk factor, and the estimated betas on the Fama-French SMB $\left(\beta_{S M B}\right), H M L\left(\beta_{H M L}\right)$ and Mom $\left(\beta_{M o m}\right)$ factors. Panel $C$ are the results from the specification that augments the regressions with market value (Size), book-to-market value $(B / M)$, and the prior six month return, $R(-6)$. Panel $D$ extends the model further by including two alternative measures of liquidity, the Roll (1984) effective spread (Spread) and turnover (Turnover).. The * implies significance at a $10 \%$ level, ${ }^{* *}$ at a $5 \%$ level and ${ }^{* * *}$ at a $1 \%$ level using Shanken (1992) adjusted t-statistics. $N$ is the number of firm months in the sample. Two-Stage are the results of the two stage regression in which ILLIQMA_A is regressed against ILLIQMA. Second stage results are reported in which these residuals, risk factors and characteristics are regressed against one year ahead returns. In this second stage regression the illiquidity variable are the residuals from the first stage regression.

\begin{tabular}{|c|c|c|c|c|c|c|c|c|}
\hline & \multicolumn{4}{|c|}{ Panel A } & \multicolumn{4}{|c|}{ Panel B } \\
\hline & ILLIQMA & ILLIQMA_A & DIF & Two-Stage & ILLIQMA & ILLIQMA_A & DIF & Two-Stage \\
\hline \multirow[t]{2}{*}{ Illiquidity } & 0.140 & 0.165 & -0.025 & 0.654 & 0.117 & 0.138 & -0.021 & 0.543 \\
\hline & $(4.21)^{* * *}$ & $(4.52)^{* * *}$ & $(-3.71)^{* * *}$ & $(3.1)^{* * *}$ & $(3.05)^{* * *}$ & $(3.26)^{* * *}$ & $(-2.88)^{* * *}$ & $(2.96)^{* * *}$ \\
\hline \multirow[t]{2}{*}{$\beta_{\mathrm{rm}}$} & 0.361 & 0.411 & -0.050 & 0.165 & 0.533 & 0.572 & -0.038 & 0.396 \\
\hline & ( 0.79$)$ & $(0.90)$ & $(-4.16)^{* * *}$ & $(0.35)$ & ( 1.48$)$ & ( 1.60$)$ & $(-3.01)^{* * *}$ & (1.09) \\
\hline \multirow[t]{2}{*}{$\beta_{\mathrm{SMB}}$} & - & - & - & & -0.111 & 0.066 & 0.045 & 0.147 \\
\hline & - & - & - & & $(0.22)$ & $(0.13)$ & $(3.42)^{* * *}$ & $(0.3)$ \\
\hline \multirow[t]{2}{*}{$\beta_{\mathrm{HML}}$} & - & - & - & & 0.532 & 0.537 & -0.005 & 0.488 \\
\hline & - & - & - & & (1.28) & $(1.28)$ & $(-1.72)^{*}$ & ( 1.21$)$ \\
\hline \multirow[t]{2}{*}{$\beta_{\mathrm{ps}}$} & - & - & - & & 0.044 & 0.040 & 0.004 & 0.062 \\
\hline & - & - & - & & $(2.14)^{* *}$ & $(1.95)^{*}$ & $(3.37)^{* * *}$ & $(3.47)^{* * *}$ \\
\hline \multirow[t]{4}{*}{ Size } & - & - & - & & -1.667 & -1.659 & -0.008 & -1.775 \\
\hline & - & - & - & & $(-1.75)^{*}$ & $(-1.74)^{*}$ & $(-0.67)$ & $(-1.87)^{*}$ \\
\hline & \multicolumn{4}{|c|}{ Panel C } & \multicolumn{4}{|c|}{ Panel D } \\
\hline & ILLIQMA & ILLIQMA_A & DIF & Two-Stage & ILLIQMA & ILLIQMA_A & DIF & Two-Stage \\
\hline \multirow[t]{2}{*}{ Illiquidity } & 0.072 & 0.083 & -0.012 & 0.611 & 0.033 & 0.041 & -0.008 & 0.457 \\
\hline & $(1.88)^{*}$ & $(2.02)^{* *}$ & $(-2.55)^{* *}$ & $(2.5)^{* *}$ & (1.3) & (1.63) & $(-1.7)^{*}$ & $(1.99)^{* *}$ \\
\hline \multirow[t]{2}{*}{$\beta_{\mathrm{rm}}$} & 1.285 & 1.294 & -0.009 & 1.272 & 1.338 & 1.341 & -0.002 & 1.352 \\
\hline & $(3.33)^{* * *}$ & $(3.38)^{* * *}$ & $(-1.71)^{*}$ & $(3.12)^{* * *}$ & $(3.67)^{* * *}$ & $(3.7)^{* * *}$ & $(-0.53)$ & $(3.55)^{* * *}$ \\
\hline \multirow[t]{2}{*}{$\beta_{\mathrm{SMB}}$} & -1.771 & -1.764 & -0.007 & -1.862 & -1.674 & -1.670 & -0.004 & -1.725 \\
\hline & $(-4.01)^{* * *}$ & $(-4.01)^{* * *}$ & $(-1.55)$ & $(-4.06)^{* * *}$ & $(-4.14)^{* * *}$ & $(-4.14)^{* * *}$ & $(-0.89)$ & $(-4.19)^{* * *}$ \\
\hline \multirow[t]{2}{*}{$\beta_{\mathrm{HML}}$} & 0.987 & 0.981 & 0.006 & 1.000 & 0.888 & 0.884 & 0.004 & 0.896 \\
\hline & $(2.75)^{* * *}$ & $(2.75)^{* * *}$ & $(2.33)^{* *}$ & $(2.72)^{* * *}$ & $(2.73)^{* * *}$ & $(2.73)^{* * *}$ & $(1.69)^{*}$ & $(2.74)^{* * *}$ \\
\hline \multirow[t]{2}{*}{$\beta_{\mathrm{ps}}$} & -0.021 & -0.022 & 0.001 & -0.017 & -0.011 & -0.012 & 0.001 & -0.010 \\
\hline & $(-0.94)$ & $(-0.99)$ & $(2.52)^{* *}$ & $(-0.75)$ & $(-0.58)$ & $(-0.63)$ & $(1.96)^{*}$ & $(-0.49)$ \\
\hline \multirow[t]{2}{*}{$\beta_{\text {Mom }}$} & -2.278 & -2.258 & -0.020 & -2.380 & -2.267 & -2.255 & -0.012 & -2.298 \\
\hline & $(-2.71)^{* * *}$ & $(-2.71)^{* * *}$ & $(-1.87)^{*}$ & $(-2.75)^{* * *}$ & $(-2.74)^{* * *}$ & $(-2.73)^{* * *}$ & $(-1.17)$ & $(-2.71)^{* * *}$ \\
\hline \multirow[t]{2}{*}{ Size } & -0.310 & -0.304 & -0.006 & -0.331 & -0.260 & -0.259 & -0.002 & -0.268 \\
\hline & $(-2.84)^{* * *}$ & $(-2.8)^{* * *}$ & $(-3.01)^{* * *}$ & $(-3.14)^{* * *}$ & $(-2.63)^{* * *}$ & $(-2.62)^{* * *}$ & $(-1.66)^{*}$ & $(-2.76)^{* * *}$ \\
\hline \multirow[t]{2}{*}{$R(-6)$} & 0.848 & 0.847 & 0.001 & 0.838 & 0.753 & 0.752 & 0.001 & 0.736 \\
\hline & $(2.36)^{* *}$ & $(2.37)^{* *}$ & $(0.41)$ & $(2.24)^{* *}$ & $(2.18)^{* *}$ & $(2.19)^{* *}$ & $(0.35)$ & $(2.09)^{* *}$ \\
\hline \multirow[t]{2}{*}{$\mathrm{B} / \mathrm{M}$} & 0.082 & 0.080 & 0.001 & 0.095 & 0.078 & 0.078 & 0.001 & 0.086 \\
\hline & $(0.82)$ & $(0.82)$ & (0.99) & ( 0.89$)$ & $(0.85)$ & $(0.85)$ & $(0.55)$ & $(0.88)$ \\
\hline \multirow[t]{2}{*}{ Spread } & & & & & 0.112 & 0.105 & 0.007 & 0.116 \\
\hline & & & & & ( 1.44$)$ & ( 1.33$)$ & $(1.72)^{*}$ & $(1.78)^{*}$ \\
\hline \multirow[t]{2}{*}{ Turnover } & & & & & -0.027 & -0.026 & -0.001 & -0.030 \\
\hline & & & & & $(-1.98)^{* *}$ & $(-1.93)^{*}$ & $(-2.11)^{* *}$ & $(-1.99)^{* *}$ \\
\hline
\end{tabular}


Reported estimates are the time series average of coefficients from cross-sectional Fama-MacBeth regressions 1960-2000. Panel A reports results of monthly returns regressed on the estimated market beta $\left(\beta_{\mathrm{rm}}\right)$ and one of the two illiquidity measures ILLIQMA, or ILLIQMA_A. ILLIQMA has been computed as described in Amihud (2002) and omits any zero volume days. ILLIQMA_A is ILLIQMA scaled by (2T- $\tau$ )/2T, where $T$ is the number of possible trading days and $\tau$ is the number of zero volume days within $T$. The column headed DIF reports the time series average of the difference between the cross section coefficients obtained from the regressions using each of the two illiquidity measures. Panel B contains estimates where the cross-section model specification also includes $\beta$ ps the market-wide illiquidity risk factor, and the estimated betas on the Fama-French SMB $\left(\beta_{\mathrm{SMB}}\right), \mathrm{HML}\left(\beta_{\mathrm{HML}}\right)$ and Mom $\left(\beta_{\mathrm{Mom}}\right)$ factors. Panel $\mathrm{C}$ are the results from the specification that augments the regressions with market value (Size), book-to-market value (B/M), and the prior six month return, $R(-6)$. Panel $D$ extends the model further by including two alternative measures of liquidity, the Roll (1984) effective spread (Spread) and turnover (Turnover). The * implies significance at a $10 \%$ level, ${ }^{* *}$ at a $5 \%$ level and $* * *$ at a $1 \%$ level using Shanken (1992) adjusted t-statistics. $\mathrm{N}$ is the number of firm months in the sample. Two-Stage are the results of the two stage regression in which ILLIQMA_A is regressed against ILLIQMA. Second stage results are reported in which these residuals, risk factors and characteristics are regressed against one year ahead returns. In this second stage regression the illiquidity variable are the residuals from the first stage regression.

\begin{tabular}{|c|c|c|c|c|c|c|c|c|}
\hline & \multicolumn{4}{|c|}{ Panel A } & \multicolumn{4}{|c|}{ Panel B } \\
\hline & ILLIQMA & ILLIQMA_A & DIF & Two-Stage & ILLIQMA & ILLIQMA_A & DIF & Two-Stage \\
\hline \multirow[t]{2}{*}{ Illiquidity } & 0.179 & 0.201 & -0.022 & 0.533 & 0.144 & 0.168 & -0.024 & 0.262 \\
\hline & $(3.59)^{* * *}$ & $(3.60)^{* * *}$ & $(-3.42)^{* * *}$ & $(2.54)^{* *}$ & $(4.28)^{* * *}$ & $(4.36)^{* * *}$ & $(-4.22)^{* * *}$ & $(2.28)^{* *}$ \\
\hline \multirow[t]{2}{*}{$\beta_{\mathrm{rm}}$} & 0.111 & 0.119 & -0.008 & -0.083 & 0.461 & 0.546 & -0.085 & -0.197 \\
\hline & $(0.33)$ & $(0.35)$ & $(-1.35)$ & $(-0.25)$ & ( 1.31$)$ & (1.54) & $(-4.20)^{* * *}$ & $(-0.55)$ \\
\hline \multirow{2}{*}{$\beta_{\mathrm{SMB}}$} & & & & & -0.095 & -0.145 & 0.049 & 0.251 \\
\hline & & & & & $(-0.40)$ & $(-0.61)$ & $(4.28)^{* * *}$ & (1.02) \\
\hline \multirow[t]{2}{*}{$\beta_{\mathrm{HML}}$} & & & & & 0.703 & 0.702 & 0.001 & 0.526 \\
\hline & & & & & $(2.92)^{* * *}$ & $(2.91)^{* * *}$ & $(0.24)$ & $(2.26)^{* *}$ \\
\hline \multirow[t]{2}{*}{$\beta_{p s}$} & & & & & 0.000 & 0.000 & 0.000 & 0.007 \\
\hline & & & & & $(-0.01)$ & $(-0.02)$ & (0.94) & $(0.71)$ \\
\hline \multirow[t]{4}{*}{ Size } & & & & & 0.286 & 0.411 & -0.125 & -0.448 \\
\hline & & & & & $(0.50)$ & $(0.72)$ & $(-4.22)^{* * *}$ & $(-0.76)$ \\
\hline & & Pan & & & & & & \\
\hline & ILLIQMA & ILLIQMA_A & DIF & Two-Stage & ILLIQMA & ILLIQMA_A & DIF & Two-Stage \\
\hline \multirow[t]{2}{*}{ Illiquidity } & 0.123 & 0.133 & -0.011 & 0.151 & 0.087 & 0.096 & -0.008 & 0.036 \\
\hline & $(3.24)^{* * *}$ & $(3.28)^{* * *}$ & $(-2.5)^{* *}$ & $(1.73)^{*}$ & $(2.57)^{* * *}$ & $(2.62)^{* * *}$ & $(-1.99)^{* *}$ & $(1.72)^{*}$ \\
\hline \multirow[t]{2}{*}{$\beta_{\mathrm{rm}}$} & 1.000 & 1.032 & -0.031 & 0.645 & 0.938 & 0.960 & -0.022 & 0.702 \\
\hline & $(2.51)^{* *}$ & $(2.57)^{* * *}$ & $(-2.75)^{* * *}$ & ( 1.54$)$ & $(2.36)^{* *}$ & $(2.41)^{* *}$ & $(-2.02)^{* *}$ & $(1.7)^{*}$ \\
\hline \multirow[t]{2}{*}{$\beta_{\mathrm{SMB}}$} & -0.819 & -0.829 & 0.010 & -0.773 & -0.650 & -0.659 & 0.009 & -0.607 \\
\hline & $(-2.98)^{* * *}$ & $(-3.01)^{* * *}$ & $(2.36)^{* *}$ & $(-2.69)^{* * *}$ & $(-2.49)^{* *}$ & $(-2.52)^{* *}$ & $(1.93)^{*}$ & $(-2.24)^{* *}$ \\
\hline \multirow[t]{2}{*}{$\beta_{\mathrm{HML}}$} & 0.513 & 0.508 & 0.005 & 0.446 & 0.351 & 0.347 & 0.004 & 0.304 \\
\hline & $(2.01)^{* *}$ & $(2 .)^{* *}$ & $(1.71)^{*}$ & $(1.68)^{*}$ & ( 1.47$)$ & ( 1.46$)$ & (1.21) & (1.23) \\
\hline \multirow[t]{2}{*}{$\beta_{\mathrm{ps}}$} & -0.014 & -0.013 & 0.000 & -0.012 & -0.012 & -0.012 & 0.000 & -0.011 \\
\hline & $(-1.25)$ & $(-1.24)$ & $(-1.23)$ & $(-1.03)$ & $(-1.14)$ & $(-1.13)$ & $(-1.07)$ & $(-1)$. \\
\hline \multirow[t]{2}{*}{$\beta_{\mathrm{Mom}}$} & 0.484 & 0.547 & -0.063 & -0.117 & 0.372 & 0.417 & -0.045 & -0.040 \\
\hline & $(0.85)$ & $(0.96)$ & $(-3.01)^{* * *}$ & $(-0.19)$ & $(0.65)$ & (0.73) & $(-2.28)^{* *}$ & $(-0.07)$ \\
\hline \multirow[t]{2}{*}{ Size } & -0.192 & -0.188 & -0.003 & -0.244 & -0.181 & -0.179 & -0.001 & -0.211 \\
\hline & $(-2.8)^{* * *}$ & $(-2.77)^{* * *}$ & $(-2.34)^{* *}$ & $(-3.31)^{* * *}$ & $(-2.76)^{* * *}$ & $(-2.74) * * *$ & $(-1.06)$ & $(-3.11)^{* * *}$ \\
\hline \multirow[t]{2}{*}{$R(-6)$} & 1.107 & 1.108 & -0.001 & 1.134 & 1.168 & 1.168 & 0.000 & 1.183 \\
\hline & $(3.36)^{* * *}$ & $(3.38)^{* * *}$ & $(-0.4)$ & $(3.23)^{* * *}$ & $(3.73)^{* * *}$ & $(3.74)^{* * *}$ & $(-0.13)$ & $(3.61)^{* * *}$ \\
\hline \multirow[t]{2}{*}{$\mathrm{B} / \mathrm{M}$} & 0.071 & 0.071 & 0.000 & 0.083 & 0.049 & 0.049 & 0.000 & 0.055 \\
\hline & ( 1.05$)$ & ( 1.05$)$ & $(0.46)$ & ( 1.15$)$ & $(0.76)$ & $(0.76)$ & $(0.5)$ & $(0.82)$ \\
\hline \multirow[t]{2}{*}{ Spread } & & & & & 0.016 & 0.011 & 0.004 & 0.042 \\
\hline & & & & & $(0.33)$ & $(0.24)$ & $(3.01)^{* * *}$ & $(0.82)$ \\
\hline \multirow[t]{2}{*}{ Turnover } & & & & & -0.059 & -0.058 & -0.002 & -0.073 \\
\hline & & & & & $(-2.47)^{* *}$ & $(-2.41)^{* *}$ & $(-2.04)^{* *}$ & $(-2.77)^{* * *}$ \\
\hline
\end{tabular}


Reported estimates are the time series average of coefficients from cross-sectional Fama-MacBeth regressions using monthly return data for NYSE/AMEX stocks over the period 2001-2008. Panel A reports results of monthly returns regressed on the estimated market beta $\left(\beta_{\mathrm{rm}}\right)$ and one of the two illiquidity measures ILLIQMA, or ILLIQMA_A. ILLIQMA has been computed as described in Amihud (2002) and omits any zero volume days. ILLIQMA_A is ILLIQMA scaled by $(2 T-\tau) / 2 T$, where $T$ is the number of possible trading days and $\tau$ is the number of zero volume days within $T$. The column headed DIF reports the time series average of the difference between the cross section coefficients obtained from the regressions using each of the two illiquidity measures. Panel B contains estimates where the cross-section model specification also includes $\beta$ ps the market-wide illiquidity risk factor, and the estimated betas on the Fama-French SMB ( $\left.\beta_{\mathrm{SMB}}\right)$, HML $\left(\beta_{\mathrm{HML}}\right)$ and Mom ( $\left.\beta_{\mathrm{Mom}}\right)$ factors. Panel $C$ are the results from the specification that augments the regressions with market value (Size), book-to-market value $(B / M)$, and the prior six month return, $R(-6)$. Panel $D$ extends the model further by including two alternative measures of liquidity, the Roll (1984) effective spread (Spread) and turnover (Turnover). The * implies significance at a 10\% level, $* *$ at a $5 \%$ level and $* * *$ at a $1 \%$ level using Shanken (1992) adjusted t-statistics. Two-Stage are the results of the two stage regression in which ILLIQMA_A is regressed against ILLIQMA. Second stage results are reported in which these residuals, risk factors and characteristics are regressed against one year ahead returns. In this second stage regression the illiquidity variable are the residuals from the first stage regression.

\begin{tabular}{|c|c|c|c|c|c|c|c|c|}
\hline & \multicolumn{4}{|c|}{ Panel A } & \multicolumn{4}{|c|}{ Panel B } \\
\hline & ILLIQMA & ILLIQMA_A & DIF & Two-Stage & ILLIQMA & ILLIQMA_A & DIF & Two-Stage \\
\hline \multirow[t]{2}{*}{ Illiquidity } & 0.102 & 0.118 & -0.015 & 0.566 & 0.071 & 0.085 & -0.015 & 0.433 \\
\hline & $(2.23)^{* *}$ & $(2.18)^{* *}$ & $(-1.75)^{*}$ & $(1.97)^{* *}$ & $(2.15)^{* *}$ & $(2.19)^{* *}$ & $(-1.88)^{*}$ & $(1.98)^{* *}$ \\
\hline \multirow[t]{2}{*}{$\beta_{\mathrm{rm}}$} & 0.412 & 0.425 & -0.012 & 0.244 & -0.167 & -0.072 & -0.095 & -0.581 \\
\hline & $(0.48)$ & (0.49) & $(-1.47)$ & $(0.3)$ & $(-0.24)$ & $(-0.10)$ & $(-1.82)^{*}$ & $(-0.86)$ \\
\hline \multirow{2}{*}{$\beta_{\mathrm{SMB}}$} & & & & & 0.397 & 0.355 & 0.042 & 0.604 \\
\hline & & & & & $(0.84)$ & $(0.77)$ & $(1.76)^{*}$ & (1.3) \\
\hline \multirow{2}{*}{$\beta_{\mathrm{HML}}$} & & & & & 0.346 & 0.335 & 0.011 & 0.165 \\
\hline & & & & & $(0.47)$ & $(0.46)$ & $(1.44)$ & $(0.23)$ \\
\hline \multirow{2}{*}{$\beta_{\mathrm{ps}}$} & & & & & 0.026 & 0.026 & 0.000 & 0.036 \\
\hline & & & & & $(0.70)$ & $(0.70)$ & $(-0.31)$ & ( 1.02$)$ \\
\hline \multirow{2}{*}{ Size } & & & & & -1.631 & -1.423 & -0.207 & -2.048 \\
\hline & & & & & $(-1.09)$ & $(-0.97)$ & $(-1.93)^{*}$ & $(-1.42)$ \\
\hline \multirow[t]{3}{*}{$\mathrm{N}$} & 125549 & & & & 125549 & & & \\
\hline & \multicolumn{4}{|c|}{ Panel C } & \multicolumn{4}{|c|}{ Panel D } \\
\hline & ILLIQMA & ILLIQMA_A & DIF & Two-Stage & ILLIQMA & ILLIQMA_A & DIF & Two-Stage \\
\hline \multirow[t]{2}{*}{ Illiquidity } & 0.075 & 0.081 & -0.006 & 1.261 & 0.067 & 0.073 & -0.007 & 1.134 \\
\hline & $(2.05)^{* *}$ & $(2.13)^{* *}$ & $(-1.88)^{*}$ & $(2.48)^{* *}$ & $(1.9)^{*}$ & $(2 .)^{* *}$ & $(-2.00)^{* *}$ & $(2.27)^{* *}$ \\
\hline \multirow[t]{2}{*}{$\beta_{\mathrm{rm}}$} & 0.129 & 0.161 & -0.031 & -0.080 & 0.185 & 0.215 & -0.030 & 0.013 \\
\hline & (0.14) & ( 0.17$)$ & $(-2.16)^{* *}$ & $(-0.09)$ & $(0.22)$ & $(0.25)$ & $(-2.19)^{* *}$ & $(0.02)$ \\
\hline \multirow[t]{2}{*}{$\beta_{\mathrm{SMB}}$} & 0.111 & 0.116 & -0.005 & 0.063 & 0.039 & 0.045 & -0.006 & -0.005 \\
\hline & $(0.21)$ & $(0.22)$ & $(-2.04)^{* *}$ & $(0.11)$ & $(0.08)$ & (0.09) & $(-2.28)^{* *}$ & $(-0.01)$ \\
\hline \multirow[t]{2}{*}{$\beta_{\mathrm{HML}}$} & 0.466 & 0.455 & 0.012 & 0.341 & 0.564 & 0.554 & 0.010 & 0.441 \\
\hline & $(0.75)$ & $(0.73)$ & $(1.79)^{*}$ & $(0.54)$ & (0.94) & $(0.92)$ & $(1.78)^{*}$ & $(0.73)$ \\
\hline \multirow[t]{2}{*}{$\beta_{\mathrm{ps}}$} & 0.012 & 0.013 & 0.000 & 0.019 & 0.018 & 0.018 & 0.000 & 0.024 \\
\hline & $(0.34)$ & $(0.35)$ & $(-1)$. & $(0.52)$ & $(0.5)$ & $(0.51)$ & $(-0.48)$ & ( 0.69$)$ \\
\hline \multirow[t]{2}{*}{$\beta_{\text {Mom }}$} & -1.604 & -1.495 & -0.109 & -1.972 & -1.404 & -1.300 & -0.104 & -1.698 \\
\hline & $(-1.04)$ & $(-0.98)$ & $(-2.18)^{* *}$ & $(-1.23)$ & $(-0.93)$ & $(-0.87)$ & $(-2.24)^{* *}$ & $(-1.1)$ \\
\hline \multirow[t]{2}{*}{ Size } & -0.073 & -0.068 & -0.005 & -0.123 & -0.043 & -0.038 & -0.004 & -0.084 \\
\hline & $(-0.48)$ & $(-0.45)$ & $(-2.18)^{* *}$ & $(-0.76)$ & $(-0.29)$ & $(-0.26)$ & $(-2.28)^{* *}$ & $(-0.55)$ \\
\hline \multirow[t]{2}{*}{$R(-6)$} & 1.598 & 1.595 & 0.003 & 1.632 & 1.584 & 1.582 & 0.002 & 1.609 \\
\hline & $(1.99)^{* *}$ & $(1.98)^{* *}$ & $(0.77)$ & $(2 .)^{* *}$ & $(2.01)^{* *}$ & $(2.01)^{* *}$ & $(0.66)$ & $(2 .)^{* *}$ \\
\hline \multirow[t]{2}{*}{$\mathrm{B} / \mathrm{M}$} & -0.099 & -0.098 & 0.000 & -0.096 & -0.080 & -0.080 & 0.000 & -0.077 \\
\hline & $(-0.81)$ & $(-0.81)$ & $(-1.08)$ & $(-0.78)$ & $(-0.71)$ & $(-0.71)$ & $(-1)$. & $(-0.67)$ \\
\hline \multirow[t]{2}{*}{ Spread } & & & & & 0.216 & 0.212 & 0.004 & 0.232 \\
\hline & & & & & $(1.78)^{*}$ & $(1.75)^{*}$ & $(2.22)^{* *}$ & $(1.89)^{*}$ \\
\hline \multirow[t]{2}{*}{ Turnover } & & & & & -0.007 & -0.007 & 0.000 & -0.010 \\
\hline & & & & & $(-0.55)$ & $(-0.52)$ & $(-2.21)^{* *}$ & $(-0.71)$ \\
\hline
\end{tabular}


Table 9: Fama-MacBeth Cross Section Results NASDAQ 1983-2000

Reported estimates are the time series average of coefficients from cross-sectional Fama-MacBeth regressions using monthly return data for NASDAQ stocks over the period 1983-2000. Panel A reports results of monthly returns regressed on the estimated market beta $\left(\beta_{\mathrm{rm}}\right)$ and one of the two illiquidity measures ILLIQMA, or ILLIQMA_A. ILLIQMA has been computed as

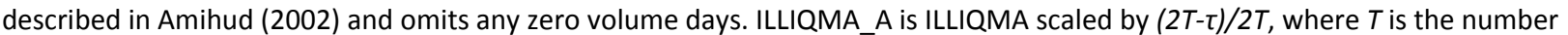
of possible trading days and $\tau$ is the number of zero volume days within $T$. The column headed DIF reports the time series average of the difference between the cross section coefficients obtained from the regressions using each of the two illiquidity measures. Panel $B$ contains estimates where the cross-section model specification also includes $\beta p s$ the market-wide illiquidity risk factor, and the estimated betas on the Fama-French SMB $\left(\beta_{\mathrm{SMB}}\right), \mathrm{HML}\left(\beta_{\mathrm{HML}}\right)$ and Mom $\left(\beta_{\mathrm{Mom}}\right)$ factors. Panel $\mathrm{C}$ are the results from the specification that augments the regressions with market value (Size), book-to-market value $(B / M)$, and the prior six month return R(-6). Panel D extends the model further by including two alternative measures of liquidity, the Roll (1984) effective spread (Spread) and turnover (Turnover). The * implies significance at a $10 \%$ level, $* *$ at a $5 \%$ level and $* * *$ at a $1 \%$ level using Shanken (1992) adjusted t-statistics. Two-Stage are the results of the two stage regression in which ILLIQMA_A is regressed against ILLIQMA. Second stage results are reported in which these residuals, risk factors and characteristics are regressed against one year ahead returns. In this second stage regression the illiquidity variable are the residuals from the first stage regression.

\begin{tabular}{|c|c|c|c|c|c|c|c|c|}
\hline & \multicolumn{4}{|c|}{ Panel A } & \multicolumn{4}{|c|}{ Panel B } \\
\hline & ILLIQMA & ILLIQMA_A & DIF & Two-Stage & ILLIQMA & ILLIQMA_A & DIF & Two-Stage \\
\hline \multirow[t]{2}{*}{ Illiquidity } & 0.147 & 0.173 & -0.026 & 0.614 & 0.133 & 0.156 & -0.023 & 0.547 \\
\hline & $(3.42)^{* *}$ & $(3.72)^{* * *}$ & $(-3.08)^{* *}$ & $(2.25)^{* *}$ & $(2.63)^{* * *}$ & $(2.80)^{* * *}$ & $(-2.41)^{* *}$ & $(2.28)^{* *}$ \\
\hline \multirow[t]{2}{*}{$\beta_{\mathrm{rm}}$} & 0.272 & 0.327 & -0.055 & 0.072 & 0.516 & 0.561 & -0.045 & 0.353 \\
\hline & $(0.52)$ & $(0.63)$ & $(-3.58)^{* * *}$ & $(0.13)$ & ( 1.24$)$ & ( 1.36$)$ & $(-2.67)^{* * *}$ & $(0.83)$ \\
\hline \multirow[t]{2}{*}{$\beta_{\mathrm{SMB}}$} & & & & & 0.34 & -0.017 & 0.051 & 0.079 \\
\hline & & & & & $(0.05)$ & $(-0.03)$ & $(3.00)^{* * *}$ & $(0.13)$ \\
\hline \multirow[t]{2}{*}{$\beta_{\mathrm{HML}}$} & & & & & 0.540 & 0.547 & -0.007 & 0.482 \\
\hline & & & & & $(1.04)$ & (1.05) & $(-1.95)^{*}$ & $(0.96)$ \\
\hline \multirow[t]{2}{*}{$\beta_{p s}$} & & & & & 0.035 & 0.031 & 0.003 & 0.053 \\
\hline & & & & & ( 1.36$)$ & ( 1.21$)$ & $(2.64) * * *$ & $(2.42)^{* *}$ \\
\hline \multirow[t]{4}{*}{ Size } & & & & & -1.419 & -1.424 & 0.005 & -1.519 \\
\hline & & & & & $(-1.21)$ & $(-1.21)$ & (0.39) & $(-1.29)$ \\
\hline & \multicolumn{4}{|c|}{ Panel C } & \multicolumn{4}{|c|}{ Panel D } \\
\hline & ILLIQMA & ILLIQMA_A & DIF & Two-Stage & ILLIQMA & ILLIQMA_A & DIF & Two-Stage \\
\hline \multirow[t]{2}{*}{ Illiquidity } & 0.080 & 0.093 & -0.013 & 0.606 & 0.033 & 0.041 & -0.008 & 0.410 \\
\hline & ( 1.38$)$ & ( 1.56$)$ & $(-2.05)^{* *}$ & $(2.77)^{* * *}$ & ( 1.05$)$ & ( 1.49$)$ & $(-1.43)$ & $(1.93)^{*}$ \\
\hline \multirow[t]{2}{*}{$\beta_{\mathrm{rm}}$} & 1.417 & 1.429 & -0.011 & 1.401 & 1.524 & 1.525 & -0.002 & 1.540 \\
\hline & $(3.1)^{* * *}$ & $(3.16)^{* * *}$ & $(-1.47)$ & $(2.85)^{* * *}$ & $(3.49)^{* * *}$ & $(3.52)^{* * *}$ & $(-0.29)$ & $(3.37)^{* * *}$ \\
\hline \multirow[t]{2}{*}{$\beta_{S M B}$} & -2.106 & -2.100 & -0.006 & -2.195 & -1.997 & -1.995 & -0.002 & -2.034 \\
\hline & $(-3.57) * * *$ & $(-3.59)^{* * *}$ & $(-0.96)$ & $(-3.56)^{* * *}$ & $(3.76)^{* * *}$ & $(-3.77)^{* * *}$ & $(-0.35)$ & $(-3.77)^{* * *}$ \\
\hline \multirow[t]{2}{*}{$\beta_{\mathrm{HML}}$} & 1.061 & 1.055 & 0.006 & 1.069 & 0.918 & 0.915 & 0.003 & 0.922 \\
\hline & $(2.16)^{* *}$ & $(2.17)^{* *}$ & $(1.78)^{*}$ & $(2.11)^{* *}$ & $(2.12)^{* *}$ & $(2.13)^{* *}$ & (1.26) & $(2.13)^{* *}$ \\
\hline \multirow[t]{2}{*}{$\beta_{\mathrm{ps}}$} & -0.038 & -0.039 & 0.001 & -0.035 & -0.026 & -0.027 & 0.001 & -0.026 \\
\hline & $(-1.27)$ & $(-1.32)$ & $(1.76)^{*}$ & $(-1.16)$ & $(-1.01)$ & $(-1.05)$ & (1.35) & $(-0.97)$ \\
\hline \multirow[t]{2}{*}{$\beta_{\mathrm{Mom}}$} & -2.172 & -2.155 & -0.017 & -2.247 & -2.145 & -2.137 & -0.008 & -2.141 \\
\hline & $(-2 .)^{* *}$ & $(-2 .)^{* *}$ & $(-1.22)$ & $(-1.98)^{* *}$ & $(-2 .)^{* *}$ & $(-2.01)^{* *}$ & $(-0.58)$ & $(-1.95)^{*}$ \\
\hline \multirow[t]{2}{*}{ Size } & -0.356 & -0.349 & -0.007 & -0.377 & -0.296 & -0.295 & -0.001 & -0.302 \\
\hline & $(-2.41)^{* *}$ & $(-2.38)^{* *}$ & $(-2.5)^{* *}$ & $(-2.64)^{* * *}$ & $(-2.23)^{* *}$ & $(-2.22)^{* *}$ & $(-1.13)$ & $(-2.32)^{* *}$ \\
\hline \multirow[t]{2}{*}{$R(-6)$} & 0.678 & 0.677 & 0.000 & 0.656 & 0.565 & 0.565 & 0.000 & 0.534 \\
\hline & ( 1.55$)$ & ( 1.57$)$ & $(0.12)$ & ( 1.43$)$ & (1.38) & (1.39) & (0.) & ( 1.27$)$ \\
\hline \multirow[t]{2}{*}{$\mathrm{B} / \mathrm{M}$} & 0.076 & 0.074 & 0.001 & 0.090 & 0.067 & 0.066 & 0.001 & 0.074 \\
\hline & (0.55) & $(0.55)$ & (0.81) & $(0.6)$ & ( 0.54$)$ & ( 0.54$)$ & $(0.4)$ & $(0.56)$ \\
\hline \multirow[t]{2}{*}{ Spread } & & & & & 0.110 & 0.102 & 0.008 & 0.111 \\
\hline & & & & & (1.08) & ( 0.98$)$ & ( 1.44$)$ & (1.31) \\
\hline \multirow[t]{2}{*}{ Turnover } & & & & & -0.038 & -0.036 & -0.001 & -0.041 \\
\hline & & & & & $(-1.93)^{*}$ & $(-1.89)^{*}$ & $(-1.96)^{*}$ & $(-1.93)^{*}$ \\
\hline
\end{tabular}


Reported estimates are the time series average of coefficients from cross-sectional Fama-MacBeth regressions using monthly return data for NASDAQ stocks over the period 2001-2008. Panel A reports results of monthly returns regressed on the estimated market beta $\left(\beta_{\mathrm{rm}}\right)$ and one of the two illiquidity measures ILLIQMA, or ILLIQMA_A. ILLIQMA has been computed as described in Amihud (2002) and omits any zero volume days. ILLIQMA_A is ILLIQMA scaled by $(2 T-\tau) / 2 T$, where $T$ is the number of possible trading days and $\tau$ is the number of zero volume days within $T$. The column headed DIF reports the time series average of the difference between the cross section coefficients obtained from the regressions using each of the two illiquidity measures. Panel $B$ contains estimates where the cross-section model specification also includes $\beta p$ s the market-wide illiquidity risk factor, and the estimated betas on the Fama-French SMB $\left(\beta_{\mathrm{SMB}}\right), \mathrm{HML}\left(\beta_{\mathrm{HML}}\right)$ and Mom $\left(\beta_{\mathrm{Mom}}\right)$ factors. Panel $C$ are the results from the specification that augments the regressions with market value (Size), book-to-market value (B/M), and the six month return, $R(-6)$. Panel $D$ extends the model further by including two alternative measures of liquidity, the Roll (1984) effective spread (Spread) and turnover (Turnover). The * implies significance at a $10 \%$ level, $* *$ at a $5 \%$ level and $* * *$ at a $1 \%$ level using Shanken (1992) adjusted t-statistics. Two-Stage are the results of the two stage regression in which ILLIQMA_A is regressed against ILLIQMA. Second stage results are reported in which these residuals, risk factors and characteristics are regressed against one year ahead returns. In this second stage regression the illiquidity variable are the residuals from the first stage regression.

\begin{tabular}{|c|c|c|c|c|c|c|c|c|}
\hline & \multicolumn{4}{|c|}{ Panel A } & \multicolumn{4}{|c|}{ Panel B } \\
\hline & ILLIQMA & ILLIQMA_A & DIF & Two-Stage & ILLIQMA & ILLIQMA_A & DIF & Two-Stage \\
\hline \multirow[t]{2}{*}{ Illiquidity } & 0.123 & 0.145 & -0.022 & 0.761 & 0.076 & 0.092 & -0.016 & 0.532 \\
\hline & $(2.64)^{* * *}$ & $(2.60)^{* * *}$ & $(-2.10)^{* *}$ & $(2.5)^{* *}$ & $(2.07)^{* *}$ & $(2.26)^{* *}$ & $(-2.20)^{* *}$ & $(2.47)^{* *}$ \\
\hline \multirow[t]{2}{*}{$\beta_{\mathrm{rm}}$} & 0.599 & 0.637 & -0.038 & 0.413 & 0.580 & 0.601 & -0.021 & 0.513 \\
\hline & $(0.62)$ & $(0.65)$ & $(-2.18)^{* *}$ & ( 0.44) & $(0.77)$ & $(0.80)$ & $(-2.27)^{* *}$ & $(0.68)$ \\
\hline \multirow[t]{2}{*}{$\beta_{\mathrm{SMB}}$} & & & & & 0.317 & 0.288 & 0.029 & 0.329 \\
\hline & & & & & $(0.35)$ & $(0.32)$ & $(2.11)^{* *}$ & $(0.38)$ \\
\hline \multirow[t]{2}{*}{$\beta_{\mathrm{HML}}$} & & & & & 0.512 & 0.510 & 0.002 & 0.503 \\
\hline & & & & & $(0.72)$ & $(0.71)$ & $(0.57)$ & $(0.73)$ \\
\hline \multirow[t]{2}{*}{$\beta_{\mathrm{ps}}$} & & & & & 0.069 & 0.065 & 0.004 & 0.088 \\
\hline & & & & & $(2.09)^{* *}$ & $(2.03)^{* *}$ & $(2.26)^{* *}$ & $(2.71)^{* * *}$ \\
\hline \multirow[t]{4}{*}{ Size } & & & & & -2.326 & -2.284 & -0.043 & -2.456 \\
\hline & & & & & $(-1.49)$ & $(-1.46)$ & $(-1.56)$ & $(-1.6)$ \\
\hline & \multicolumn{4}{|c|}{ Panel C } & \multicolumn{4}{|c|}{ Panel D } \\
\hline & ILLIQMA & ILLIQMA_A & DIF & Two-Stage & ILLIQMA & ILLIQMA_A & DIF & Two-Stage \\
\hline \multirow[t]{2}{*}{ Illiquidity } & 0.049 & 0.057 & -0.008 & 0.622 & 0.035 & 0.041 & -0.006 & 0.581 \\
\hline & $(1.81)^{*}$ & $(2.13)^{* *}$ & $(-1.85)^{*}$ & $(2.45)^{* *}$ & (0.97) & (1.35) & $(-1.31)$ & $(2.36)^{* *}$ \\
\hline \multirow[t]{2}{*}{$\beta_{\mathrm{rm}}$} & 0.932 & 0.935 & -0.003 & 0.927 & 0.845 & 0.849 & -0.004 & 0.849 \\
\hline & ( 1.17$)$ & (1.17) & $(-1.72)^{*}$ & ( 1.14$)$ & (1.15) & (1.15) & $(-1.68)^{*}$ & ( 1.12$)$ \\
\hline \multirow[t]{2}{*}{$\beta_{S M B}$} & -0.879 & -0.870 & -0.010 & -0.975 & -0.813 & -0.804 & -0.008 & -0.900 \\
\hline & $(-1.58)$ & $(-1.56)$ & $(-1.92)^{*}$ & $(-1.73)^{*}$ & $(-1.53)$ & $(-1.52)$ & $(-1.75)^{*}$ & $(-1.67)^{*}$ \\
\hline \multirow[t]{2}{*}{$\beta_{\mathrm{HML}}$} & 0.791 & 0.784 & 0.006 & 0.818 & 0.808 & 0.802 & 0.005 & 0.826 \\
\hline & ( 1.52$)$ & $(1.51)$ & $(1.38)$ & ( 1.56$)$ & (1.58) & $(1.57)$ & $(1.04)$ & ( 1.59$)$ \\
\hline \multirow[t]{2}{*}{$\beta_{p s}$} & 0.025 & 0.024 & 0.001 & 0.033 & 0.028 & 0.027 & 0.001 & 0.033 \\
\hline & $(0.92)$ & $(0.87)$ & $(2.16)^{* *}$ & ( 1.12$)$ & ( 1.02$)$ & ( 0.99) & $(1.72)^{*}$ & ( 1.11$)$ \\
\hline \multirow[t]{2}{*}{$\beta_{\mathrm{Mom}}$} & -2.560 & -2.533 & -0.028 & -2.735 & -2.594 & -2.571 & -0.023 & -2.719 \\
\hline & $(-1.94)^{*}$ & $(-1.91)^{*}$ & $(-1.7)^{*}$ & $(-2.03)^{* *}$ & $(-2.02)^{* *}$ & $(-2 .)^{* *}$ & $(-1.44)$ & $(-2.06)^{* *}$ \\
\hline \multirow[t]{2}{*}{ Size } & -0.190 & -0.187 & -0.003 & -0.208 & -0.165 & -0.163 & -0.002 & -0.176 \\
\hline & $(-1.3)$ & $(-1.28)$ & $(-1.82)^{*}$ & $(-1.49)$ & $(-1.25)$ & $(-1.23)$ & $(-1.37)$ & $(-1.39)$ \\
\hline \multirow[t]{2}{*}{$R(-6)$} & 1.302 & 1.299 & 0.003 & 1.322 & 1.254 & 1.251 & 0.003 & 1.275 \\
\hline & $(1.94)^{*}$ & $(1.94)^{*}$ & (1.59) & $(1.95)^{*}$ & $(1.9)^{*}$ & $(1.9)^{*}$ & (1.38) & $(1.91)^{*}$ \\
\hline \multirow[t]{2}{*}{$\mathrm{B} / \mathrm{M}$} & 0.097 & 0.097 & 0.001 & 0.106 & 0.108 & 0.107 & 0.001 & 0.117 \\
\hline & $(0.85)$ & $(0.85)$ & $(1.86)^{*}$ & $(0.9)$ & ( 0.97$)$ & ( 0.97) & (1.51) & ( 1.01$)$ \\
\hline \multirow[t]{2}{*}{ Spread } & & & & & 0.117 & 0.114 & 0.003 & 0.130 \\
\hline & & & & & (01.) & $(0.96)$ & ( 1.16$)$ & ( 1.28$)$ \\
\hline \multirow[t]{2}{*}{ Turnover } & & & & & 0.000 & 0.000 & 0.000 & 0.000 \\
\hline & & & & & $(0.04)$ & $(0.05)$ & $(-1.27)$ & $(-0.02)$ \\
\hline
\end{tabular}


Table 11: Fama-MacBeth Cross-Section Results using VILLIQMA, NYSE/AMEX 1960-2008

Reported estimates are the time series averages of coefficients from cross-sectional Fama-MacBeth regressions using monthly return data for NYSE/AMEX stocks over the period 1960-2008. Panel A reports results of monthly returns regressed on the estimated market beta $\left(\beta_{\mathrm{rm}}\right)$ and one of the two illiquidity measures VILLIQMA, or VILLIQMA_A. VILLIQMA has been computed as described by Hasbrouck (2009). VILLIQMA_A is VILLIQMA scaled by $(V T+V(T-\tau)) / 2 V T$, where $T$ is the number of possible trading days and $\tau$ is the number of zero volume days within $T$. The column headed DIF reports the time series average of the difference between the cross section coefficients obtained from the regressions using each of the two illiquidity measures. Panel B contains estimates where the cross-section model specification also includes $\beta p$ s the market-wide illiquidity risk factor, and the estimated betas on the Fama-French SMB $\left(\beta_{\mathrm{SMB}}\right), \mathrm{HML}\left(\beta_{\mathrm{HML}}\right)$ and Mom $\left(\beta_{\mathrm{Mom}}\right)$ factors. Panel $C$ are the results from the specification that augments the regressions with market value (Size), book-to-market value (B/M), and the six month return, $\mathrm{R}(-$ 6). Panel $D$ extends the model further by including two alternative measures of liquidity, the Roll (1984) effective spread (Spread) and turnover (Turnover). The * implies significance at a $10 \%$ level, ${ }^{* *}$ at a $5 \%$ level and ${ }^{* * *}$ at a $1 \%$ level using Shanken (1992) adjusted t-statistics. $\mathrm{N}$ is the number of firm months in the sample.

\begin{tabular}{|c|c|c|c|c|c|c|}
\hline & \multicolumn{3}{|c|}{ Panel A } & \multicolumn{3}{|c|}{ Panel B } \\
\hline & VILLIQMA & VILLIQMA_A & DIF & VILLIQMA & VILLIQMA_A & DIF \\
\hline \multirow[t]{2}{*}{ Illiquidity } & 0.357 & 0.377 & -0.021 & 0.367 & 0.400 & -0.033 \\
\hline & $(3.85)^{* * *}$ & $(3.85)^{* * *}$ & $(-3.51)^{* * *}$ & $(5.21)^{* * *}$ & $(5.33)^{* * *}$ & $(-3.20)^{* * *}$ \\
\hline \multirow[t]{2}{*}{$\beta_{\mathrm{rm}}$} & 0.225 & 0.223 & 0.002 & 0.725 & 0.772 & -0.047 \\
\hline & $(0.7)$ & $(0.7)$ & ( 0.59$)$ & ( 2.24$)$ & (2.38) & $(-3.22)$ \\
\hline \multirow[t]{2}{*}{$\beta_{S M B}$} & - & - & - & -0.309 & -0.348 & 0.038 \\
\hline & - & - & - & $(-1.32)$ & $(-1.49)$ & $(4.37)$ \\
\hline \multirow[t]{2}{*}{$\beta_{\mathrm{HML}}$} & - & - & - & 0.708 & 0.697 & 0.011 \\
\hline & - & - & - & $(3.01)^{* * *}$ & $(2.96)^{* * *}$ & $(2.63)^{* * *}$ \\
\hline \multirow[t]{2}{*}{$\beta_{\mathrm{ps}}$} & - & - & - & -0.001 & -0.001 & 0.000 \\
\hline & - & - & - & $(-0.09)$ & $(-0.08)$ & $(-0.96)^{* * *}$ \\
\hline \multirow[t]{4}{*}{ Size } & - & - & - & 0.193 & 0.250 & -0.057 \\
\hline & - & - & - & $(0.36)$ & $(0.46)$ & $(-2.82)^{* * *}$ \\
\hline & & Panel C & & & Panel D & \\
\hline & VILLIQMA & VILLIQMA_A & DIF & VILLIQMA & VILLIQMA_A & DIF \\
\hline \multirow[t]{2}{*}{ Illiquidity } & 0.287 & 0.298 & -0.011 & 0.189 & 0.195 & -0.006 \\
\hline & $(3.67)^{* * *}$ & $(3.7)^{* * *}$ & $(-2.32)^{* *}$ & $2.56)^{* * *}$ & $(2.54)^{* *}$ & $(-1.79)^{*}$ \\
\hline \multirow[t]{2}{*}{$\beta_{\mathrm{rm}}$} & 1.038 & 1.048 & -0.010 & 0.927 & 0.933 & -0.006 \\
\hline & $(2.94)^{* * *}$ & $(2.97)^{* * *}$ & $(-1.15)$ & $(2.67)^{* * *}$ & $(2.69)^{* * *}$ & $(-0.72)$ \\
\hline \multirow[t]{2}{*}{$\beta_{\mathrm{SMB}}$} & -0.776 & -0.785 & 0.008 & -0.624 & -0.631 & 0.007 \\
\hline & $(-3.1)^{* * *}$ & $(-3.13)^{* * *}$ & $(2.91)^{* * *}$ & $(-2.65)$ & $(-2.68)^{* *}$ & $(1.73)^{*}$ \\
\hline \multirow[t]{2}{*}{$\beta_{\mathrm{HML}}$} & 0.531 & 0.524 & 0.007 & 0.412 & 0.408 & 0.004 \\
\hline & $(2.3)^{* *}$ & $(2.27)^{* *}$ & $(2.38)^{* *}$ & $(1.9)^{*}$ & $(1.89)^{*}$ & (1.21) \\
\hline \multirow[t]{2}{*}{$\beta_{p s}$} & -0.012 & -0.012 & 0.000 & -0.010 & -0.010 & 0.000 \\
\hline & $(-1.15)$ & $(-1.14)$ & $(-1.69)^{*}$ & $(-0.95)$ & $(-0.94)$ & $(-1.15)$ \\
\hline \multirow[t]{2}{*}{$\beta_{\text {Mom }}$} & 0.273 & 0.289 & -0.016 & 0.183 & 0.196 & -0.013 \\
\hline & $(0.51)$ & $(0.54)$ & $(-1.06)$ & $(0.35)$ & $(0.37)$ & $(-0.85)$ \\
\hline \multirow[t]{2}{*}{ Size } & -0.147 & -0.146 & -0.001 & -0.146 & -0.146 & 0.000 \\
\hline & $(-2.24)^{* *}$ & $(-2.22)^{* *}$ & $(-1.2)$ & $(-2.32)^{* *}$ & $(-2.31)^{* *}$ & $(-0.05)$ \\
\hline \multirow[t]{2}{*}{$R(-6)$} & 1.170 & 1.173 & -0.002 & 1.219 & 1.220 & -0.002 \\
\hline & $(3.93)^{* * *}$ & $(3.94)^{* * *}$ & $(-1.02)$ & $(4.25)^{* * *}$ & $(4.26)^{* * *}$ & $(-0.74)$ \\
\hline \multirow[t]{2}{*}{$\mathrm{B} / \mathrm{M}$} & 0.045 & 0.045 & 0.000 & 0.028 & 0.028 & 0.000 \\
\hline & ( 0.74$)$ & ( 0.74$)$ & ( 0.18$)$ & $(0.5)$ & ( 0.49$)$ & (1.05) \\
\hline \multirow[t]{2}{*}{ Spread } & & & & 0.045 & 0.043 & 0.002 \\
\hline & & & & ( 1.01$)$ & $(0.97)$ & $(2.95)^{* * *}$ \\
\hline \multirow[t]{2}{*}{ Turnover } & & & & -0.047 & -0.046 & -0.001 \\
\hline & & & & $(-2.22)^{* *}$ & $(-2.17)^{* *}$ & $(-0.9)$ \\
\hline
\end{tabular}


Reported estimates are the time series averages of coefficients from cross-sectional Fama-MacBeth regressions using monthly return data for NASDAQ securities over the period 1983-2008. Panel A reports results of monthly returns regressed on the estimated market beta $\left(\beta_{\mathrm{rm}}\right)$ and one of the two illiquidity measures VILLIQMA, or VILLIQMA_A. VILLIQMA has been computed as described by Hasbrouck (2009). VILLIQMA_A is VILLIQMA scaled by $(V T+V(T-\tau)) / 2 V T$, where $\bar{T}$ is the number of possible trading days and $\tau$ is the number of zero volume days within $T$. The column headed DIF reports the time series average of the difference between the cross section coefficients obtained from the regressions using each of the two illiquidity measures. Panel B contains estimates where the cross-section model specification also includes $\beta_{\mathrm{ps}}$ the market-wide illiquidity risk factor, and the estimated betas on the Fama-French $\operatorname{SMB}\left(\beta_{S M B}\right), H M L\left(\beta_{H M L}\right)$ and Mom $\left(\beta_{\text {Mom }}\right)$ factors. Panel $C$ are the results from the specification that augments the regressions with market value (Size), book-to-market value $(B / M)$, and the six month return $R(-6)$. Panel $D$ extends the model further by including two alternative measures of liquidity, the Roll (1984) effective spread (Spread) and turnover (Turnover). The * implies significance at a $10 \%$ level, ${ }^{* *}$ at a $5 \%$ level and ${ }^{* * *}$ at a $1 \%$ level using Shanken (1992) adjusted t-statistics. $N$ is the number of firm months in the sample.

\begin{tabular}{|c|c|c|c|c|c|c|}
\hline & \multicolumn{3}{|c|}{ Panel A } & \multicolumn{3}{|c|}{ Panel B } \\
\hline & VILLIQMA & VILLIQMA_A & DIF & VILLIQMA & VILLIQMA_A & DIF \\
\hline \multirow[t]{2}{*}{ Illiquidity } & 0.341 & 0.369 & -0.028 & 0.316 & 0.349 & -0.032 \\
\hline & $(4.63)^{* * *}$ & $(4.68)^{* * *}$ & $(-3.47)^{* * *}$ & $(3.03)^{* * *}$ & $(3.12)^{* * *}$ & $(-3.05)^{* * *}$ \\
\hline \multirow[t]{2}{*}{$\beta_{\mathrm{rm}}$} & 0.604 & 0.635 & -0.030 & 0.786 & 0.824 & -0.038 \\
\hline & ( 1.34$)$ & ( 1.40$)$ & $(-3.21)^{* * *}$ & $(2.17)^{* *}$ & $(2.26)^{* *}$ & $(-3.01)^{* * *}$ \\
\hline \multirow[t]{2}{*}{$\beta_{S M B}$} & - & - & - & -0.156 & -0.216 & 0.060 \\
\hline & - & - & - & $(-0.27)$ & $(-0.37)$ & $(3.53) * * *$ \\
\hline \multirow[t]{2}{*}{$\beta_{\mathrm{HML}}$} & - & - & - & 0.613 & 0.619 & -0.006 \\
\hline & - & - & - & (1.37) & (1.38) & $(-1.99)^{* *}$ \\
\hline \multirow[t]{2}{*}{$\beta_{\mathrm{ps}}$} & - & - & - & 0.030 & 0.028 & 0.002 \\
\hline & - & - & - & (1.26) & ( 1.17$)$ & $(2.49)^{* *}$ \\
\hline \multirow[t]{4}{*}{ Size } & - & - & - & -1.789 & -1.814 & 0.025 \\
\hline & - & - & - & $(-1.82)^{*}$ & $(-1.84)^{*}$ & $(2.87)^{* * *}$ \\
\hline & & Panel C & & & Panel D & \\
\hline & VILLIQMA & VILLIQMA_A & DIF & VILLIQMA & VILLIQMA_A & DIF \\
\hline \multirow[t]{2}{*}{ Illiquidity } & 0.169 & 0.183 & -0.014 & 0.067 & 0.078 & -0.010 \\
\hline & $(1.81)^{*}$ & $(1.92)^{*}$ & $(-2.81)^{* * *}$ & $(0.7)$ & $(0.78)$ & $(-1.88)^{*}$ \\
\hline \multirow[t]{2}{*}{$\beta_{\mathrm{rm}}$} & 1.345 & 1.356 & -0.011 & 1.337 & 1.342 & -0.005 \\
\hline & $(3.77)^{* * *}$ & $(3.82)^{* * *}$ & $(-2.21)^{* *}$ & $(3.9)^{* * *}$ & $(3.93)^{* * *}$ & $(-1.02)$ \\
\hline \multirow[t]{2}{*}{$\beta_{\mathrm{SMB}}$} & -1.781 & -1.785 & 0.004 & -1.677 & -1.679 & 0.001 \\
\hline & $(-4.1)^{* * *}$ & $(-4.12)^{* * *}$ & $(0.7)$ & $(-4.17)^{* * *}$ & $(-4.18)^{* * *}$ & (0.24) \\
\hline \multirow[t]{2}{*}{$\beta_{\mathrm{HML}}$} & 0.989 & 0.986 & 0.003 & 0.890 & 0.889 & 0.001 \\
\hline & $(2.78)^{* * *}$ & $(2.78)^{* * *}$ & $(1.66)^{*}$ & $(2.69)^{* * *}$ & $(2.69) * * *$ & $(0.85)$ \\
\hline \multirow[t]{2}{*}{$\beta_{p s}$} & -0.021 & -0.022 & 0.000 & -0.011 & -0.012 & 0.000 \\
\hline & $(-0.99)$ & $(-1.01)$ & ( 1.14$)$ & $(-0.59)$ & $(-0.62)$ & ( 1.65$)$ \\
\hline \multirow[t]{2}{*}{$\beta_{\text {Mom }}$} & -2.285 & -2.283 & -0.003 & -2.277 & -2.272 & -0.005 \\
\hline & $(-2.78)^{* * *}$ & $(-2.79) * * *$ & $(-0.43)$ & $(-2.76)^{* * *}$ & $(-2.77)^{* * *}$ & $(-0.84)$ \\
\hline \multirow[t]{2}{*}{ Size } & -0.290 & -0.285 & -0.005 & -0.255 & -0.253 & -0.002 \\
\hline & $(-2.5)^{* *}$ & $(-2.46)^{* *}$ & $(-2.8)^{* * *}$ & $(-2.42)^{* *}$ & $(-2.41)^{* *}$ & $(-1.73)^{*}$ \\
\hline \multirow[t]{2}{*}{$R(-6)$} & 0.844 & 0.841 & 0.003 & 0.756 & 0.753 & 0.002 \\
\hline & $(2.43)^{* *}$ & $(2.44)^{* *}$ & $(1.74)^{*}$ & $(2.23)^{* *}$ & $(2.23)^{* *}$ & ( 1.54$)$ \\
\hline \multirow[t]{2}{*}{$\mathrm{B} / \mathrm{M}$} & 0.076 & 0.076 & 0.000 & 0.077 & 0.077 & 0.000 \\
\hline & $(0.82)$ & $(0.82)$ & $(0.61)$ & $(0.88)$ & $(0.88)$ & $(0.29)$ \\
\hline \multirow[t]{2}{*}{ Spread } & & & & 0.109 & 0.104 & 0.004 \\
\hline & & & & ( 1.26$)$ & $(1.2)$ & ( 1.57$)$ \\
\hline \multirow[t]{2}{*}{ Turnover } & & & & -0.023 & -0.022 & -0.001 \\
\hline & & & & $(-1.79)^{*}$ & $(-1.74)^{*}$ & $(-2.02)^{* *}$ \\
\hline
\end{tabular}




\section{Figure 1}

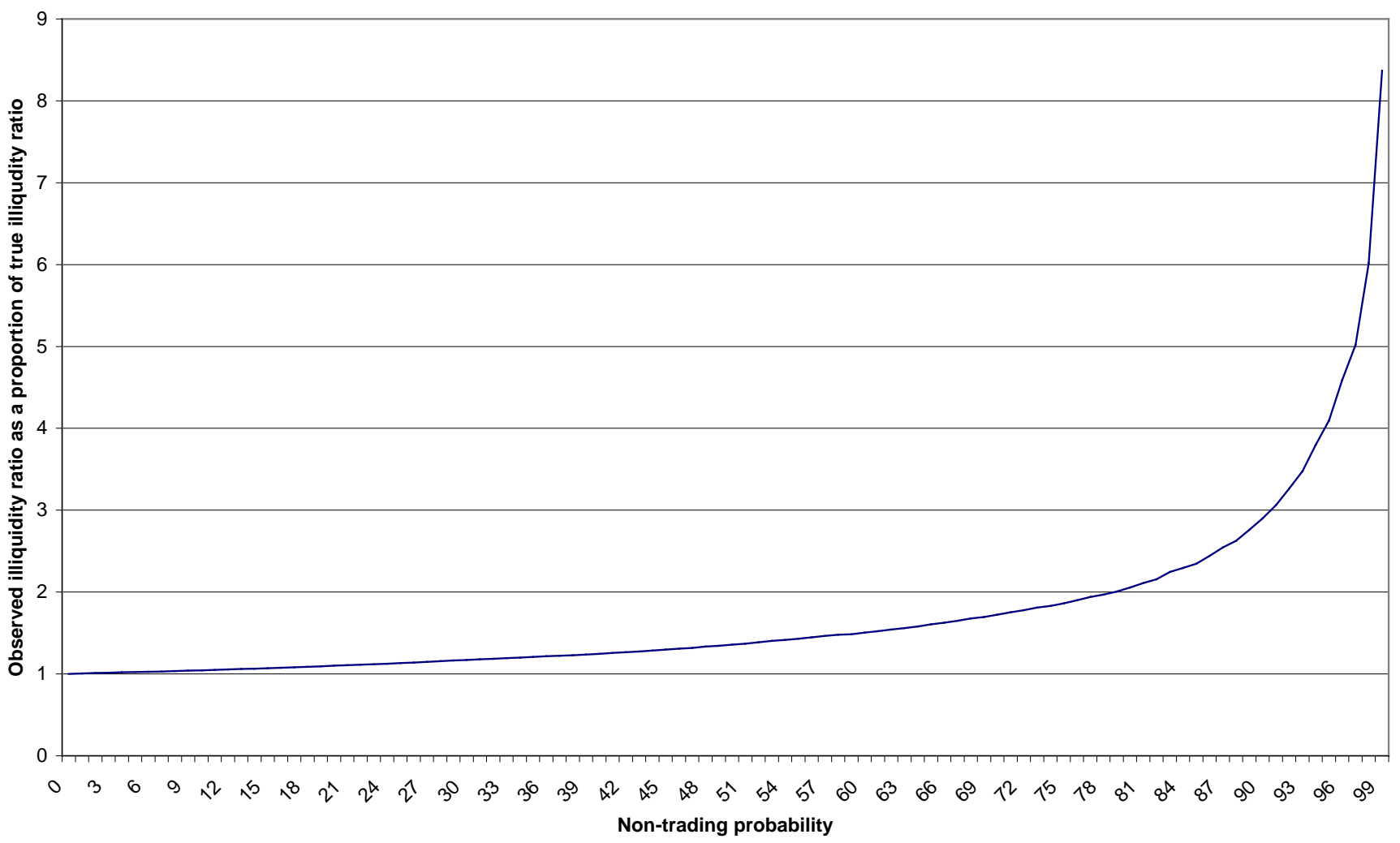

Figure 1: The ratio of the observed illiquidity ratio (ILLIQ) for a stock (in the presence of thin trading) to the unobserved illiquidity ratio (when there is no thin trading) is plotted against the probability of non-trading. The unobserved illiquidity ratio is the Amihud (2002) measure applied to 100,000 simulated stock returns, with annualized expected return and standard deviation of 8 percent and 20 percent, respectively, and 100,000 corresponding volume data. The observed illiquidity ratio for a given non-trading probability is obtained from "observed" returns and volume data that stochastically include non-trading days, in proportion to the non-trading probability, into the simulated data. The observed ratio on a non-trading day is excluded in the annual average calculation. 


\section{Figure 2}

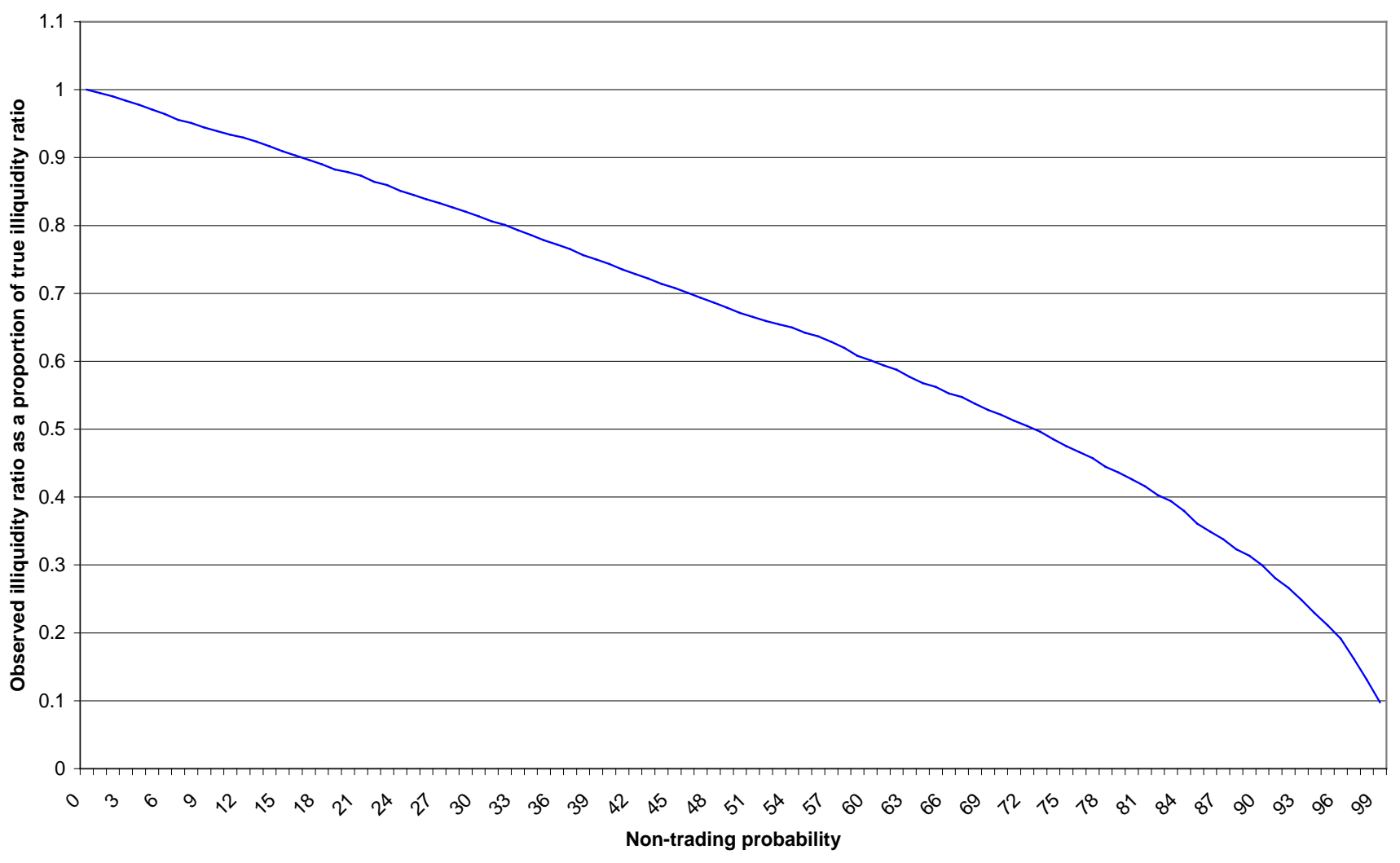

Figure 2: The ratio of the observed illiquidity ratio $\left(\operatorname{ILLIQ}^{\circ}\right)$ for a stock (in the presence of thin trading) to the unobserved illiquidity ratio (when there is no thin trading) is plotted against the probability of non-trading. The unobserved illiquidity ratio is the Amihud (2002) measure applied to 100,000 simulated stock returns, with annualized expected return and standard deviation of 8 percent and 20 percent, respectively, and 100,000 corresponding volume data. The observed illiquidity ratio for a given non-trading probability is obtained from "observed" returns and volume data that stochastically include non-trading days, in proportion to the nontrading probability, into the simulated data. The observed ratio on a non-trading day is set to zero, and is included in the annual average calculation. 
Figure 3

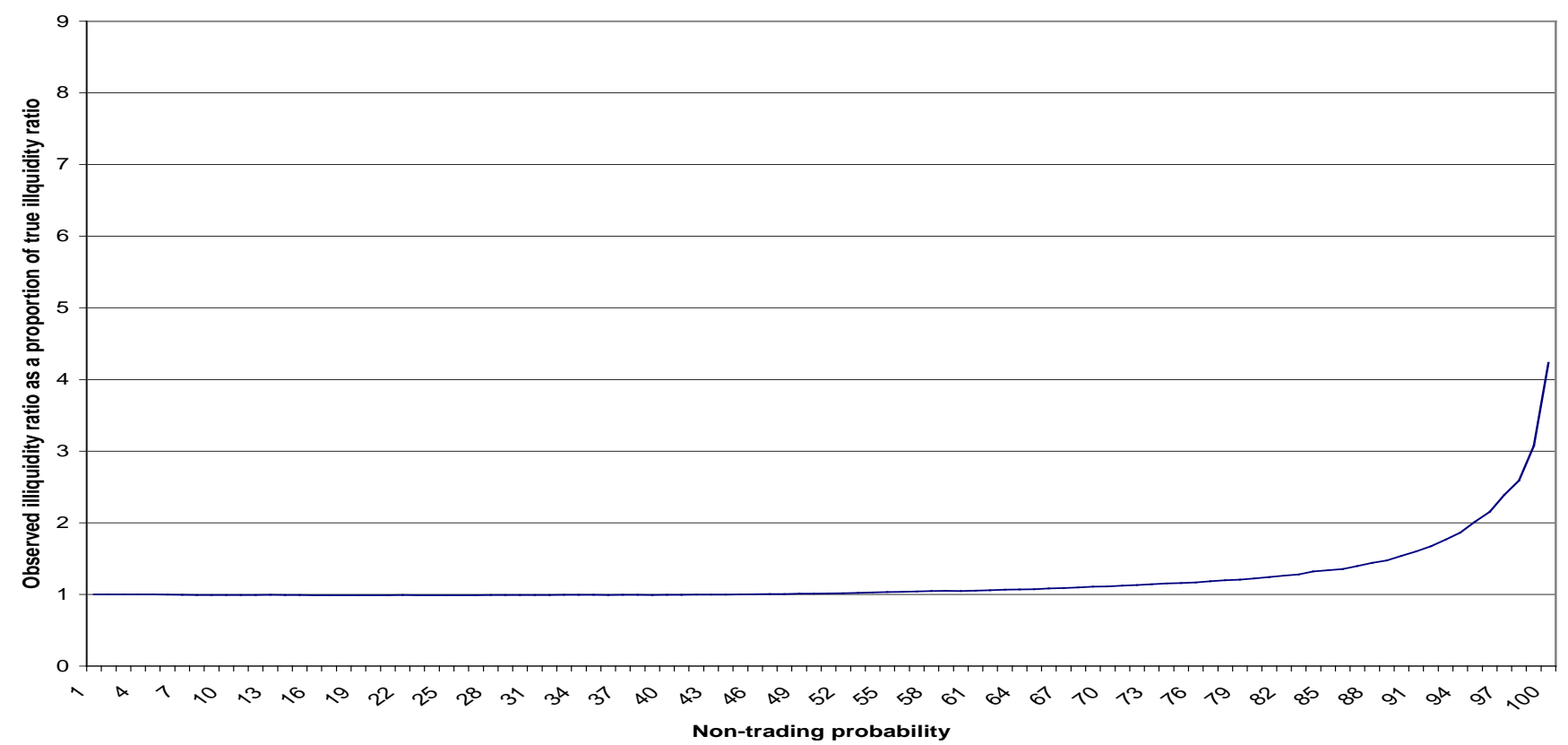

Figure 3: The ratio of the observed adjusted illiquidity ratio (ILLIQ_A) for a stock (in the presence of thin trading) to the unobserved illiquidity ratio (when there is no thin trading) is plotted against the probability of non-trading. The unobserved illiquidity ratio is the Amihud (2002) measure applied to 100,000 simulated stock returns, with annualized expected return and standard deviation of 8 percent and 20 percent, respectively, and 100,000 corresponding volume data. The observed illiquidity ratio for a given non-trading probability is obtained from "observed" returns and volume data that stochastically include non-trading days, in proportion to the nontrading probability, into the simulated data. The observed adjusted ratio (ILLIQ_A) is computed as ((2T$\tau) / 2 T$ )*ILLIQ, where $T$ is the number of potential trading days and $\tau$ is the number of non-trading days within $T$. 


\section{Figure 4}

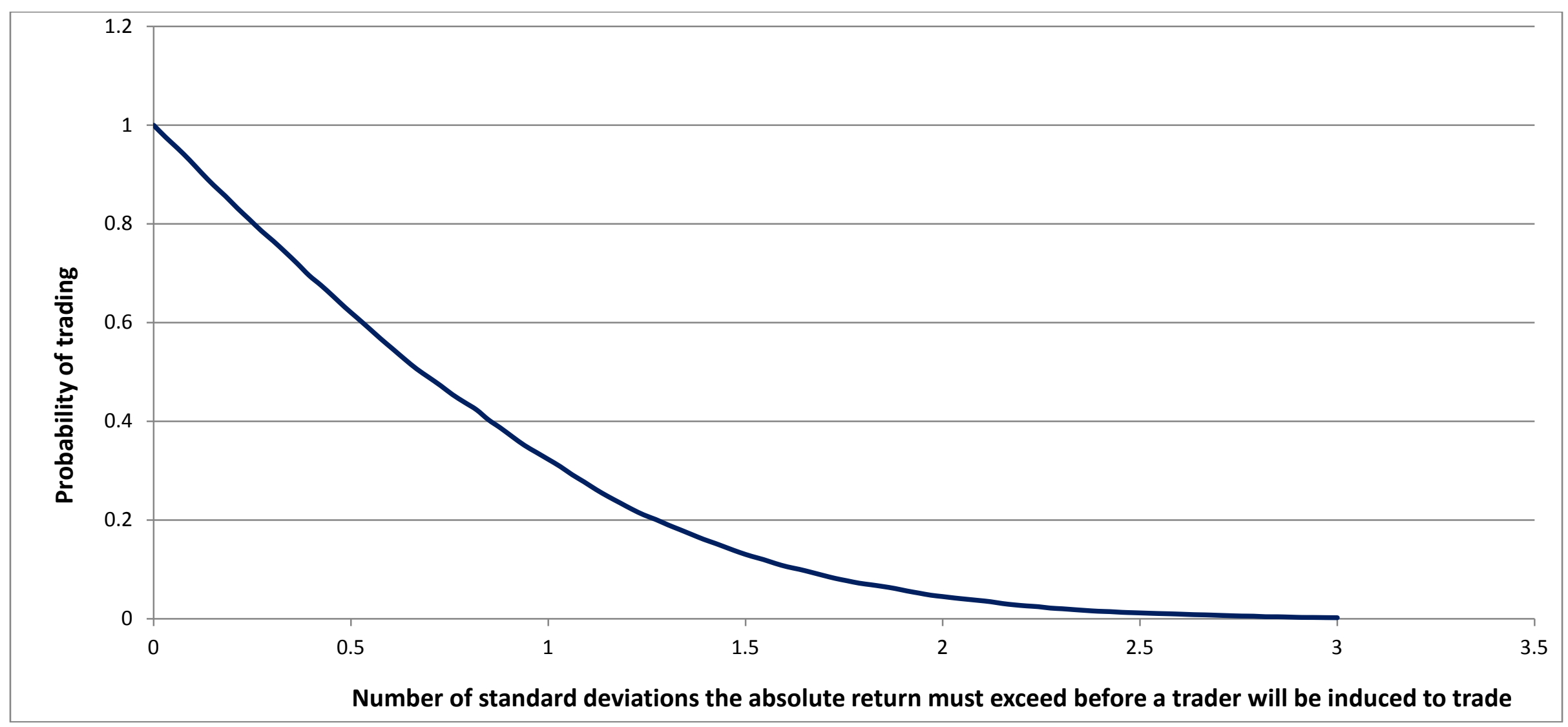

Figure 4: The probability of trading when the value of the absolute unobserved return exceeds the given number of standard deviations away from the mean unobserved return. The greater the standard deviation threshold, the less likely are absolute returns to exceed it, and the lower the inducement to trade. Unobserved returns are taken from 100,000 simulated stock returns, with annualized expected return and standard deviation of 8 percent and 20 percent, respectively. 


\section{Figure 5}

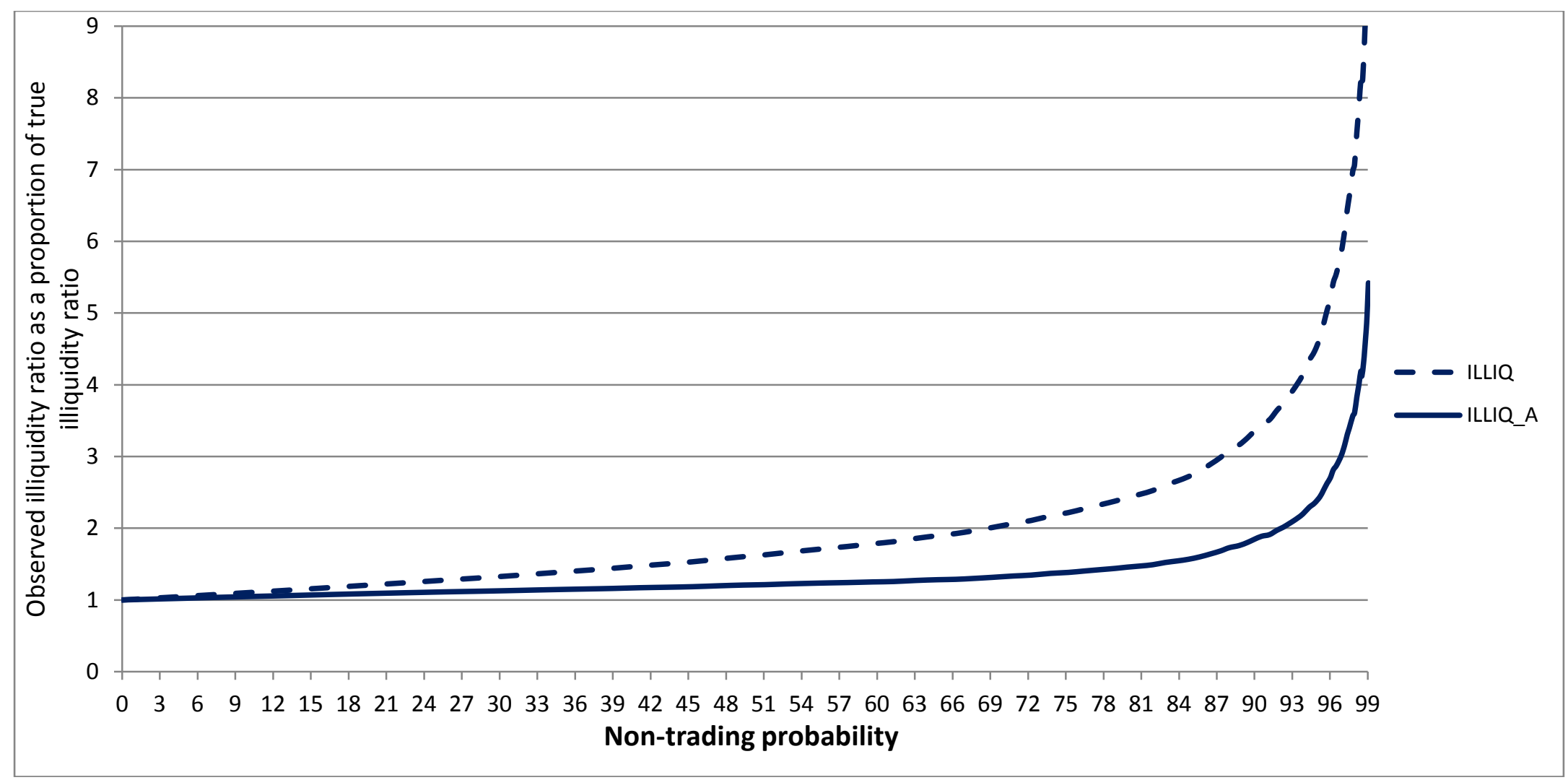

Figure 5: The ratio of the observed adjusted illiquidity ratio (ILLIQ_A) for a stock (in the presence of thin trading) to the unobserved illiquidity ratio (when there is no thin trading) and the ratio of the observed unadjusted illiquidity ratio (ILLIQ) (in the presence of thin trading) to the unobserved illiquidity ratio (when there is no thin trading) are plotted against the probability of non-trading. The probability of non-trading depends upon the absolute value of the unobserved return as shown in Figure 4. The unobserved illiquidity ratio is the Amihud (2002) measure applied to 100,000 simulated stock returns, with annualized expected return and standard deviation of 8 percent and 20 percent, respectively, and 100,000 corresponding volume data. The observed illiquidity ratio for a given non-trading probability is obtained from "observed" returns and volume data that include non-trading days that are determined by the magnitude of absolute returns. The observed adjusted ratio (ILLIQ_A) is computed as $((2 T-\tau) / 2 T) *$ ILLIQ, where $T$ is the number of potential trading days and $\tau$ is the number of non-trading days within $T$. 


\section{Figure 6}

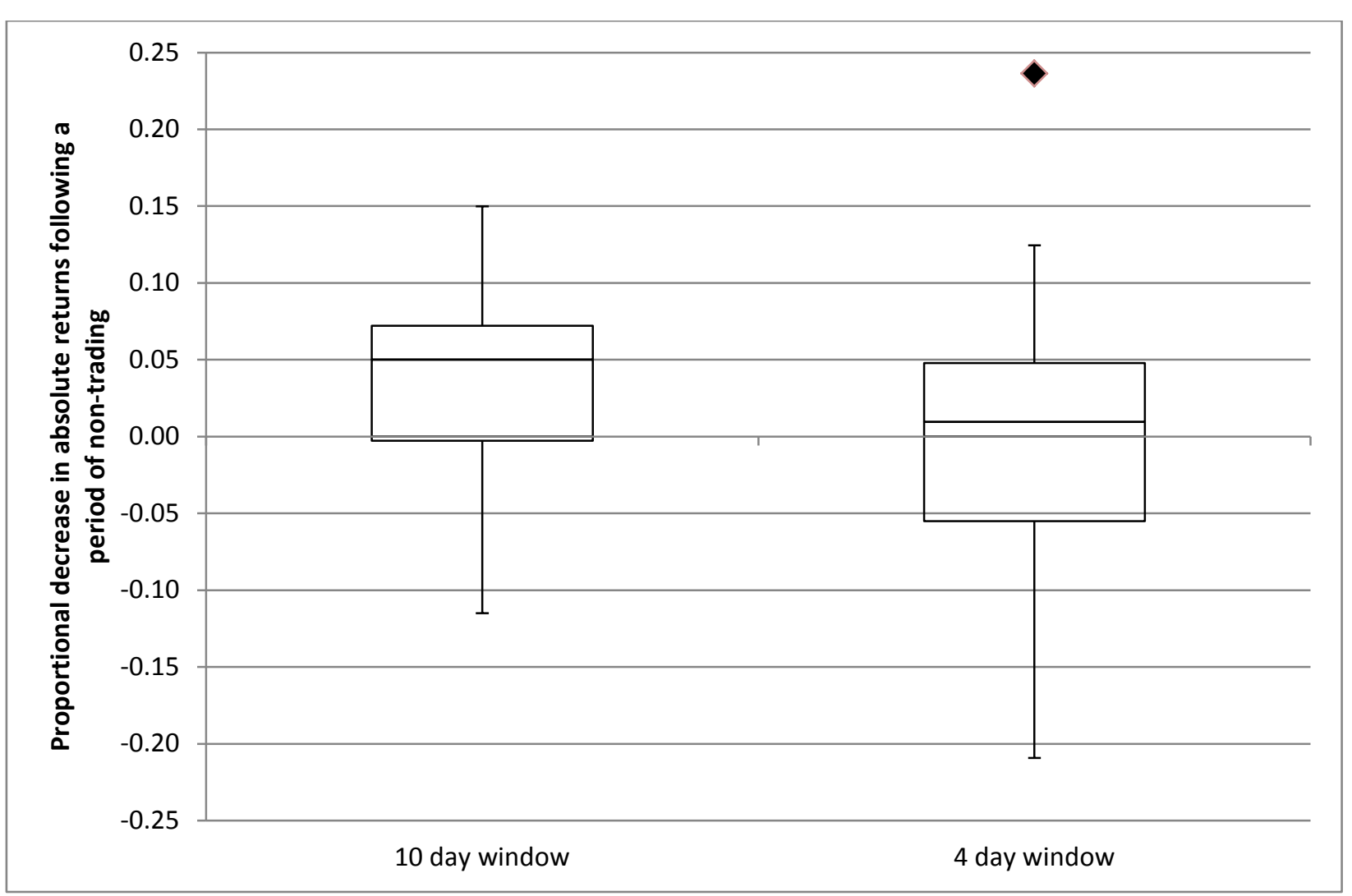

Figure 6: The distribution of changes in absolute returns before and after periods of non-trading (excluding non-trading periods starting on a Monday). Each sample point in the box plots is the proportional decrease in the annual average (across firms) absolute return averaged across the 10 (or 4) day window prior to a period of non-trading compared to the same measure across a similar length window following a period of non-trading.The plots measure decreases (increases) as positive (negative) values. The boxes show the median decreases, and the inter-quartile ranges (IQR), while the "whiskers" show the furthest points within 1.5 IQR of the outer quartiles. The single outlying observation is indicated by the diamond-shaped marker. 


\section{Figure 7}

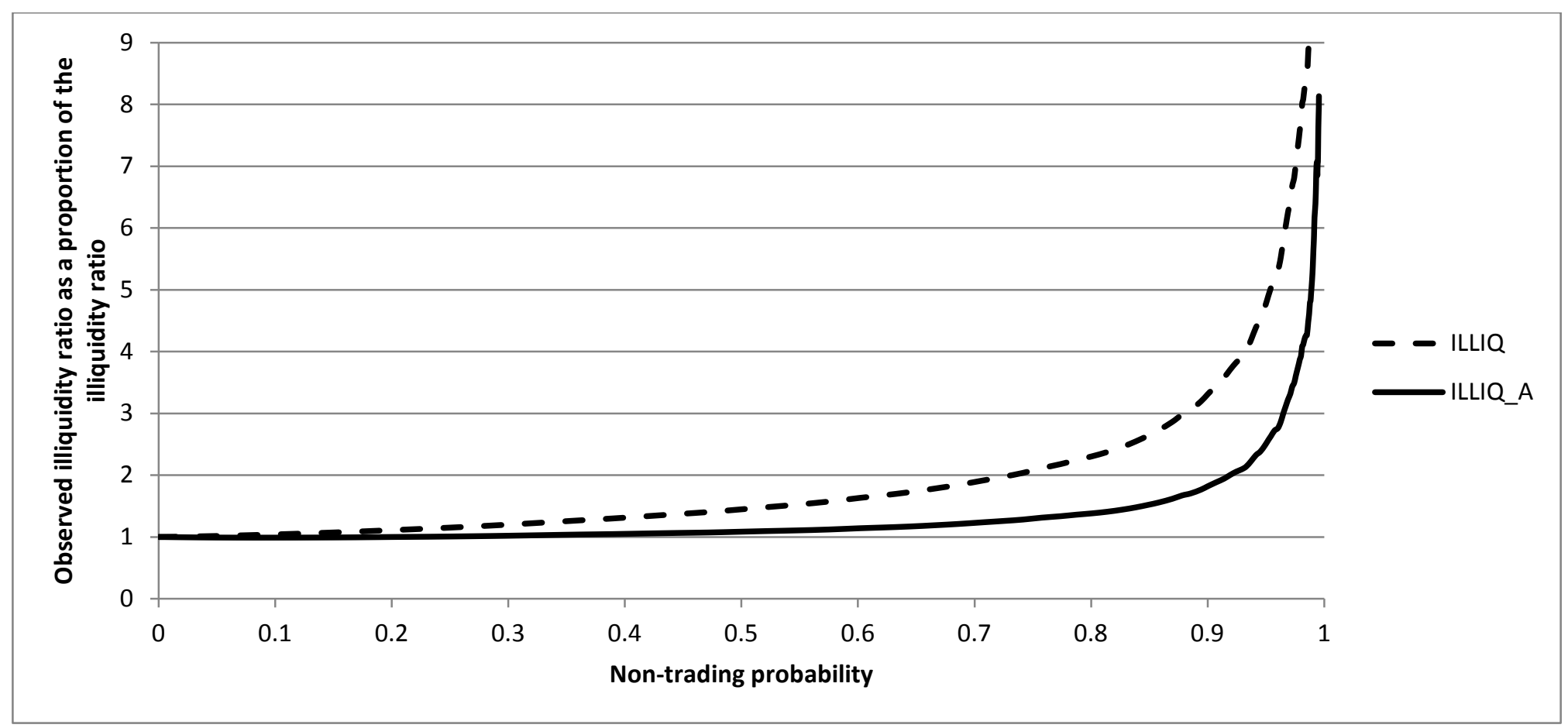

Figure 7: The ratio of the observed adjusted illiquidity ratio (ILLIQ_A) for a stock (in the presence of thin trading) to the unobserved illiquidity ratio (when there is no thin trading) and the ratio of the observed unadjusted illiquidity ratio (ILLIQ) (in the presence of thin trading) to the unobserved illiquidity ratio (when there is no thin trading) are plotted against the probability of non-trading. The probability of non-trading depends upon the absolute value of the unobserved return as shown in Figure 4. The unobserved illiquidity ratio is the Amihud (2002) measure applied to 100,000 simulated stock returns, with annualized expected return and unconditional standard deviation of 8 percent and 20 percent, respectively, and 100,000 corresponding volume data. The conditional variance of the returns follows an ARCH(1) process with an autoregressive parameter $=0.90$. The observed illiquidity ratio for a given non-trading probability is obtained from "observed" returns and volume data that include non-trading days that are determined by the magnitude of absolute returns, and where following periods of non-trading, absolute returns drop by 15 percent and then have increasing volatility that reverts back to the 20 percent unconditional standard deviation after 10 trading days. The observed adjusted ratio (ILLIQ_A) is computed as $((2 T-\tau) / 2 T) *$ ILLIQ, where $T$ is the number of potential trading days and $\tau$ is the number of non-trading days within $T$. 
Figure 8

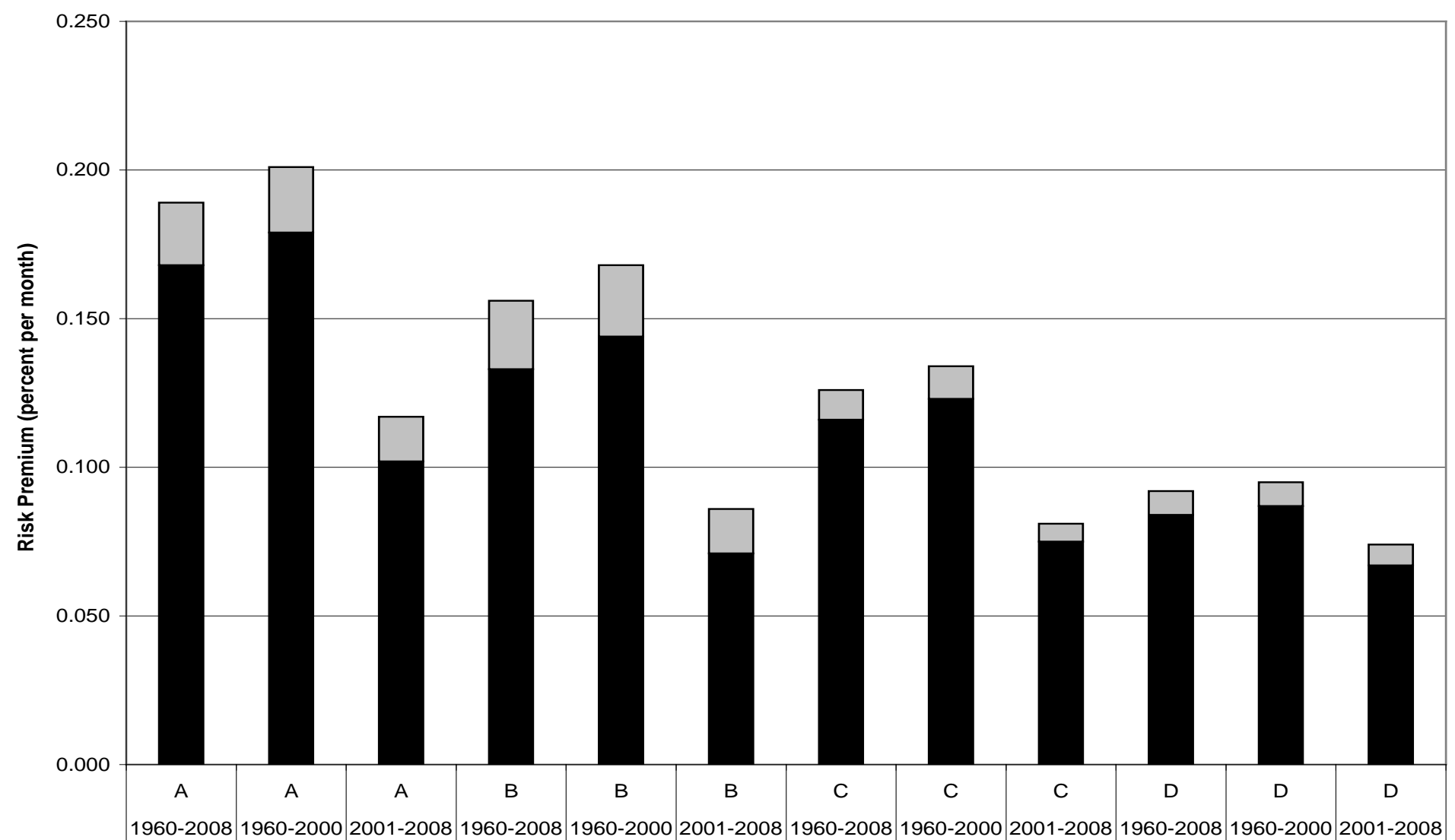

Figure 8: Estimated bias in the illiquidity premium of NYSE/AMEX stocks, using ILLIQMA as the illiquidity ratio. The risk premium is the product of the corresponding coefficient estimate on ILLIQMA in Tables 5, 7 and 8, and the average value of ILLIQMA. Estimates in columns labeled A, B, C and D use the data from the corresponding Panels in Tables 5, 7 and 8. In those tables, Panel A reports results of monthly returns regressed on the estimated market beta $(\beta \mathrm{rm})$ and ILLIQMA. Panel B contains estimates where the cross-section model specification also includes $\beta_{p s}$ the market-wide illiquidity risk factor, and the estimated betas on the Fama-French SMB ( $\left.\beta_{\mathrm{SMB}}\right)$, HML $\left(\beta_{\mathrm{HML}}\right)$ and Mom $\left(\beta_{\mathrm{Mom}}\right)$ factors. Panel C are the results from the specification that augments the regressions with market value (Size), book-to-market value (B/M), and the prior six month return, R(-6). Panel $D$ extends the model further by including two alternative measures of liquidity, the Roll (1984) effective spread (Spread) and turnover (Turnover). The height of a lower bar is the estimate from using ILLIQMA, and the downward bias this has is the additional height in the upper portion (shaded) of a bar. 
Figure 9

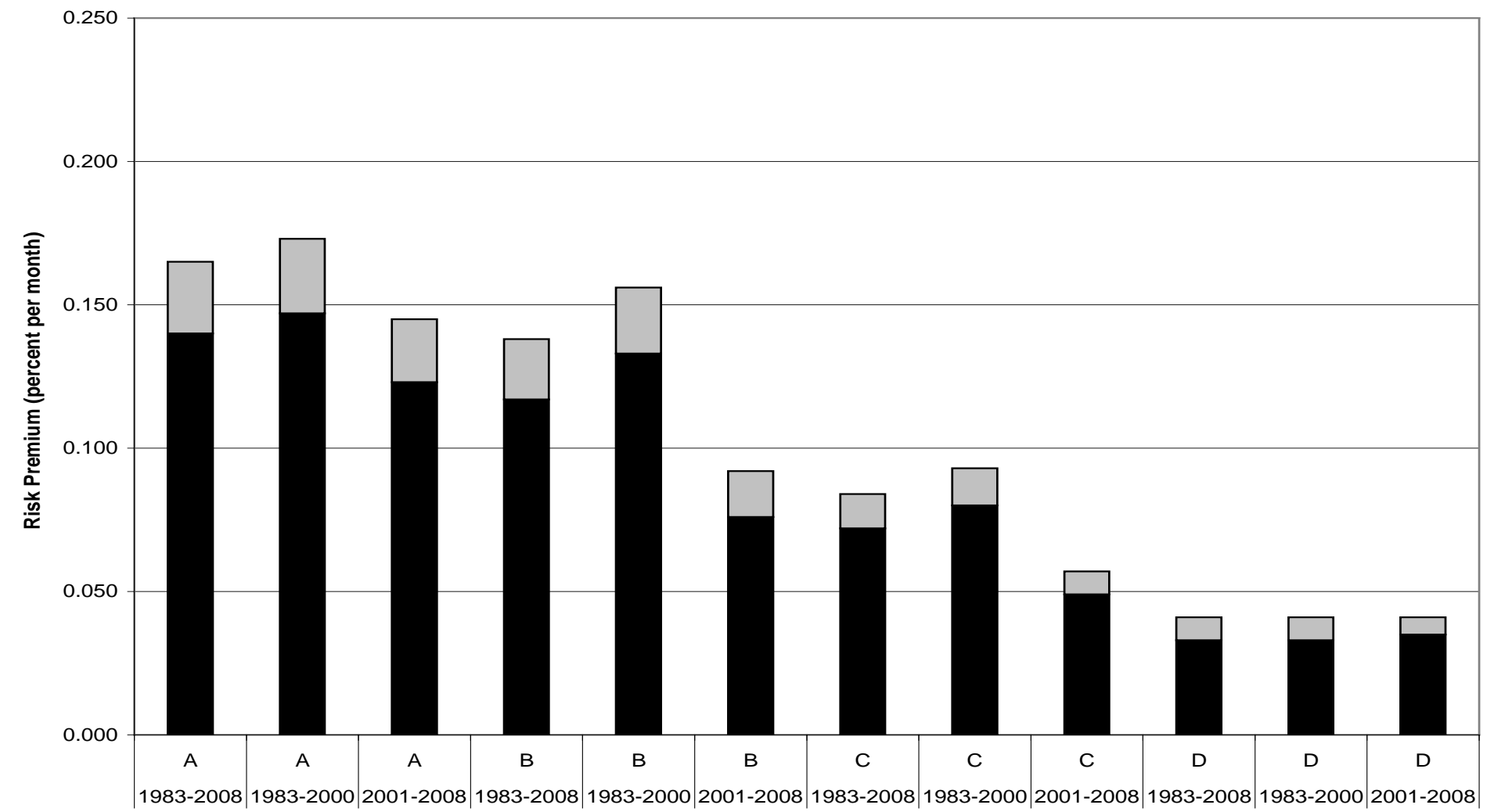

Figure 9: Estimated bias in the illiquidity premium of NASDAQ stocks, using ILLIQMA as the illiquidity ratio. The risk premium is the product of the corresponding coefficient estimate on ILLIQMA in Tables 6, 9 and 10, and the average value of ILLIQMA. Estimates in columns labeled A, B, C and $\mathrm{D}$ use the data from the corresponding Panels in Tables 6, 9 and 10. In those tables, Panel A reports results of monthly returns regressed on the estimated market beta $(\beta \mathrm{rm})$ and ILLIQMA. Panel B contains estimates where the cross-section model specification also includes $\beta_{p s}$ the market-wide illiquidity risk factor, and the estimated betas on the Fama-French SMB $\left(\beta_{\mathrm{SMB}}\right)$, HML $\left(\beta_{\mathrm{HML}}\right)$ and Mom $\left(\beta_{\mathrm{Mom}}\right)$ factors. Panel C are the results from the specification that augments the regressions with market value (Size), book-to-market value (B/M), and the prior six month return, R(-6). Panel D extends the model further by including two alternative measures of liquidity, the Roll (1984) effective spread (Spread) and turnover (Turnover). The height of a lower bar is the estimate from using ILLIQMA, and the downward bias this has is the additional height in the upper portion (shaded) of a bar. 


\section{Internet Appendix to: \\ The Effects of Non-Trading on the Illiquidity Ratio}

\section{A.1 Introduction}

This appendix contains results from the simulation exercises that were undertaken to examine the robustness of using the adjusted measure of the illiquidity ratio, ILLIQ_A, in place of the unadjusted illiquidity measure ILLIQ when the measurement interval features zero volume days. The results detailed in this appendix are noted in the main paper in footnotes 8, 9, 11, 14, 18 and 19, in Sections 2.1 and 2.2, between pages 8-18.

The unadjusted illiquidity ratio is the measure developed by Amihud (2002), see equation (1) in the main paper. The adjusted illiquidity ratio scales the unadjusted measure by the factor $(2 T-\tau) / 2 T$, where $T$ is the number of trading days in the measurement interval (a year) and $\tau$ is the number of zero volume days in the measurement interval. This scaling is developed in Section 2.2, equation (8) of the main paper.

Results from the following simulation exercises are reported in this appendix. Section A.2 explores the effects of variations in the parameters generating the unobservable returns series, which is used to measure the benchmark illiquidity ratio, and from which bias due to the introduction of non-trading days into the returns series can be measured. Section A.3 explores the effects of potential time dependence in the probability of non-trading, such that the non-trading probability depends on the occurrence of non-trading on prior days. Both variation in the underlying parameters and the introduction of forms of dependent non-trading has little impact on the bias in the unadjusted illiquidity ratio found using the benchmark settings in the simulations, or upon the ability of the adjusted ratio to correct for it. 
Section A.4 examines how close the adjusted illiquidity ratio, ILLIQ_A, is likely to be to the illiquidity ratio from unobserved returns, by comparing the fit of alternative functional forms to this unobservable ratio. With simulated data it is possible to find close fitting functions to the unobservable ratio, and compare this to the fit of the simple functional form of the adjusted ratio, ILLIQ_A. We find that the adjusted ILLIQ_A ratio can approximate the unobservable ratio as well as alternative more complicated functions, and always an order of magnitude better than the unadjusted ratio, ILLIQ. Since, in empirical data, it would not be possible to establish which functional form is optimal (as only one quantity of non-trading is observed in a given sample of data), using the scaling embodied in ILLIQ_A represents an adjustment that is simple and feasible to apply in empirical data, and is at least as good as much more complex adjustments.

Section A.5 reports the results of further simulations that vary the specification of the notrade generator to allow for non-zero returns on zero volume days. These enhanced simulations show that there is unlikely to be much to gain from developing a more complicated adjustment for a wider variety of "thin trading" symptoms, that there is most to gain from adjusting for zero volume days and that adjusting for zero volume days is robust to confounding symptoms of thin trading. Specifically, we find that using ILLIQ_A as the illiquidity ratio continues to provide a less biased measure of illiquidity than ILLIQ, even when the returns process is more general.

Section A.6 reports the results of simulations that draw the simulated returns from a distribution that has a time varying -conditional variance. These simulations show that including ARCH-type variance processes does not diminish the ability of ILLIQ_A to provide a less biased measure of illiquidity. Section A.7 reports the results of simulations that permit the volatility of returns to respond to periods of non-trading, such that after a period of non-trading, the volatility drops, remains persistently lower until gradually reverting back to its unconditional mean. This adjustment generates a positive correlation between volume and volatility, and reduces the bias in 
ILLIQ. However, using parameters calibrated from market data, we find that ILLIQ_A is able to continue to offer an improved measurement of illiquidity relative to ILLIQ. Moreover, in the empirical data, increases in volatility following non-trading periods are also observed with high frequency. These increase the bias in ILLIQ, but in all cases, ILLIQ_A is able to reduce this bias.

\section{A.2 Variation in the parameter values of the unobservable}

\section{returns model}

To establish the generality of the potential biases in the observed illiquidity ratio, we examine simulated observed illiquidity ratios for a range of different parameter values for the unobservable returns series (see equation (3) in the main paper). Specifically, we consider a range of alternative combinations of annualized security standard deviations ranging from $10 \%$ to $30 \%$, and annualized expected excess returns (risk premia) of between $2 \%$ and $20 \%$.

For each of the alternative mean and standard deviation scenarios, we recomputed the ratio of the observed illiquidity measure in the presence of non-trading, $(p=0,1,2, \ldots, 99)$, to the unobserved illiquidity ratio, $(p=0)$, to produce graphs similar to those presented in Figure 1 in the main paper but using the changed parameter values. When plotted together, differences between the graphs are barely detectible visually, and so Figure A.1 plots the percentage maximum difference, positive and negative, between the base case curve in Figure 1 in the main paper, for ILLIQ, and the same curve drawn for each of the other scenarios. ${ }^{37}$ The differences arising from changing the parameter values in the simulations are less than one tenth of one percent for nontrading probabilities less than 27 percent, and less than one percent for probabilities up to 93

\footnotetext{
${ }^{37}$ As the maximum difference at adjacent non-trading probabilities can arise from different sets of parameter values (scenarios), the curves in Figure A.1 are not smooth. By contrast, if the difference between the base curve and the curve that showed the greatest deviation, on average across the range of probabilities, had been drawn, then a smooth difference curve would have been produced, since both components are themselves smooth.
} 
percent. These results suggest that the biases in the illiquidity measures, ILLIQ, observed in Figure 1 are robust to changes in parameter values.

[Figure A.1]

\section{A.3 Time dependent non-trading}

To capture time dependency, the probability of non-trading temporarily is allowed to increase above the level $p$ if there was non-trading in the previous time interval. This can be written as

$$
\begin{aligned}
& p_{t+1}=p\left(1+\pi V_{t}\right) \\
& V_{t}=\left\{\begin{array}{lll}
0 & \text { if } & U_{t} \leq p \\
1 & \text { if } & U_{t}>p
\end{array}\right.
\end{aligned}
$$

where $\pi$ is the proportion by which non-trading increases in period $t+1$ if there was non-trading in period $t, V_{t}$ is the volume indicator in equation (4) in the main paper, and $U_{t}$ are the sequence of uniformly distributed variates.

Figure A.2 shows the observed illiquidity ratio, ILLIQ, as a proportion of the illiquidity ratio calculated from unobserved returns, ILLIQ*, plotted against the probability of non-trading, where non-trading is dependent on the previous days non-trading. The graph also shows the time independent case, with both cases using the same set of parameters as in Figure 1 in the main paper. In the case shown, $\pi=0.25$, which means that the non-trading probability increases by 25 percentage points above the base level if there was non-trading on the previous day, and so only base level non-trading probabilities up to 75 percent are considered. With time dependent nontrading, the bias in the illiquidity appears to be greater, but only noticeably so for non-trading probabilities greater than 50 percent. For more modest, and so more realistic levels, time dependency has little additional impact on the bias. 
[Figure A.2]

\section{A.4 Exploring the $(2 T-\tau) / 2 T$ scaling?}

In the main paper, we use the fact that the biases in unadjusted illiquidity ratio, ILLIQ, and the ratio ILLIQ ${ }^{\circ}$ (see equation (7) in the main paper) are roughly equal and opposite across the range of non-trading probabilities, to motivate the use of an average of these two measures as a natural choice for an adjusted measure that will be free of bias. This average then turns out to be the simple scaling (2T- $\tau) / 2 T$ on ILLIQ (see equation (8) in the main paper, for the derivation of the adjusted measure ILLIQ_A), where $T$ is the number of days in the interval being used to calculate the illiquidity ratio, and $\tau$ is the number of zero volume days in this interval.

It is possible, however, that other scalings, corresponding to an unevenly weighted linear combination or a non-linear combination of ILLIQ and ILLIQ ${ }^{\circ}$ could provide a less biased measure. This section provides evidence that the scaling arising from an equal linear weighting (the simple average) of ILLIQ and ILLIQ ${ }^{\circ}$ is likely to be very close to an unobservable (in empirical data) optimal combination.

With our simulated data, we can search for the optimal value of the mixing parameters, $\gamma_{1}, \gamma_{2}$, that make the linear combination (vector ILLIQ_A) of adjusted illiquidity measure vectors,

$$
\underline{\text { ILLIQ } \_ \text {A }}=\underline{\gamma_{1} \text { ILLIQ }^{0}}+\gamma_{2} \underline{\text { ILLIQ }}
$$

as close as possible to the true value, across all non-trading probabilities. ${ }^{38}$ The vector ILLIQ is a column vector of the illiquidity measure ILLIQ, where each element of the vector corresponds to

\footnotetext{
38 We also explored three non-linear combinations of the two measures; a weighted harmonic mean, an exponentially weighted average of log measures and a weighted geometric average (like a Cobb-Douglas function), but none provided smaller values of the loss function across the range of simulations and parameter setting scenarios, so we report the results here for just the linear combinations.
} 
this measure evaluated at the successive non-trading probabilities from zero to 99 percent. Similarly, ILLIQ ${ }^{0}$ is a column vector containing the equivalent values for ILLIQ $^{0}$

We find $\gamma_{1}, \gamma_{2}$ by minimizing the squared errors, between the true liquidity ratio and the combination, that is

$$
\operatorname{Min}\left(\underline{\text { ILLIQ }^{*}}-\underline{\text { ILLIQ_A }}\left(\gamma_{1}, \gamma_{2}\right)\right)^{\prime}\left(\underline{\operatorname{ILLIQ}^{*}}-\underline{\text { ILLIQ_A }}\left(\gamma_{1}, \gamma_{2}\right)\right)
$$

where ILLIQ*is a vector with each element equal to ILLIQ* ILLIQ*, the true illiquidity ratio.

We further consider the restricted combination

$$
\underline{\text { ILLIQ_A }}=\underline{\gamma \mathrm{ILLIQ}^{0}}+(1-\gamma) \underline{\mathrm{ILLIQ}}
$$

and also test the restriction $\gamma_{1}+\gamma_{2}=1$.

Table A.1 summarizes the estimates of the parameters, $\gamma_{1}, \gamma_{2}$, and $\gamma$. All the estimated parameters are statistically different from zero at a 5\% level. The values reported for each parameter, for a given range of non-trading probabilities, are the average, minimum and maximum values obtained across the range of underlying model parameter scenarios, described in Section A.2 above. For non-trading levels up to about 50 percent, the average values of the parameters $\gamma_{1}, \gamma_{2}$ cluster around 0.5 . This suggests that, for real data, the simple average $\gamma=0.5$ might be a reasonable mixing parameter for the two measures of illiquidity, ILLIQ and ILLIQ ${ }^{\circ}$. This would be a simple measure to compute and all measures would be equal in the absence of thin trading.

\section{[Table A.1]}

In empirical data, it will never be possible to determine an optimal combination of ILLIQ and ILLIQ ${ }^{\circ}$, as only one level of non-trading is ever observed and would itself be measured with error, and so some pre-determined combination would have to be set. Therefore, it is worthwhile determining, within our simulated data, whether the simple average of ILLIQ and ILLIQ ${ }^{\circ}$ 
produces an observed illiquidity measure as close to the true value as the measure given the (least squares) optimal (but unobservable) combination of ILLIQ and ILLIQ ${ }^{\circ}$, or whether the simple average represents little additional improvement over ILLIQ.

In Table A.2, we summarize the mean absolute error, across different ranges of nontrading probabilities, between the true illiquidity ratio and the observed liquidity ratio. For each underlying parameter scenario, we calculate the mean absolute error

$$
\text { mae }=\frac{1}{100} \sum_{p=0.00}^{p=0.99} \mid \text { ILLIQ }^{*} \text {-ILLIQ_A }{ }_{p}\left(\gamma_{1}, \gamma_{2}\right) \mid
$$

where ILLIQ_A $A_{p}\left(\gamma_{1}, \gamma_{2}\right)=\gamma_{1}$ ILLIQ $_{p}^{0}+\gamma_{2}$ ILLIQ $_{p}$, which is the adjusted measure, ILLIQ_A, evaluated for non-trading probability $p$, and then compute and report the average of the means $\left(\times 10^{3}\right)$ across the range of underlying parameter scenarios. We report these averages for the four measures of observed illiquidity given by (i) $\gamma_{1}=1, \gamma_{2}=0$ (ILLIQ), (ii) $\gamma_{1}=0.5, \gamma_{2}=0.5$, which is an average of measures ILLIQ and ILLIQ ${ }^{0}$, and is the adjusted measure ILLIQ_A developed and used in the main paper, (iii) $\gamma_{1}=\gamma, \gamma_{2}=(1-\gamma)$, which is the (least squares) optimal restricted weighted average of measures ILLIQ and ILLIQ ${ }^{0}$, and (iv) the optimal unrestricted weighted combination of measures ILLIQ and ILLIQ ${ }^{0}$. We note again that neither (iii) nor (iv) are possible to calculate in empirical data.

\section{[Table A.2]}

In addition to the averages for each of the four liquidity measures, we also compute the ratio of the averages of each of the restricted measures to the unrestricted measure, (iv), to provide evidence on differences in orders of magnitude. These ratios are reported in the line in the table immediately beneath the averages. Below these ratios, we report the ratio of the minimum (across the range of parameter scenarios) mean absolute error of the restricted measure to the maximum mean absolute error of the unrestricted measure to determine whether the range 
of the errors is non-overlapping, to provide further evidence of differences in orders of magnitude.

For the unrestricted optimal weighted combination of measures, (iv), the average mean absolute errors are around the same order of magnitude for all but the two highest deciles, which correspond to the unrealistic situation of non-trading probabilities in excess of 80 percent. These two deciles then also influence the average mean absolute errors of the highest quintile, highest quartile and the entire range of probabilities in excess of 50 percent. The errors of the optimal restricted parameter model, (iii), $\gamma_{1}=\gamma, \gamma_{2}=(1-\gamma)$, relative to the unrestricted model, (iv), given by the ratio of averages in the table, indicate that they are of the same order of magnitude as those of the unrestricted model. The correspondence indicated by the overlap of the range of errors in the two models, given by the Min/Max ratio in the table, is even closer, where there is much overlap in the ranges of errors for the two models for non-trading probabilities up to 50 percent.

By contrast, for ILLIQ alone, case (i), the errors tend to be at least one, but often two, orders of magnitude greater than for the unrestricted model. However, ILLIQ_A, the average of ILLIQ and ILLIQ ${ }^{0}$, provides an improvement in the error statistics that makes them much more often of the same order of magnitude as the optimal (empirically unobservable) unrestricted model, both in terms of relative averages of the errors and overlap in the ranges of errors. This suggests that computing our non-trading adjusted measure, ILLIQ_A, as simple average of ILLIQ and ILLIQ ${ }^{0}$, which corresponds to simple scaling on ILLIQ (see equation (11) in the main paper), provides a convenient and substantially less biased measure of illiquidity than ILLIQ, the unadjusted measure. 


\section{A.5 Variation in the specification of the no-trade generator}

In Section A.2, we examined the sensitivity of the bias in the unadjusted measure ILLIQ to changes in the parameter values of the underlying returns process, but keeping the specification of the no-trade generator (equation (4) in the main paper) fixed. It that case, zero volume days arose stochastically with a given probability and were always accompanied by a zero return. In this section, we summarise the results of further simulations that vary the specification of the no-trade generator to allow for non-zero returns on zero volume days. This investigation is designed to determine whether adjusting the illiquidity ratio, as in ILLIQ_A, for non-trading (zero volume) days is still appropriate when the returns process takes on a more general form.

It is straightforward to adapt the simulations to model the effects on the illiquidity ratio of zero volume days sometimes having non-zero returns. This can be achieved by augmenting equation (4) in the main paper with a term that is proportional to the distance between the true price and the previous period's observed price, that gives,

$$
s_{p, t}=s_{p, t-1}+V_{p, t}\left(s_{t}^{*}-s_{p, t-1}\right)+\alpha_{t}\left(s_{t}^{*}-s_{p, t-1}\right)\left(1-V_{p, t}\right)
$$

which is easier to interpret if re-arranged to give

$$
s_{p, t}=s_{p, t-1}+V_{p, t}\left(1-\alpha_{t}\right)\left(s_{t}^{*}-s_{p, t-1}\right)+\alpha_{t}\left(s_{t}^{*}-s_{p, t-1}\right)
$$

If trading does occur, that is, if $V_{p, t}=1$, then as in the simpler model, $s_{p, t}=s_{t}^{*}$, but if trading does not take place, $V_{p, t}=0$, then the observed price is assumed to follow the partial adjustment mechanism 


$$
s_{p, t}=s_{p, t-1}+\alpha_{t}\left(s_{t}^{*}-s_{p, t-1}\right)
$$

The stochastic coefficient of mean reversion is defined as, $\alpha_{t}=\alpha I_{q, t}$, the product of a constant proportion, $\alpha$, and an indicator variable $I_{q, t}=0$ (if $U_{t}^{\prime} \leq q$ ) or $I_{q, t}=1$ (if $U_{t}^{\prime}>q$ ) where, $q$, is the probability of a zero volume day experiencing a zero return, and $U_{t}^{\prime}$ is an independent drawing from a uniform distribution on the range $0-1$. If the indicator variable takes the value 0 , then zero volume is accompanied by a zero return, but if the indicator variable takes on the value 1 , then

$$
s_{p, t}=s_{p, t-1}+\alpha\left(s_{t}^{*}-s_{p, t-1}\right)
$$

The observed price adjusts by some fraction $\alpha$ of the true, unobserved, price adjustment. ${ }^{39}$

Figures A.3, A.4 and A.5 summarise the impact of varying either the frequency with which zero volume days occur, or the proportion of the unobserved return that is observed on a zero volume day.

In all of the figures referred to in this section of the appendix, the variable being reported in the graphs (on the vertical axis) is the difference between two mean absolute percentage errors (MAPE). In each panel of Table 1 of the main paper, we measured the potential bias in the illiquidity ratio as the MAPE relative to the true illiquidity ratio, ILLIQ*, and report this separately for each of the unadjusted measure, ILLIQ, and the adjusted measure, ILLIQ_A. If the MAPE for ILLIQ_A is less than the MAPE for ILLIQ, then ILLIQ_A is a less biased measure of illiquidity, in the presence of zero volume days. To capture this same effect in the Figures A.3 A.5, we present the difference between the two MAPEs, such that a positive difference indicates that ILLIQ_A is less biased.

\footnotetext{
${ }^{39}$ Amihud and Mendelson (1987) pioneered the use of a partial adjustment mechanism to model the adjustment of stock prices.
} 
In Figure A.3 and A.4, the vertical axis is the difference between the MAPEs, while the two horizontal axes capture the interaction of changes in the probability of zero volume days and changes in the proportion of unobserved return observed on the zero volume day. Figure A.3 fixes the probability of a zero volume day having a non-zero return at 0.2, while Figure A.4 fixes the probability at 0.5 . Relative to the base line case, at the front of the Figures, of observing a zero return on a zero volume day, the impact on the reduction in bias by using ILLIQ_A is slight, regardless of the probability of non-zero returns occurring. The difference between Figures A.3 and A.4 that suggests that the benefits from using ILLIQ_A lessen slightly as the probability of observing a non-zero return increases. In Figure A.5, the proportion of the unobserved return observed on a zero volume day is held at 0.5 , while the probability of a non-zero return occurring on a zero volume day is permitted to vary. Again, the benefit of using ILLIQ_A is still present and only reduces from the base line case at high probabilities of non-zero returns occurring and at high levels of the probability of zero volume days.

[Figure A.3]

[Figure A.4]

[Figure A.5]

Thus, the adjusted illiquidity ratio continues to always improve the measurement of illiquidity, even in this more generalized returns and volume scenario.

\section{A.6 Variation in the heteroskedasticity and persistence in the variance of the unobserved returns series.}

The base case scenario for the simulated series of daily unobserved returns, used in Figures 1-5 in the main body of the paper, takes independent draws from a normal distribution with mean of 8 percent and a standard deviation of 20 percent (annualized). It is well established 
that equity market returns display time varying conditional variances that are well represented by ARCH models (Engle, 1982, and the survey paper by Bollerslev et al, 1992). To ensure that our proposed adjustment to the illiquidity ratio is robust to this empirical characteristic of equity returns, we adjust the simulated returns to have a conditional variance process that follows an $\mathrm{ARCH}(1)$ process, whereby the conditional variance at time $t$ is an affine function of the immediate past squared innovation. The coefficient on the linear term, the ARCH coefficient, which is bounded between zero and one, measures the degree of persistence of innovations to the variance process, while the ratio of the constant term to one minus the linear term measures the unconditional variance. By varying the $\mathrm{ARCH}$ coefficient, we explore a range of levels of persistence and, in each case, set the constant term to ensure that the unconditional variance matches the 20 percent annualized value in the homoscedastic base case. The ARCH model generates excess kurtosis in the unobservable returns series and this and the autocorrelation of squared returns are shown in Table A.3 for a range of values of the ARCH coefficient. The greatest kurtosis and autocorrelation are generated with an ARCH coefficient of 0.90 and so we report the results for simulations based upon this parameter.

In Figure A.6, we show graphs of ILLIQ and ILLIQ_A relative to the true unobservable illiquidity ratio, as in Figures 1 to 7 in the body of the paper, that show that introducing ARCH effects into the variance does not change the ability of ILLIQ_A to reduce the bias in ILLIQ.

\section{A.7 Variations in variance caused by periods of non-trading}

In the body of the paper, we report the results of two variations to our base line simulations that permit a correlation between volume and volatility. The first is that volume

is induced during a volatile market, because investors will trade when the value of accumulated information has exceeded the costs of trading. This modification induces a 
correlation between volume and volatility (squared unobserved returns) of 60 percent, on average (the correlation differs depending on the extent of the non-trading). Even without this modification, but because our base line (homoscedastic) simulations require that returns are zero if volume is zero, the correlation between volume and volatility (squared observed returns) in the presence of thin trading is on average 32 percent. Our second modification is to have non-trading periods result in a decline in variance that persists for some length of time after the non-trading period. The ARCH process described above, will in any case induce some persistence to a change in variance, but we build in a more rigid structure to ensure that the change in variance persists. This modification to the simulations results in a correlation between volume and volatility (squared observed returns) of 35 percent on average. The drop in volatility is reversed gradually over the subsequent 10 trading days, such that over a period of 10 days following a period of non-trading, the volatility returns to its pre-non-trading level. Specifically, the time dependent scaling factor $\varphi_{q}$ is applied to absolute unobserved returns, where $q \leq 10$ is the number of days following a period of non-trading, and $\left(1-\varphi_{0}\right)$ is the proportional fall in absolute returns immediately following the period of non-trading. The scaling factor operates like a reverse partial adjustment mechanism, specifically $\varphi_{q-1}=\varphi_{q}+\omega\left(\varphi_{0}-\varphi_{q}\right)$, where $\omega$ is an adjustment coefficient and $\varphi_{10}=1$. Following a drop in the magnitude of the returns of size $(1-\varphi)$, the return magnitude adjustment reverts back to 1 , over a period of 10 days by following a convex increasing path. Initially, the reversion from the initial drop in volatility is slow, to build in persistence, but it speeds up as the end of the 10 day window is approached. Figure A.7 shows the path of the variance scaling factor over a 10 day window for $\left(1-\varphi_{0}\right)=0.85$ and $\omega=0.5$.

Using the returns data from the empirical analysis, that is, all stocks on the NYSE/AMEX (1960-2008) and NASDAQ (1983-2008) exchanges, we determined the distribution of changes to 
volatility following non-trading periods. This is shown in Figure 6 in the body of the paper. The maximum drop in absolute returns was 15 percent (equivalent to a 28 percent reduction in variance), with a median decline in absolute returns between 1 and 5 percent (depending upon the data window used). In the body of the paper, we use the 15 percent maximum reduction as a conservative measure. In this appendix, we provide more detail on the effects of differing declines (or increases) on the ability of the adjusted illiquidity ratio, ILLIQ_A, to correct the bias in ILLIQ due to non-trading. Specifically, Figures A.8 and A.9, show the bias in ILLIQ and the reduced or eliminated bias from using ILLIQ_A, for changes in absolute returns of \{Figure A.8: $30 \%,-20 \%,-15 \%,-10 \%\}$ and $\{$ Figure A.9: $+10 \%,+20 \%,+30 \%$ and $+50 \%\}$ following nontrading periods. In each case, we set the parameter $\omega=0.5$. We find that variation in this parameter had only negligible impact on the results compare to varying the initial drop in absolute returns, and so we report only the results for $\omega=0.5$ which are representative.

In Figure A.8, we can see that for reductions in absolute returns of 10 or 15 percent that, with the exception of one outlying observation contain the entire distribution of empirically observed falls in volatility following periods of non-trading, the bias in ILLIQ is around the same or slightly lower than was the case without this adjustment to absolute returns (comparing the upper two panels in Figure A.8 to Figures 1 and 5 in the body of the paper). At all levels of nontrading, the adjusted ratio, ILLIQ_A, continues to largely eliminate or substantially reduce this bias. For larger falls in volatility, however, we see that the adjusted ratio may over-correct the bias in ILLIQ at low levels of non-trading. Specifically, for a fall of 20 percent in absolute returns, the adjusted ratio is only a superior measure for non-trading levels above 13 percent, while for a fall of 30 percent in absolute returns, the adjusted ratio is only a superior measure for non-trading levels above 36 percent. However, these magnitudes of falls in absolute returns are not representative of those found in the empirical data, there is only one outlier that exceeds a 20 percent fall and none that exceeds a 30 percent fall in absolute return. It appears therefore that for 
changes in variance likely to encountered in empirical data, the adjusted ratio provides a robust correction for non-trading. This is further supported by the simulations that permit absolute return to increase. Figure 6 in the body of the paper, shows that increases of up to 21 percent in absolute returns following non-trading periods can be observed in some years. Figure A.9 shows that such increases further add to the bias in ILLIQ, but that ILLIQ_A always results in a less biased measure, irrespective of the rise in absolute returns. Again, this further variation to our simulations to reflect more of the empirical regularities of stock returns, does not diminish the ability of our adjusted illiquidity ratio to correct the non-trading bias in the illiquidity ratio.

\section{References}

Amihud, Yakov, 2002. Illiquidity and stock returns: cross-section and time-series effects. Journal of Financial Markets 5, 31-56.

Amihud, Y., and Mendelson, H., 1987, Trading mechanisms and stock returns : An empirical investigation, Journal of Finance 42, 533-553.

Bollerslev, T., Chou, R.Y., Kronor, K.F., 1992. ARCH modeling in finance: a review of the theory and empirical evidence. Journal of Econometrics 52, 5-59.

Engle, R., 1982. Autoregressive conditional heteroscedasticity with estimates of the variance of United Kingdom inflation, Econometrica 50, 987-1007. 
Table A.1

Least squares estimates of the parameters of the models

$$
\begin{gathered}
\operatorname{ILLIQ}_{j}^{*}=\gamma_{1} \mathrm{ILLIQ}_{j}^{0}+\gamma_{2} \mathrm{ILLIQ}_{j}+\zeta_{j} \quad j=0,1,2, \ldots, 99 \\
\mathrm{ILLIQ}_{j}^{*}=\gamma \operatorname{ILLIQ}_{j}^{0}+(1-\gamma) \mathrm{ILLIQ}_{j}+\xi_{j} \quad j=0,1,2, \ldots, 99
\end{gathered}
$$

where the data are illiquidity measures computed from 100,000 simulated returns that feature non-trading days, with non-trading probabilities, $\mathrm{j}=0,1,2, \ldots, 99$ percent. ILLIQ ${ }^{0}$ is the Amihud (2002) illiquidity measure with zero values on non-trading days, ILLIQ is the Amihud measure with non-trading days excluded, and ILLIQ* is the value of the illiquidity measure when the probability of non-trading in the simulated data is zero. The reported values are the average (indicated by a bar above the estimate), the minimum and maximum values obtained from estimating each model for variations in the underlying parameters generating the simulated returns.

\begin{tabular}{ccccccccccccr}
\hline & \multicolumn{10}{c}{ Non-trading probability deciles } & Full \\
& \multicolumn{1}{c}{} & 1 & 2 & 3 & 4 & 5 & 6 & 7 & 8 & 9 & 10 & Sample \\
\hline $\bar{\gamma}$ & 0.579 & 0.562 & 0.536 & 0.516 & 0.496 & 0.456 & 0.420 & 0.376 & 0.312 & 0.162 & 0.218 \\
$\operatorname{Min} \gamma$ & 0.567 & 0.561 & 0.535 & 0.514 & 0.492 & 0.452 & 0.416 & 0.372 & 0.309 & 0.155 & 0.210 \\
$\operatorname{Max} \gamma$ & 0.593 & 0.565 & 0.538 & 0.518 & 0.500 & 0.461 & 0.425 & 0.381 & 0.315 & 0.167 & 0.225 \\
\hline $\bar{\gamma}_{1}$ & 0.609 & 0.549 & 0.484 & 0.496 & 0.418 & 0.351 & 0.321 & 0.289 & 0.217 & 0.096 & 0.191 \\
$\operatorname{Min} \gamma_{1}$ & 0.597 & 0.542 & 0.479 & 0.492 & 0.406 & 0.349 & 0.318 & 0.286 & 0.210 & 0.090 & 0.183 \\
$\operatorname{Max} \gamma_{1}$ & 0.623 & 0.557 & 0.490 & 0.501 & 0.432 & 0.352 & 0.326 & 0.292 & 0.222 & 0.103 & 0.197 \\
\hline $\bar{\gamma}_{2}$ & 0.389 & 0.453 & 0.534 & 0.514 & 0.647 & 0.778 & 0.861 & 0.965 & 1.313 & 2.624 & 0.993 \\
$\operatorname{Min} \gamma_{2}$ & 0.375 & 0.444 & 0.527 & 0.508 & 0.625 & 0.775 & 0.858 & 0.949 & 1.280 & 2.556 & 0.981 \\
$\operatorname{Max} \gamma_{2}$ & 0.401 & 0.462 & 0.540 & 0.521 & 0.666 & 0.783 & 0.865 & 0.981 & 1.351 & 2.699 & 1.006 \\
\hline
\end{tabular}




\section{Table A.2}

Summary statistics on the mean absolute error between a liquidity measure featuring non-trading and the measure for the same simulated returns when the non-trading probability is zero. ILLIQ ${ }^{0}$ is the Amihud (2002) illiquidity measure with zero values on non-trading days, ILLIQ is the standard Amihud measure with non-trading days excluded. "Restricted" is the linear combination $\gamma$ ILLIQ $^{0}+(1-\gamma)$ ILLIQ, where $\gamma$ takes the values (for each underlying return parameter scenario) that comprise the average in the corresponding column in Table A.1. "Unrestricted" is the linear combination $\gamma_{1}$ ILLIQ $^{0}+\gamma_{2}$ ILLIQ, where $\gamma_{1}, \gamma_{2}$ are the values (for each underlying return parameter scenarios) that comprise the average in the corresponding column in Table A.1. The mean absolute error is the mean across 100 non-trading percentiles of the absolute error between the liquidity measure with that percentile non-trading probability and the same measure with a zero non-trading probability in the returns series. The Avg. MAE is the average of the MAE obtained from each of the scenarios for the parameters of the underlying returns series. Avg. ratio is the ratio of the MAE for the measure in that panel of the table to the MAE for the Unrestricted measure. Min/Max is the ratio of the minimum MAE for the measure in that panel of the table to the maximum MAE of the Unrestricted measure. The minimum and maximum values are the extrema across the parameter scenarios. This ratio assesses the degree of overlap of the distribution of the MAEs (across the parameter scenarios) between the measure in that panel and the unrestricted measure.

\begin{tabular}{|c|c|c|c|c|c|c|c|c|c|c|c|}
\hline \multirow[b]{2}{*}{ Parameters } & \multicolumn{10}{|c|}{ Non-trading probability deciles } & \multirow{2}{*}{$\begin{array}{c}\text { Full } \\
\text { Sample }\end{array}$} \\
\hline & 1 & 2 & 3 & 4 & 5 & 6 & 7 & 8 & 9 & 10 & \\
\hline & \multicolumn{11}{|c|}{ ILLIQ } \\
\hline Avg. MAE & 0.203 & 0.673 & 1.286 & 2.021 & 2.901 & 4.194 & 5.906 & 8.501 & 13.517 & 34.919 & 7.412 \\
\hline Avg. ratio & 21.6 & 109.7 & 137.0 & 436.6 & 353.0 & 218.5 & 403.6 & 535.5 & 218.7 & 72.4 & 6.6 \\
\hline \multirow[t]{2}{*}{ Min/Max } & 6.8 & 34.9 & 46.2 & 139.0 & 125.8 & 73.5 & 131.3 & 182.3 & 71.3 & 23.7 & 2.2 \\
\hline & \multicolumn{11}{|c|}{ ILLIQ_A=(ILLIQ+ILLIQ $\left.{ }^{0}\right) / 2$} \\
\hline Avg. MAE & 0.033 & 0.097 & 0.104 & 0.067 & 0.051 & 0.334 & 0.805 & 1.680 & 3.649 & 13.570 & 2.039 \\
\hline Avg. ratio & 3.5 & 15.8 & 11.1 & 14.5 & 6.2 & 17.4 & 55.0 & 105.8 & 59.0 & 28.1 & 1.8 \\
\hline \multirow[t]{2}{*}{ Min/Max } & 1.3 & 5.2 & 3.9 & 4.6 & 1.8 & 5.2 & 16.9 & 34.7 & 19.0 & 9.1 & 0.6 \\
\hline & \multicolumn{11}{|c|}{ Restricted } \\
\hline Avg. MAE & 0.013 & 0.007 & 0.023 & 0.010 & 0.048 & 0.081 & 0.112 & 0.152 & 0.390 & 2.060 & 1.465 \\
\hline Avg. ratio & 1.4 & 1.1 & 2.4 & 2.1 & 5.8 & 4.2 & 7.7 & 9.6 & 6.3 & 4.3 & 1.3 \\
\hline \multirow[t]{2}{*}{ Min/Max } & 0.5 & 0.4 & 0.8 & 0.8 & 1.8 & 1.5 & 2.5 & 3.5 & 2.1 & 1.4 & 0.4 \\
\hline & \multicolumn{11}{|c|}{ Unrestricted } \\
\hline Avg. MAE & 0.009 & 0.006 & 0.009 & 0.005 & 0.008 & 0.019 & 0.015 & 0.016 & 0.062 & 0.483 & 1.129 \\
\hline
\end{tabular}

Table A.3

Kurtosis in returns (Normal=3) and the first order autocorrelation of squared returns from 100,000 simulated stock returns, with annualized expected return and unconditional standard deviation of 8 percent and 20 percent, respectively. The conditional variance of the returns follows an ARCH(1) process with an autoregressive parameter given in the row labeled ARCH coefficient. The "Constant Variance" case reports the statistics for the base line simulation.

\begin{tabular}{|l|r|r|r|r|r|r|r|}
\hline ARCH coefficient & 99 & 95 & 90 & 80 & 50 & Constant variance \\
\hline Kurtosis & 4.05 & 10.71 & 13.22 & 11.00 & 4.29 & 2.97 \\
\hline Autocorrelation of squared returns & 0.22 & 0.32 & 0.52 & 0.42 & 0.32 & 0.00 \\
\hline
\end{tabular}




\section{Figure A.1}

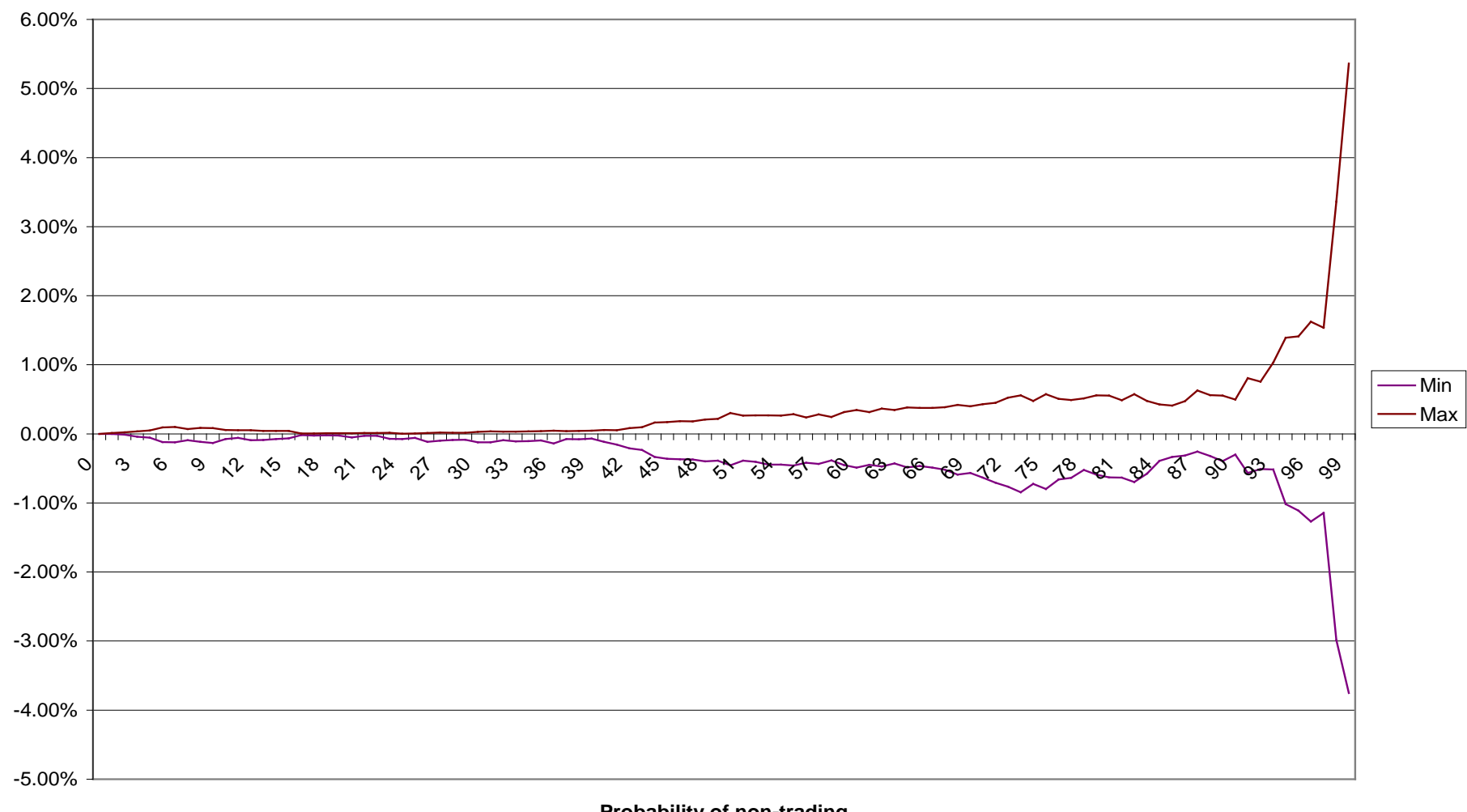

Probability of non-trading

Figure A.1: The ratio of the observed illiquidity ratio (ILLIQ) for a stock (in the presence of thin trading) to the true illiquidity ratio (when there is no thin trading) is plotted against the probability of non-trading. The true illiquidity ratio is the Amihud (2002) measure applied to 100,000 simulated stock returns and volume data. The observed illiquidity ratio for a given non-trading probability is obtained from "observed" returns and volume data that stochastically include non-trading days, in proportion to the non-trading probability, into the simulated data. The observed ratio on a non-trading day is excluded in the annual average calculation. The ratio (of illiquidity ratios) for each non-trading probability is recomputed for each of the parameter variations for the simulated returns series. The graph shows the maximum and minimum percentage difference between the ratio values obtained from the most extreme scenario and the values obtained from the initial parameters used in Figure 1 in the main paper. 


\section{Figure A.2}

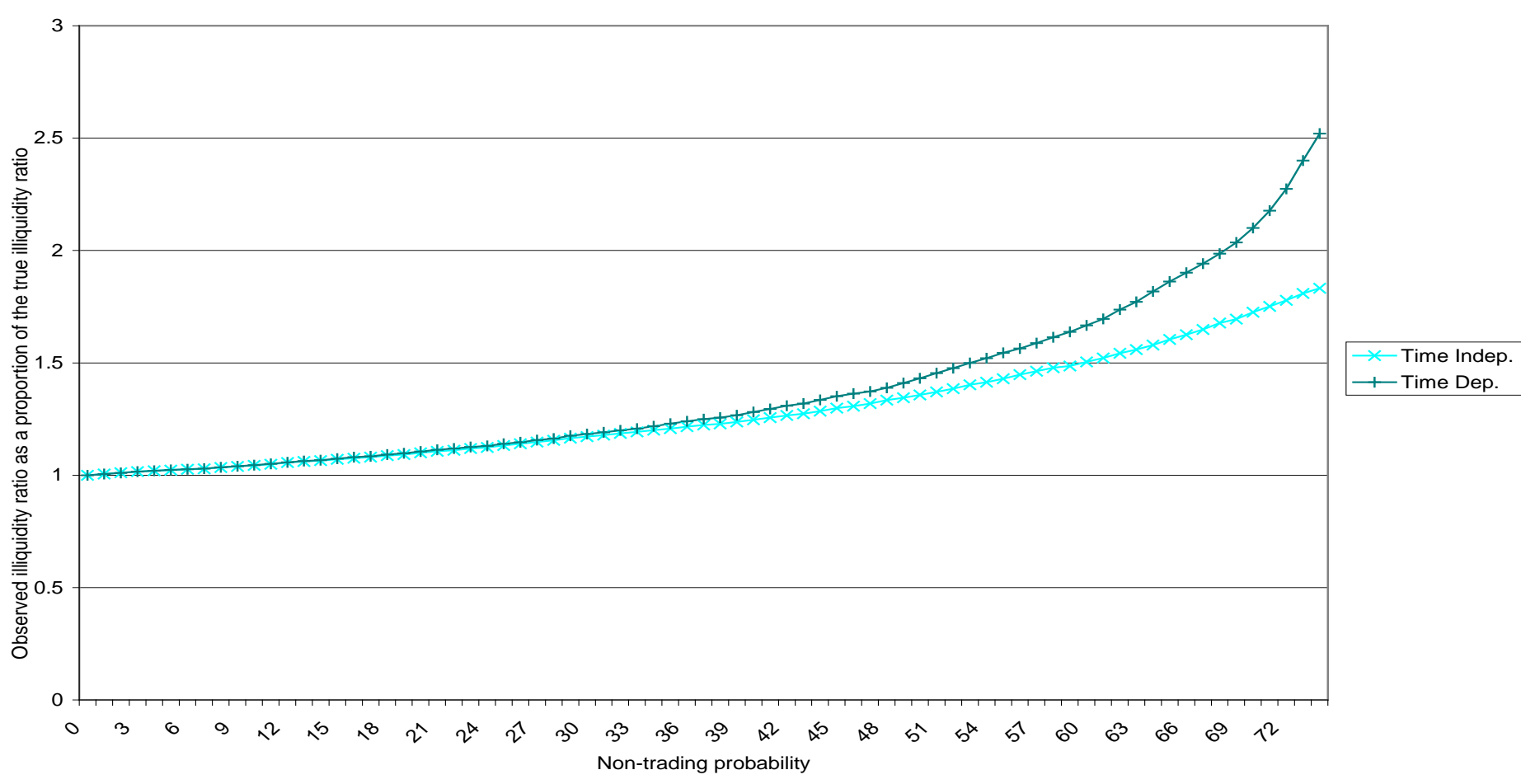

Figure A.2: The ratio of the observed illiquidity ratio (ILLIQ) for a stock (in the presence of thin trading) to the true illiquidity ratio (when there is no thin trading) is plotted against the probability of non-trading. The true illiquidity ratio is the Amihud (2002) measure applied to 100,000 simulated stock returns, with annualized expected return and standard deviation of 8 percent and 20 percent, respectively, and 100,000 corresponding volume data. The observed illiquidity ratio for a given non-trading probability is obtained from "observed" returns and volume data that stochastically include non-trading days, in proportion to the non-trading probability, into the simulated data. The observed ratio on a non-trading day is excluded in the annual average calculation. In the time independent case, non-trading probability, $p$, is the same on every day. In the time dependent case, non-trading probability on day $t+1$ is equal to $p+0.25 p$ if the stock did not trade on day $t$. 


\section{Figure A.3}

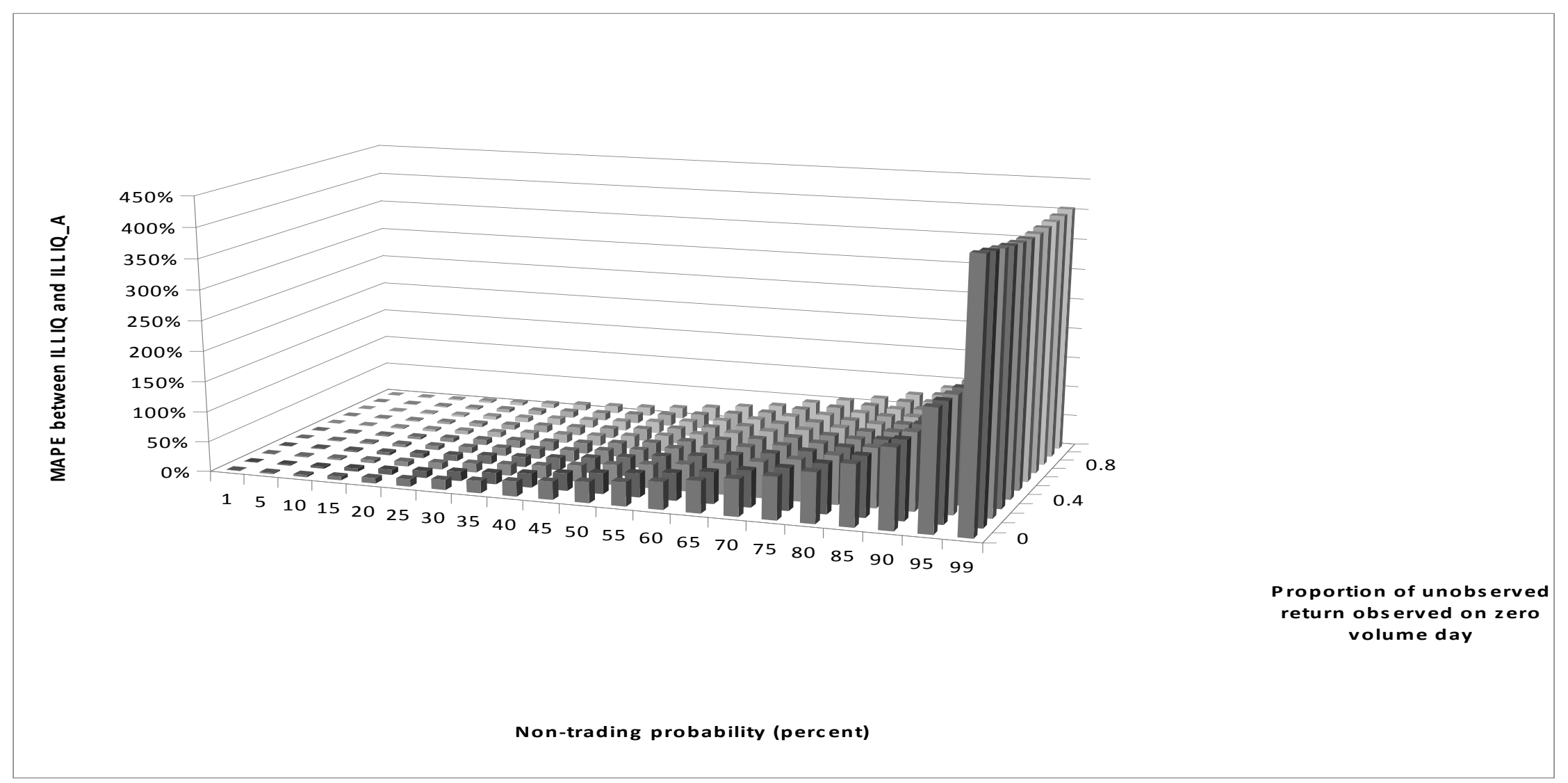

Figure A.3: The difference between the mean absolute percentage error for ILLIQ (the unadjusted illiquidity ratio) and the mean absolute percentage error for ILLIQ_A (the adjusted illiquidity ratio). In each case, the MAPE is calculated relative to the true illiquidity ratio, ILLIQ*, (when there is no thin trading). A positive difference indicates that the adjusted ratio is less biased than the unadjusted ratio. The true illiquidity ratio is the Amihud (2002) measure applied to 100,000 simulated stock returns, with annualized expected return and standard deviation of 8 percent and 20 percent, respectively, and 100,000 corresponding volume data. The observed illiquidity ratio for a given non-trading probability is obtained from "observed" returns and volume data that stochastically include non-trading days, in proportion to the non-trading probability, into the simulated data. The observed ratio on a non-trading day is excluded in the annual average calculation. Non-trading days can be accompanied by non-zero returns with probability 0.2 , and the proportion of the unobserved return observed on a nontrading day varies between zero and 100 percent in intervals of 10 percent. 
Figure A.4

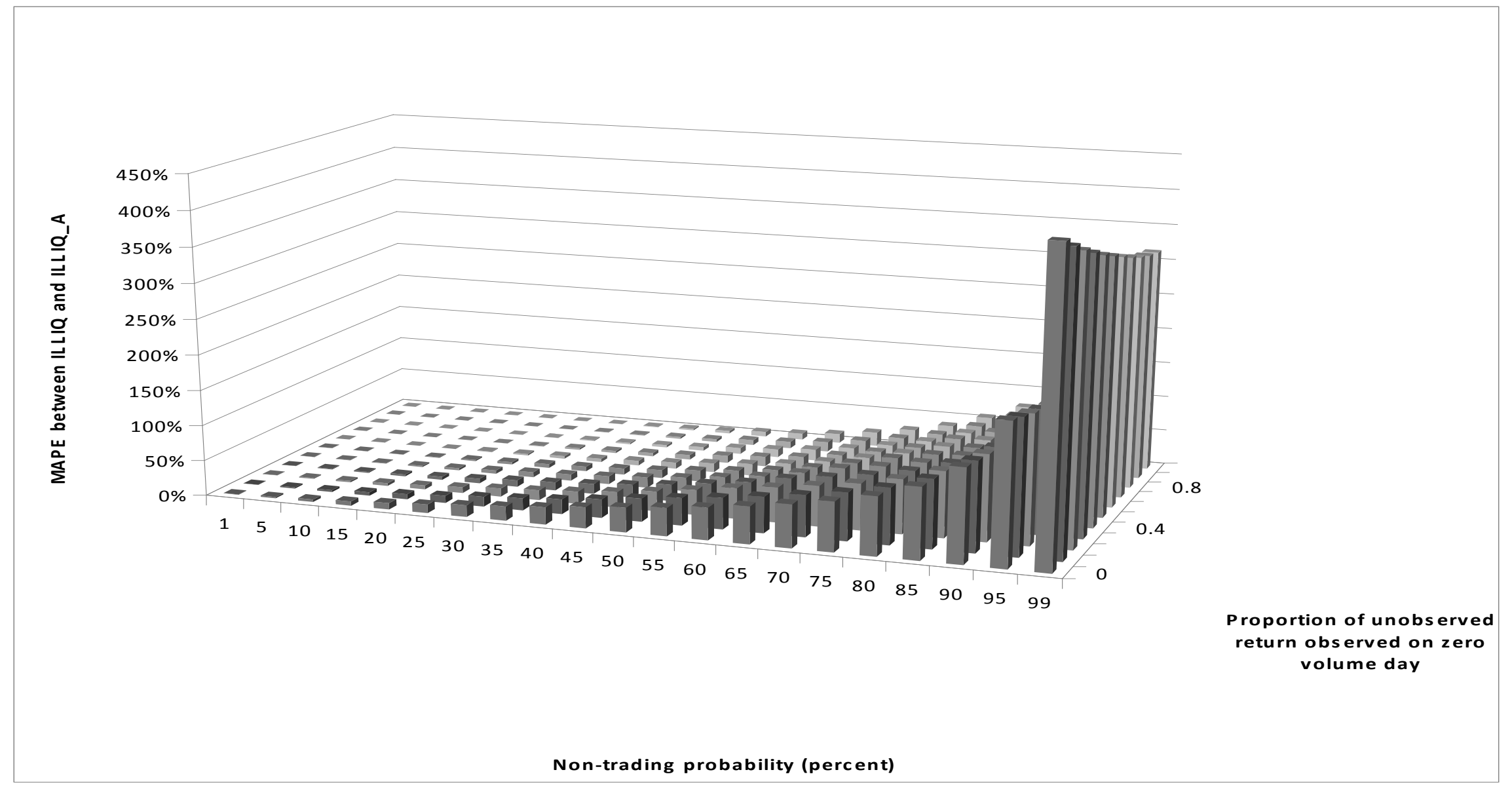

Figure A.4: The difference between the mean absolute percentage error for ILLIQ (the unadjusted illiquidity ratio) and the mean absolute percentage error for ILLIQ_A (the adjusted illiquidity ratio). In each case, the MAPE is calculated relative to the true illiquidity ratio, ILLIQ*, (when there is no thin trading). A positive difference indicates that the adjusted ratio is less biased than the unadjusted ratio. The true illiquidity ratio is the Amihud (2002) measure applied to 100,000 simulated stock returns, with annualized expected return and standard deviation of 8 percent and 20 percent, respectively, and 100,000 corresponding volume data. The observed illiquidity ratio for a given non-trading probability is obtained from "observed" returns and volume data that stochastically include non-trading days, in proportion to the non-trading probability, into the simulated data. The observed ratio on a non-trading day is excluded in the annual average calculation. Non-trading days can be accompanied by non-zero returns with probability 0.5, and the proportion of the unobserved return observed on a nontrading day varies between zero and 100 percent in intervals of 10 percent. 


\section{Figure A.5}

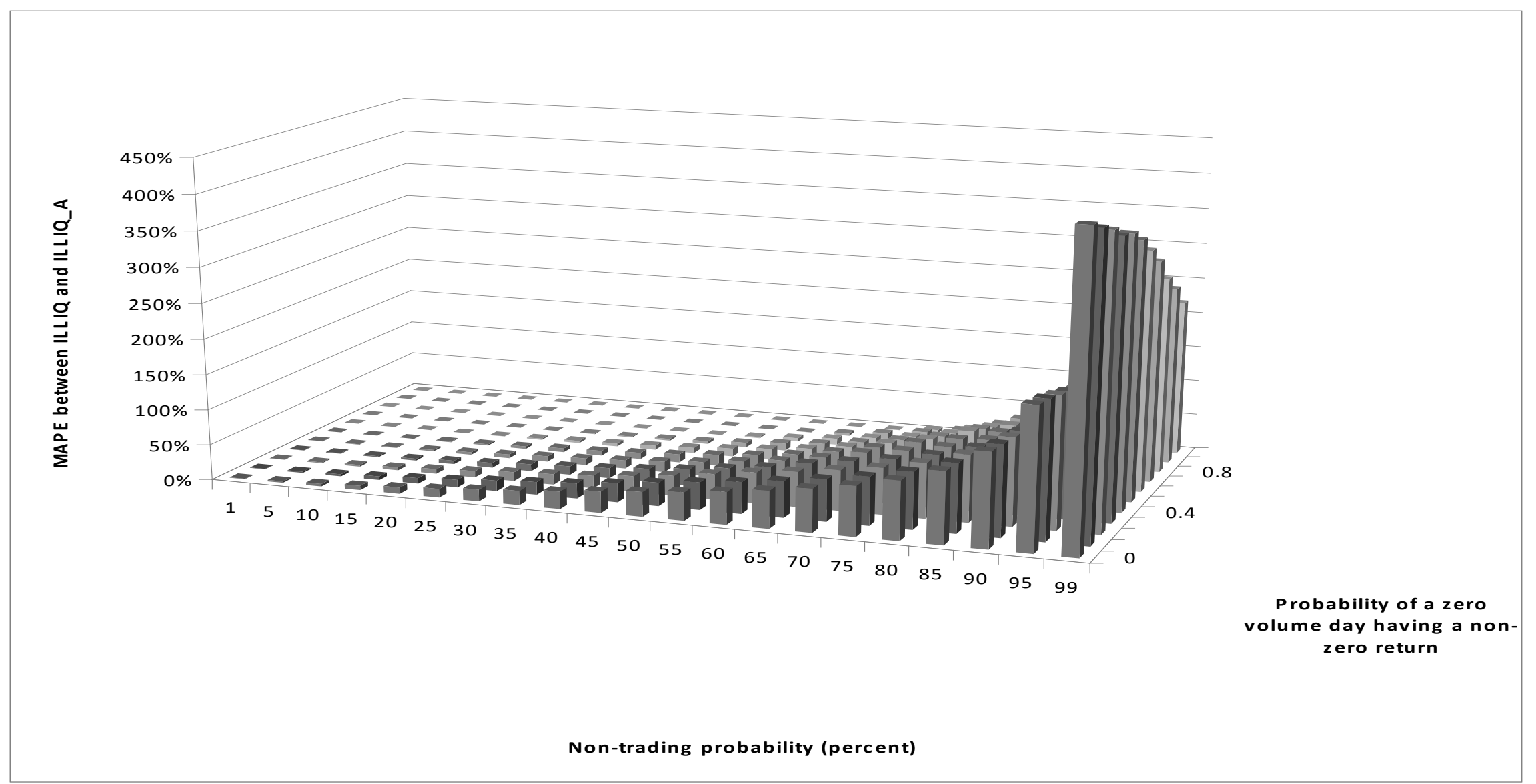

Figure A.5: The difference between the mean absolute percentage error for ILLIQ (the unadjusted illiquidity ratio) and the mean absolute percentage error for ILLIQ_A (the adjusted illiquidity ratio). In each case, the MAPE is calculated relative to the true illiquidity ratio, ILLIQ*, (when there is no thin trading). A positive difference indicates that the adjusted ratio is less biased than the unadjusted ratio. The true illiquidity ratio is the Amihud (2002) measure applied to 100,000 simulated stock returns, with annualized expected return and standard deviation of 8 percent and 20 percent, respectively, and 100,000 corresponding volume data. The observed illiquidity ratio for a given non-trading probability is obtained from "observed" returns and volume data that stochastically include non-trading days, in proportion to the non-trading probability, into the simulated data. The observed ratio on a non-trading day is excluded in the annual average calculation. Non-trading days can be accompanied by non-zero returns with probabilities ranging from zero to 100 percent. The proportion of the unobserved return observed on a non-trading day is set at 50 percent. 
Figure A.6

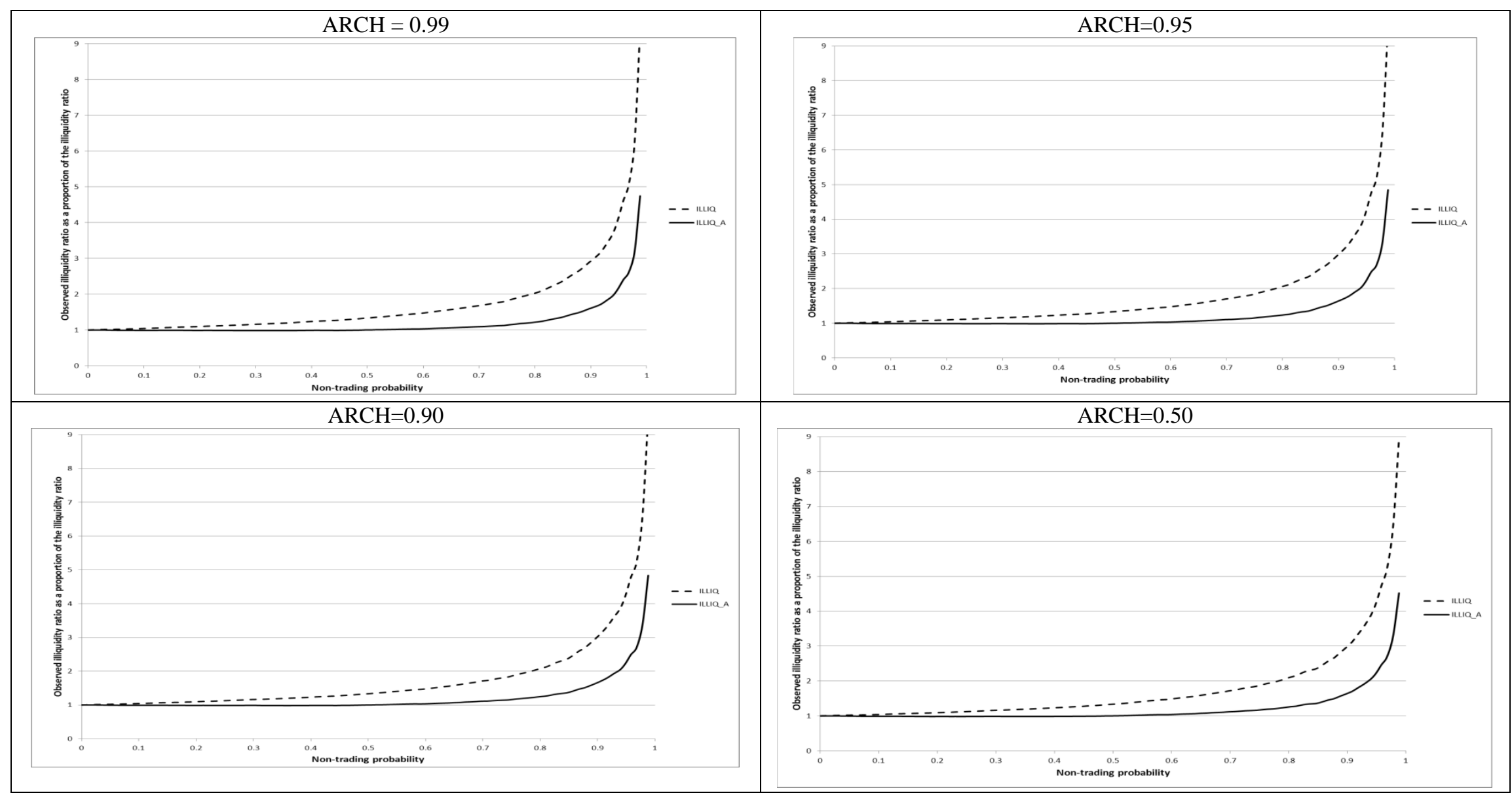

Figure A.6: The ratio of the observed adjusted illiquidity ratio (ILLIQ_A) for a stock (in the presence of thin trading) to the unobserved illiquidity ratio (when there is no thin trading) and the ratio of the observed unadjusted illiquidity ratio (ILLIQ) (in the presence of thin trading) to the unobserved illiquidity ratio (when there is no thin trading) are plotted against the probability of non-trading. The probability of non-trading depends upon the absolute value of the unobserved return as shown in Figure 4. The unobserved illiquidity ratio is the Amihud (2002) measure applied to 100,000 simulated stock returns, with annualized expected return and unconditional standard deviation of 8 percent and 20 percent, respectively, and 100,000 corresponding volume data. The conditional variance of the returns follows an $\mathrm{ARCH}(1)$ process with the autoregressive parameter indicated. The observed adjusted ratio (ILLIQ_A) is computed as ((2T- $\tau) / 2 \mathrm{~T}) *$ ILLIQ, where $\mathrm{T}$ is the number of potential trading days and $\tau$ is the number of non-trading days within $\mathrm{T}$. 


\section{Figure A.7}

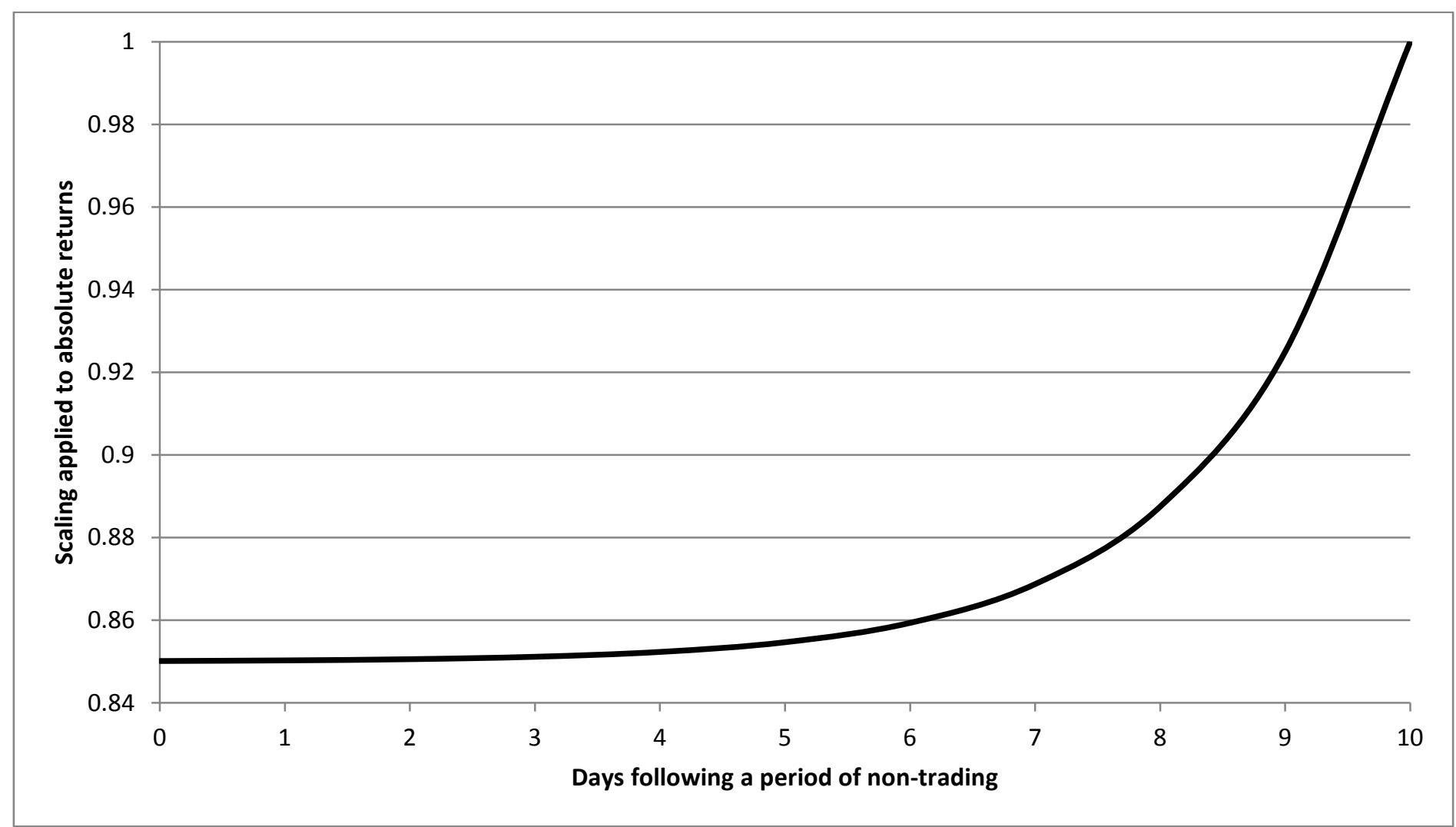

Figure A.7: The scaling applied to the magnitude of unobserved returns following a period of non-trading. The scaling factor on day $q, \varphi_{q}$, follows the reverse partial adjustment process $\varphi_{q-1}=\varphi_{q}+0.5\left(\varphi_{0}-\varphi_{q}\right)$, where $\left(1-\varphi_{0}\right)=0.85$ is the proportional fall in absolute returns immediately following the period of non-trading, $q \leq 10$ and $\varphi_{10}=1$. 
Figure A.8

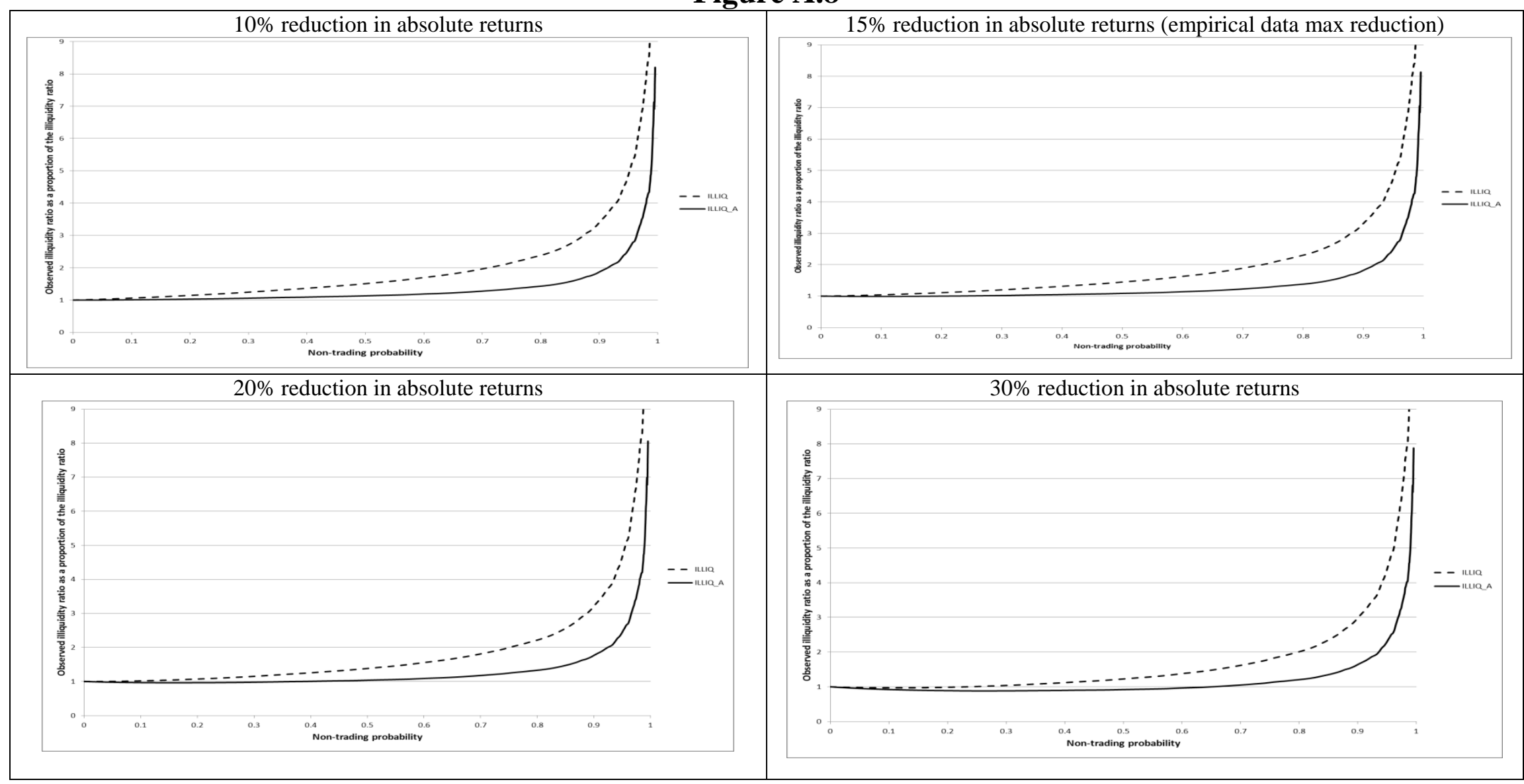

Figure A.8: The ratio of the observed adjusted illiquidity ratio (ILLIQ_A) for a stock (in the presence of thin trading) to the unobserved illiquidity ratio (when there is no thin trading) and the ratio of the observed unadjusted illiquidity ratio (ILLIQ) (in the presence of thin trading) to the unobserved illiquidity ratio (when there is no thin trading) are plotted against the probability of non-trading. The probability of non-trading depends upon the absolute value of the unobserved return as shown in Figure 4. The unobserved illiquidity ratio is the Amihud (2002) measure applied to 100,000 simulated stock returns, with annualized expected return and unconditional standard deviation of 8 percent and 20 percent, respectively, and 100,000 corresponding volume data. The conditional variance of the returns follows an $\mathrm{ARCH}(1)$ process with the autoregressive parameter $=0.90$. The observed illiquidity ratio for a given non-trading probability is obtained from "observed" returns and volume data that include non-trading days that are determined by the magnitude of absolute returns, and where following periods of nontrading, absolute returns drop by the indicated percentage and then have increasing volatility that reverts back to the 20 percent unconditional standard deviation after 10 trading daysThe observed adjusted ratio (ILLIQ_A) is computed as ((2T- $\tau) / 2 \mathrm{~T}) *$ ILLIQ, where $\mathrm{T}$ is the number of potential trading days and $\tau$ is the number of non-trading days within $\mathrm{T}$. 


\section{Figure A.9}

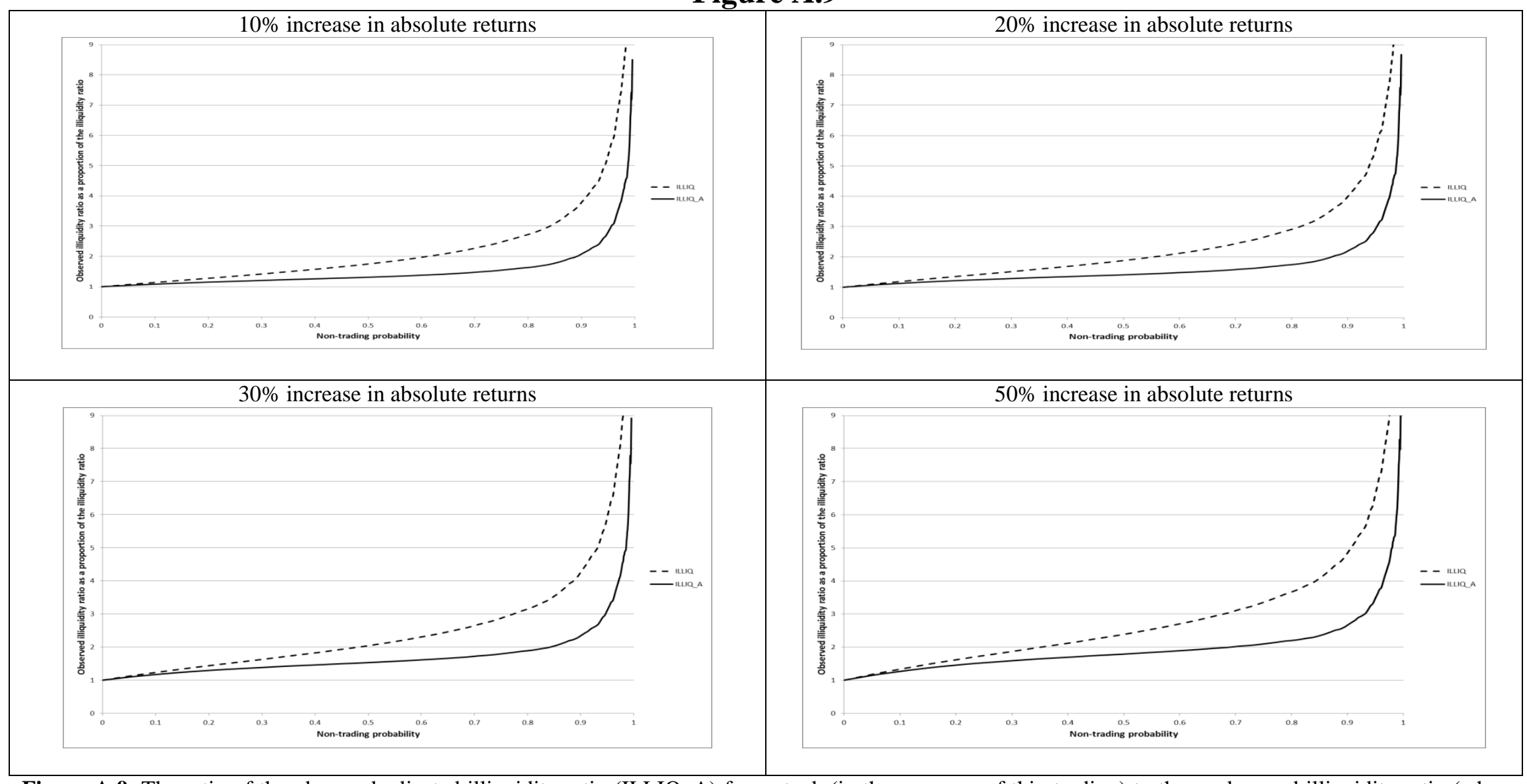

Figure A.9: The ratio of the observed adjusted illiquidity ratio (ILLIQ_A) for a stock (in the presence of thin trading) to the unobserved illiquidity ratio (when there is no thin trading) and the ratio of the observed unadjusted illiquidity ratio (ILLIQ) (in the presence of thin trading) to the unobserved illiquidity ratio (when there is no thin trading) are plotted against the probability of non-trading. The probability of non-trading depends upon the absolute value of the unobserved return as shown in Figure 4. The unobserved illiquidity ratio is the Amihud (2002) measure applied to 100,000 simulated stock returns, with annualized expected return and unconditional standard deviation of 8 percent and 20 percent, respectively, and 100,000 corresponding volume data. The conditional variance of the returns follows an $\mathrm{ARCH}(1)$ process with the autoregressive parameter $=0.90$. The observed illiquidity ratio for a given non-trading probability is obtained from "observed" returns and volume data that include non-trading days that are determined by the magnitude of absolute returns, and where following periods of nontrading, absolute returns rise by the indicated percentage and then have increasing volatility that reverts back to the 20 percent unconditional standard deviation after 10 trading daysThe observed adjusted ratio (ILLIQ_A) is computed as ((2T- $\tau) / 2 \mathrm{~T}) *$ ILLIQ, where $\mathrm{T}$ is the number of potential trading days and $\tau$ is the number of non-trading days within $\mathrm{T}$. 